\title{
INVESTIGATING PRESENT AND FUTURE INTERACTIONS BETWEEN RADIO FREQUENCY IDENTIFICATION, ADDITIVE MANUFACTURING AND SUPPLY CHAIN MANAGEMENT
}

\author{
A Thesis \\ presented to \\ the Faculty of California Polytechnic State University, \\ San Luis Obispo
}

\author{
In Partial Fulfillment \\ of the Requirements for the Degree \\ Master of Science in Industrial Engineering
}

by

Michael Nobuhiro Ochi

May 2014 
(C) 2014

Michael Nobuhiro Ochi

ALL RIGHTS RESERVED 
TITLE:

AUTHOR:

DATE SUBMITTED:

COMMITTEE CHAIR:

COMMITTEE MEMBER:

COMMITTEE MEMBER:
Investigating present and future interactions between Radio Frequency Identification, Additive Manufacturing and Supply Chain Management

Michael Nobuhiro Ochi

May 2014

Tali Freed, PhD

Professor of Industrial Engineering

Roya Javadpour, PhD

Professor of Industrial Engineering

Daniel Waldorf, PhD

Professor of Manufacturing Engineering 


\begin{abstract}
Investigating present and future interactions between Radio Frequency Identification, Additive Manufacturing and Supply Chain Management Michael Nobuhiro Ochi
\end{abstract}

A screening experiment was paired with research observing the past, present and futures of additive manufacturing (a.k.a. rapid prototyping, 3D printing), radio frequency identification, and supply chain management. The experiment tested different properties of objects created with a desktop fused deposition modelling printer to observe if any single factors or interactions affected the read range of embedded passive UHF RFID inlay. The combination of material and infill percentage had a statistically significant effect on read range, however the analysis is weak since the data could not justify the normality assumption of ANOVA. Furthermore, the size of the effect was small enough to deny any practical difference. From the experiment and research, several presently capable interactions between AM and RFID were commented on. Future interactions between AM, RFID and SCM were also discussed, and a common relationship to physical objects was drawn.

Keywords: Additive Manufacturing (AM), Internet of Things (IoT), Radio Frequency Identification (RFID), Rapid Prototyping (RP), Supply Chain Management (SCM), 3D Printing 


\section{ACKNOWLEDGMENTS}

The author would like to acknowledge Dr. Tali Freed for her continual and tireless support. She provided invaluable academic guidance, as well as personal encouragement, constant intellectual challenge, fascinating conversation, and hearty meals. Her dedication to enriching students' lives through education, and vision in directing the Poly GAIT RFID laboratory at Cal Poly has blessed the author throughout his tenure as an undergraduate and graduate student in the Industrial and Manufacturing Engineering Department. Committee members Dr. Roya Javadpour and Dr. Daniel Waldorf also provided helpful guidance.

The author would not have completed his goal of earning a bachelor's and master's degree without additional contributions and encouragement. Former Industrial Engineering classmates including Christina Boeryd, Jon Leposky, Lauren Noyes, Raj Parekh, and Victoria Francis provided key motivation and support throughout the process of writing this thesis. Lastly, the author's family, most importantly his parents and grandparents, were never short on love and assistance of all variety. 


\section{TABLE OF CONTENTS}

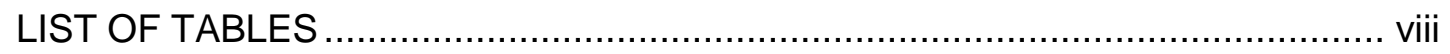

LIST OF FIGURES

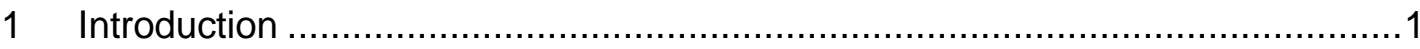

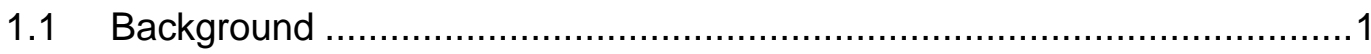

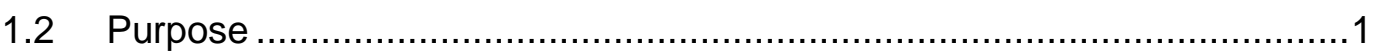

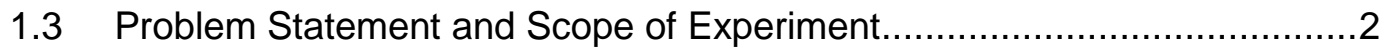

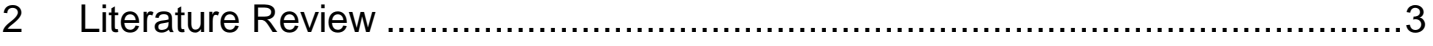

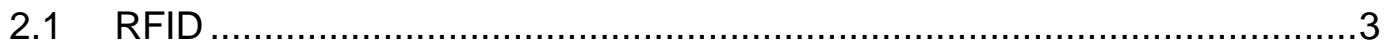

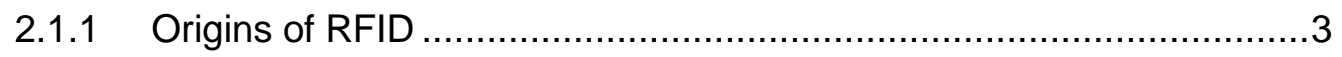

2.1.2 Basic RFID System Components ...............................................

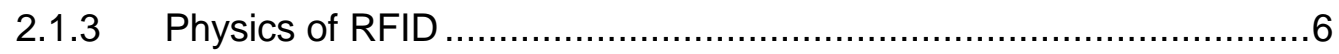

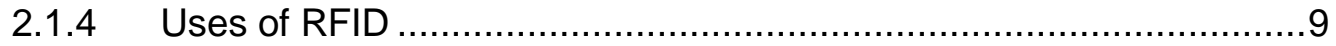

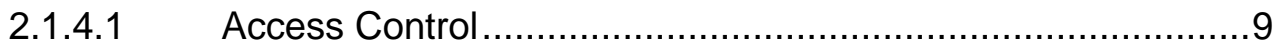

2.1.4.2 IT Asset Tracking ..........................................................10

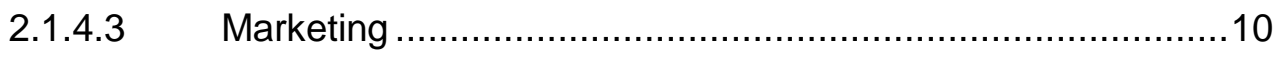

2.1.4.4 Supply Chain Management ...........................................11

2.1.4.5 Warehouse Management.................................................12

2.1.4.6 Industry Specific Uses....................................................12

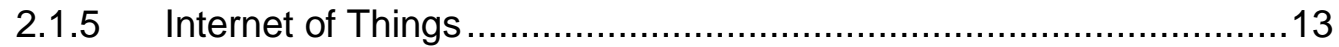

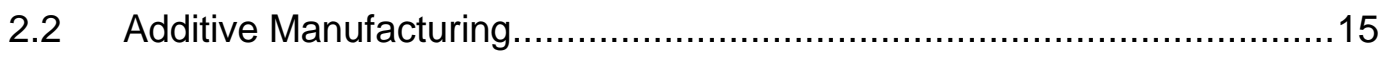

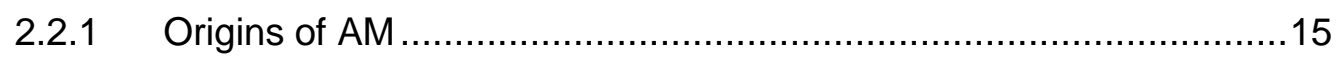

2.2.2 Uses and Growth of AM ............................................................18

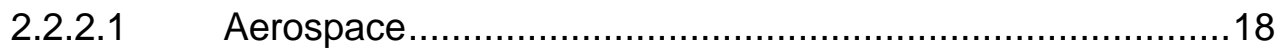

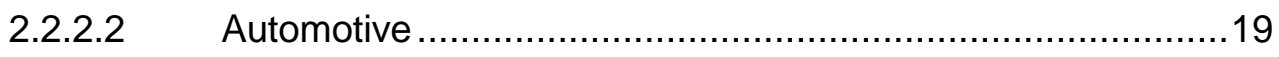

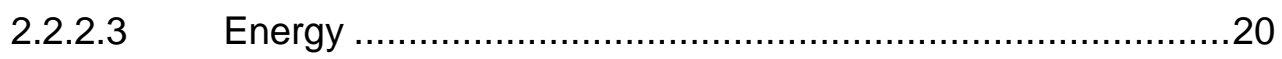

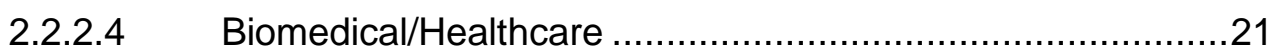

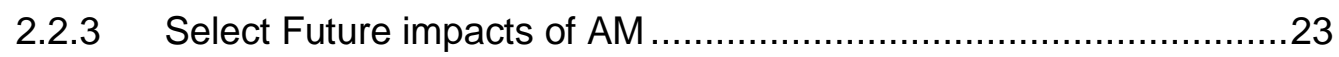

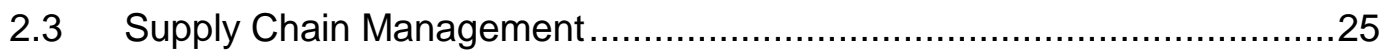

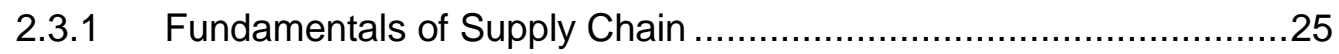

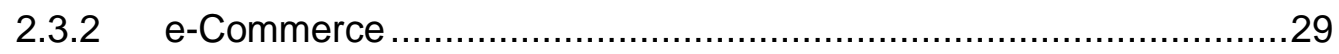

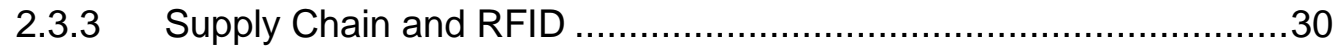

2.3.4 Supply Chain and Additive Manufacturing......................................33

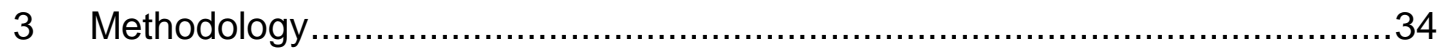


3.1 Determination of AM and RFID Technologies to Test .........................34

3.2 Selection of Factors and Levels ...................................................... 34

3.3 Design and Creation of Test Subjects ..............................................38

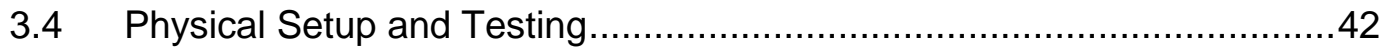

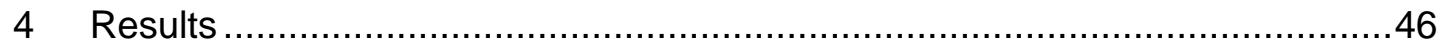

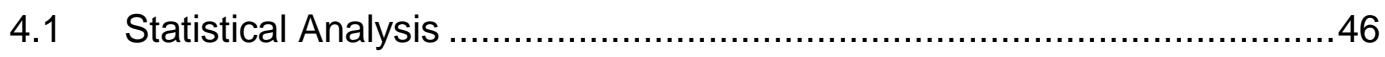

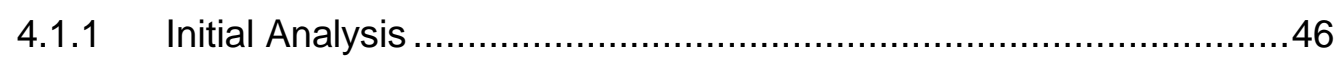

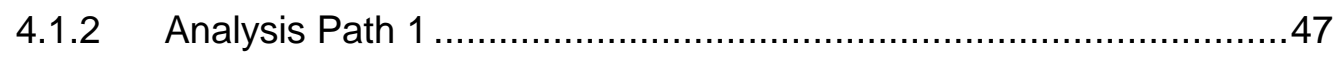

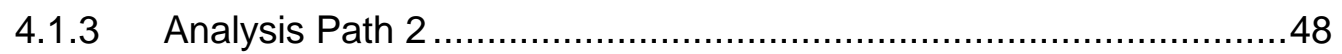

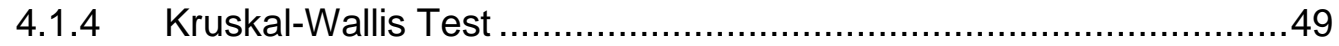

$4.2 \quad$ Experiment Results ................................................................... 49

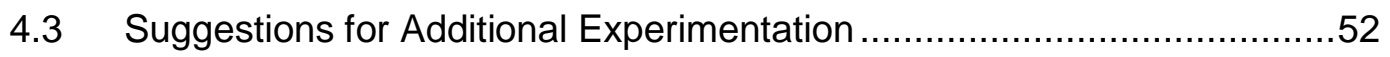

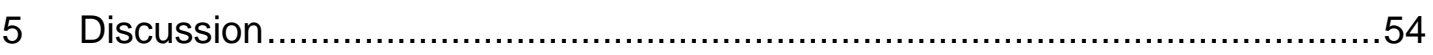

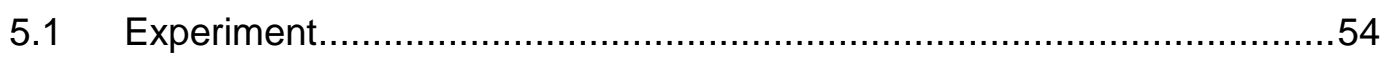

5.2 Possible Present Interactions .........................................................5

5.2.1 Automatic Identification of Part Revisions and Models ...................55

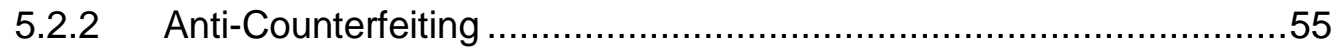

5.2.3 Customization of form factor ............................................... 59

5.3 Possible Future Interactions......................................................60

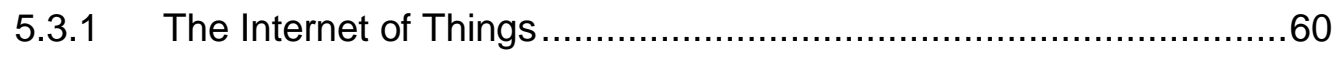

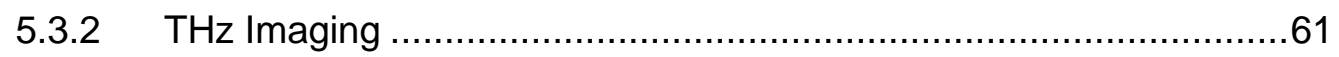

5.3.3 Modification of Low-Volume, High-Mix Supply Chains ...................62

5.4 A Brief Commentary on Governmental and Legislative Issues .................63

5.5 Symbiotic Relationships ............................................................. 63

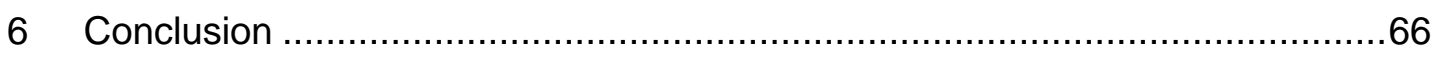

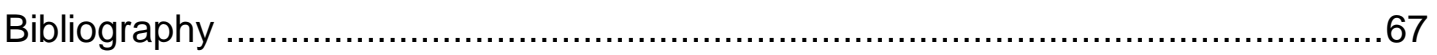

Appendix A- Data and Statistical Analysis ..................................................... 71

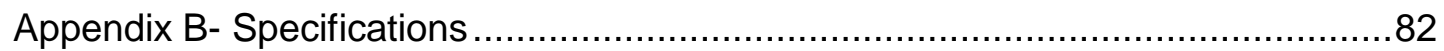




\section{LIST OF TABLES}

Table 1- Additive Manufacturing Processes and Properties.......................................17

Table 2- ANOVA without selected 3rd order interactions ...........................................48

Table 3- Effects and Coefficients without selected 3rd order interactions ......................48

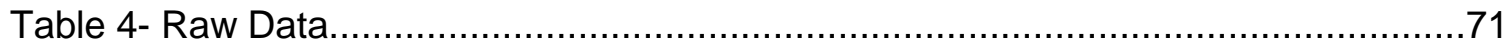

Table 5- Bare Inlay Read Range Raw Data ..........................................................

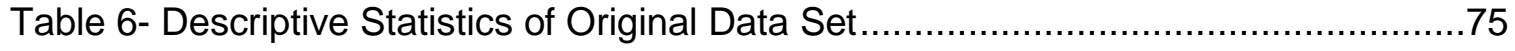

Table 7- Descriptive Statistics of Bare Inlay Read Range .............................................76

Table 8- ANOVA of all terms up to 3-Way Interactions ...............................................77

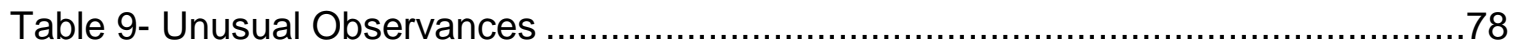

Table 10- ANOVA without Speed in main or interaction effects ...................................78

Table 11- ANOVA after removing unusual observances in original test ........................79

Table 12- Unusual Observances after removing 7 data points from original data ..........80

Table 13- Unusual Observances after removing 5 data points from modified data ........80

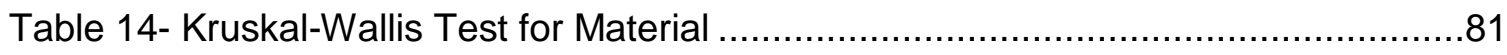

Table 15- Kruskal-Wallis Test for Infill...................................................................

Table 16- Kruskal-Wallis Test for Speed...............................................................

Table 17- Kruskal-Wallis Test for Thickness ............................................................. 


\section{LIST OF FIGURES}

Figure 1-Simple and Extended SC (Scott, Lundgren, and Thompson, 5) ....................27

Figure 2- Competitive Advantage models for RFID in Supply Chain ...........................32

Figure 3- RFID benefits to the supply chain organized by echelon ............................32

Figure 4- CAD model of 0.2 inch thickness substrate with depression for inlay.............39

Figure 5- Final Design of 0.2 inch Thickness Substrate ....................................... 40

Figure 6- RFID inlay and unconnected substrate halves......................................42

Figure 7- Assembled Substrate Halves........................................................... 42

Figure 8- Experimental Setup: cart, measurement/guide tape, and antenna................43

Figure 9- Interaction Plot for Material and Thickness ..............................................50

Figure 10- Cube Plot (3D Interaction) for Material, Infill and Thickness........................51

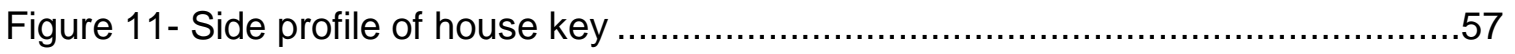

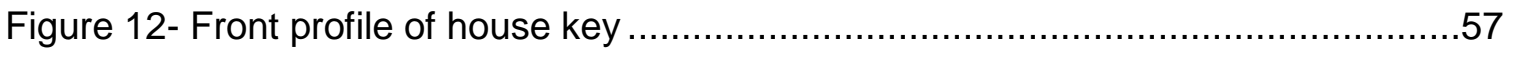

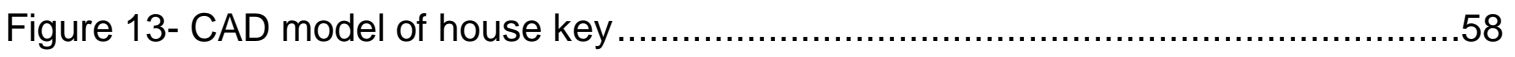

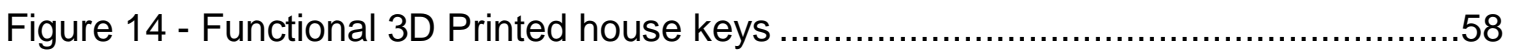

Figure 15- RFID, Additive Manufacturing, Supply Chain Relationship Diagram ............64

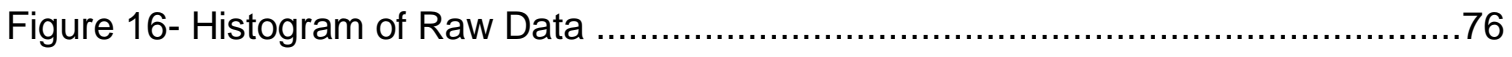

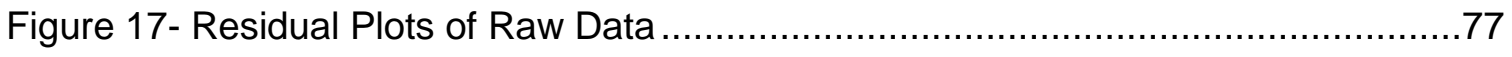

Figure 18- Half Normal Plot without selected $3^{\text {rd }}$-order interactions...........................78

Figure 19- Half Normal Plot after removing 7 unusual observations from original data ..79

Figure 20- Half Normal Plot after removing 5 unusual observances from modified data 80

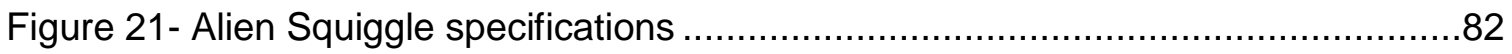

Figure 22- FlashForge Creator (FDM 3D Printer) specifications ...............................83 


\section{Introduction}

\subsection{Background}

Additive manufacturing (AM) has existed since the 1980s (then referred to as rapid prototyping, $\mathrm{RP}$ ), but it has only recently gained the attention of the general public. Groundbreaking medical research, innovative humanitarian work, and the introduction of affordable desktop printers are all subjects centered around additive manufacturing that are being covered by national and international media outlets that would not be considered technology, education, or research-oriented. Arguments are being made that advances in additive manufacturing (better known as 3D printing) have brought modern and developing societies to the doorstep of a new industrial revolution. This paper seeks to examine how other industries that have close relationships with manufacturing might fare in the wake of the expansion of 3D printing. In particular, Radio Frequency Identification (RFID) and Supply Chain Management (SCM) both stand to be radically transformed. Conversely, the future of 3D printing may be shaped by the maturation of each of those technologies and industries.

Before AM matured beyond being solely used for rapid prototyping, RFID was changing the way supply chain management was approached. Two large mandates in 2005 brought RFID into the national spotlight and suppliers of all types of products were forced to educate themselves about the technology. Additive manufacturing may be able to draw from growing pains experienced by the RFID and SCM industries to prevent problems, or predict issues and prepare for their impact.

\subsection{Purpose}

Through examination of the history, current status, and future direction of AM, RFID, and SCM, this paper will make a case for their present interactivity, as well as 
short and long-term potential. Understanding the background of where each came from will help define their true objectives, thus enabling a deeper understanding of how they may evolve. An experiment combining RFID and 3D printing will also shed light on present integration opportunities, and point towards future research, both literary and experimental.

\subsection{Problem Statement and Scope of Experiment}

Little research has been done on how RFID tags behave around 3D printed objects. The ease of creating internal scaffolding or porosity in an object to be made by additive manufacturing will allow engineers to come up with innovative ways to save materials and reduce costs. This has the potential to bring about different reactions in RFID tags, stemming from the physics of RFID systems, which cannot be observed with traditionally manufactured objects. In an effort to conduct an experiment that could have immediately applicable results, a screening test will be done, focused on inexpensive and commonly used RFID and AM technologies. One of the key performance measures of RFID tags is their read range. The experiment will test different options available to designers and determine any difference by measuring the read range of tags encased in 3D printed substrate. 


\section{Literature Review}

\subsection{RFID}

\subsubsection{Origins of RFID}

Radio Frequency Identification (RFID) is an automatic identification technology. It was first developed by the British in WWII as a way to identify friend or foe (IFF). By placing RFID transponders on aircraft the allied forces avoided friendly fire without relying on visual confirmation. Following WWII additional research was done to advance RFID as a technology. Widespread adoption didn't begin until retail stores started using a simple version of it for electronic article surveillance (EAS) in the 1970's. EAS is still used in many retail stores to prevent theft. Additional uses of RFID for livestock tracking, toll-road payment, and railcar identification were developed into the 1980's. The formation of the AutoID Lab at MIT in 1999 spurred an increase in research. According to Chao, Yang, and Jen a "series of innovations overcame RFID weaknesses, a milestone was reached in 2000 when international standards were established, setting the stage for widespread adoption of the technology. This event enticed diverse international enterprises to adopt the technology to enhance operational monitoring and efficiency." [Determining technology trends and forecasts of RFID by a historical review] (272). Major bodies such as ISO, IEEE and GS1 created standards that helped to create a unified platform for different RFID manufacturers to build inter-operable devices.

Because the world has 3 regions of RF range allocations, global standardizations were difficult to create and "the diversity in national spectrum allocation for RFID adds more hurdles to the growth of RFID systems in the world market." [Challenges to global RFID adoption] (Wu et al. 1319). Nevertheless, the mid to late 2000's experienced global expansion of the RFID industry. 
By 2003 the application of RFID in supply chains had become beneficial enough for Wal-Mart to mandate their top 100 suppliers to tag products on the pallet level. The Department of Defense joined Wal-Mart in mandating the use of RFID for tracking by 2005. These mandates by two of the United States' largest supply chain drivers forced multiple industries into the adoption of RFID. To look into the future of RFID, one can study the history of other automatic identification technologies. Wu et al. does this by examining barcode, which "showed that it took approximately 25 years from the development of the first barcode by the Drexel Institute of Technology in Philadelphia in 1949 to the first commercial barcode scanner installation at a Marsh's Supermarket in Ohio in 1974. The developmental timeframe of RFID is similar. Approximately 25 years have passed between the first RFID technology developed by the Los Alamos Scientific Laboratories in 1977 and EPCglobal's announcement of the EPC Generation 1 RFID standard in 2003." He ends this train of thought by asking "what would be a reasonable timeframe expectation for RFID to replace barcode on merchandise label?" (Wu et al., 1318).

\subsubsection{Basic RFID System Components}

Every RFID system is comprised of 3 basic components: transponders, interrogators, and a back-end/computing technology [Challenges to global RFID Adoption] (Wu et al. 1317). Transponders, more commonly known as tags, have at least an antenna, integrated circuit (IC), and substrate. Combined, the antenna and IC are referred to as an inlay. Based on the use of the RFID tag, antenna and chip sizes vary in physical size, and storage capacity of the chip. For most applications, communication and data modulation is the function of a tag's inlay. Substrate is a physical medium in which the inlay is encapsulated and may take many forms depending on the intended use of the RFID tag. The substrate for an inlay meant to track cardboard boxes around a 
distribution center may be a sticker, while an inlay used to identify household pets would be in a capsule that can safely be inserted below the animal's skin. A certain type of tag also has a power source.

All RFID tags are characterized by the way they are powered. Passive tags are powered by electromagnetic waves and have no internal power source. Semi-passive tags have some power source that is used to modulate an incoming RF wave. Lastly, active tags have a power source that is used to modulate and transmit, often at a consistent rate. Tags also are characterized by the frequency range they operate on. There are 3 major frequency classifications: low frequency (LF), high frequency (HF), and ultra-high frequency (UHF). LF tags respond to radio waves at 125 or $134 \mathrm{kHz}$ and, due to the physics of the radio waves, are most commonly used for close-range applications that have the possibility or certainty of being around liquids and/or metals. $\mathrm{HF}$ tags are on $13.56 \mathrm{MHz}$ and are often used for access control and other close-range needs. Passive (non-battery operated) UHF tags are in the $860-960 \mathrm{MHz}$ range globally. Each country that has a governmental agency controlling frequency allocation limits this range further. For example, the United States Federal Communication Commission (FCC) has set the US range for passive UHF tags to 902-928 MHz. Like HF and LF tags, the physics of the frequencies UHF tags are within dictates their use. UHF tags offer longer read ranges and faster communication, however they are much more affected by the environment surrounding the tags. Active (battery operated) UHF tags can operate around $433 \mathrm{MHz}$ and $2.40 / 2.45 \mathrm{GHz}$ and have extended read ranges, are less limited by physical surroundings, and can incorporate sensors.

Interrogators, which are readers and antennae (or a both combined) are responsible for sending radio waves out and collecting signals that come back. Static readers have ports that connect to one or more antennae placed in strategic spots. Readers are then connected to the back-end system, often directly to a computer/server 
or to a router. The back-end system analyzes the data sent to it by readers, as static readers generally only collect data. Without a back-end the RFID system will be essentially unable to make any decisions regarding RFID data. Back-ends can include software called middleware that acts as an in-between for the readers and a database already in an organization's information system. An example of an RFID system interaction is as follows: a tag comes within range of an antenna/reader which tells the middleware that the tag is being read and the software pairs a timestamp to the ID number, appending a single appearance record to the host database. In addition to reading, there are several common commands that a back-end system can send to a tag trough the interrogators. These include, but are not limited to write, lock, and kill. The complexity of commands that a reader can successfully send to a tag depends on the tag's classification and the interrogator.

Certain applications call for more mobility than static readers and antennae can provide. In these cases, handheld readers which combine the reader, antenna and possibly the back-end are used. What handheld readers gain in mobility they often lose in power and, thus, read range. A combination of static readers/antennae with handhelds can be used to leverage the existing system for multiple/flexible uses. The purpose of an RFID system and the physical/electromagnetic environment it is operated in dictates the types of tags that need to be used, which in turn drives the reader/antenna hardware requirements. Hence, no two RFID applications are exactly alike. This makes the implementation of an RFID system a complex undertaking.

\subsubsection{Physics of RFID}

RFID has much to offer but, as Goodrum, McLaren and Durfee found, "it does have limitations like any other technology. Without understanding and working with the limitations of RFID, this technology may disappoint many before its true and significant 
capabilities are realized." [Application of active RFID for tool tracking on construction job sites] (292). A key component for understanding and working with RFID's limitations is understanding the physics that drives it. As its name suggests, RFID utilizes radio waves to identify a tag. Radio is a form of electromagnetic (EM) wave and follows a set of physics rules. One of these rules is an inverse relationship between frequency and wavelength. This means that as the frequency of a radio wave increases, the wavelength decreases. For example, $\mathrm{HF}$ tags operate at a higher frequency than LF tags, so their wavelength is proportionally lower than the radio wave LF tags communicate with. The difference in wavelengths between LF, HF, and UHF change the way each is communicated with. These communication differences come with different types of practical restrictions, which directly impact the variety of applications each type of RFID tag is used for.

Passive RFID tags depend on the power of radio waves sent from interrogators recognize an incoming signal, modulate it, and send it back. There are two ways that passive tags are powered: inductive coupling and radiative coupling (backscattering). Inductive coupling works by Faraday's Law, which states that a change in magnetic flux can create a current in a nearby circuit. An RFID tag located within a wavelength of an EM emitter of the same frequency will have current induced in the tag's coil-shaped antenna. This current provides enough power for the tag's chip to operate. Because of the close proximity a tag must have to the reader, this is known as near field communication. LF and HF tags use inductive coupling. On the other hand, UHF tags use backscattering.

Instead of using a change in magnetic flux, backscattering relies on the energy of electromagnetic waves sent from the interrogator. The UHF tag's antenna picks up the EM, powers the chip for data modulation, and then reflects the signal back to the interrogator. The EM radiation in backscattering is outside of the near field, hence it is in 
the far field. Far field signal power has an inverse square relationship with the distance from its originator. For passive UHF RFID systems, this means that the further away a tag is from the reader the less power it receives. Even though power rapidly decreases outside the near field sphere, the range UHF tags are able to be read is much further than LF and HF tags, which are limited to one wavelength. Far field read range is also indirectly limited by governmental agencies regulating how much power interrogators put out. Therefore, users of passive UHF systems can only increase read range by innovation in antenna and chip design, not by increasing the outgoing power.

Besides the differences in read range, LF/HF and UHF systems have varied physical environmental considerations. The longer wavelengths of LF and HF are not absorbed by water much. This makes them, particularly LF, ideal candidates for applications that are near water. They are also not severely affected by metallic objects, which have a tendency to attenuate $\mathrm{RF}$ waves. Other factors that can affect radio waves are the dielectric effect (detuning), diffraction, interference (constructive or destructive), reflection, refraction, and scattering. Depending on what a RFID tag is in the vicinity of, any number of the aforementioned factors must be accounted for. The orientation and placement of tags also influences readability. Dense tag and dense reader environments can cause interference and EM collisions. If a tag is directly behind another tag from the perspective of a reader, it can cause reduced reading due to a shadowing effect. Antennas are either linearly or circularly polarized. Linearly polarized antennas have a longer reach in one direction, while circularly polarized antennas have a shorter reach in a wider sphere. All these factors are driven by the physics of RF waves and must be considered when designing an RFID system. 


\subsubsection{Uses of RFID}

There are many current uses for RFID and, along with advances in RFID system technology, more uses are uncovered each year. Some uses are specific to an application and can be implemented horizontally across any industry that sees the need for it. Other uses are derived from problems unique to certain verticals and are mainly seen in a particular industry. As llie-Zudor studied RFID she came to the conclusion that "all industrial and governmental operations that need to be accounted for - or merely followed as they proceed - require the tracking and, consequently, the identification of products, assets, documents or persons" [A survey of applications and requirements of unique identification system and RFID techniques] (229). Because it is an automatic identification technology, RFID is a logical candidate to facilitate tracking in any of those operations. Furthermore, the expansion of RFID use is not only driven by technology advances that directly relate to business operations. Chao, Yang and Jen claim "creativity and innovation are leading customers into new experiences and creating new needs. Thus, to survive, organizations are counting on the integration of innovative technologies with business management processes." [Determining technology trends and forecasts of RFID by historical review] (268).

\subsubsection{Access Control}

Of the many application-based uses of RFID access control, IT asset tracking, marketing, and supply chain each have RFID systems firmly established in large and small organizations. Due to the limited read range of LF and HF RF waves, they are ideal for access control. Many companies have opted to integrate LF or HF inlays into employee identification badges. Entry points that the organization wishes to protect are outfitted with readers that, through middleware, control the locking mechanism of the door or vehicle blocker. ID badges may be bought in bulk and easily programmed to 
allow the organization to issue new cards. RFID badges may also be leveraged to act as automatic time cards for hourly-paid employees. A major advantage of using RFID badges for access control is the ability to change permissions from a centralized software system. This means that new employees can be issued badges that work on their first day of work, and outgoing employees can be barred from reentry the moment HR changes their employment status.

\subsubsection{IT Asset Tracking}

IT asset tracking is another common application for any organization with enough IT assets to get a reasonable return on investment (ROI) through RFID. UHF tags, passive or active, are placed on laptops, desktop computers, projectors, electrical equipment that require calibration, and other objects. Depending on the complexity of the RFID hardware infrastructure, the system may be used simply to automate maintenance records or keep up-to-date location visibility (called real-time location systems, RTLS), and anything in between. Organizations may also use RFID to improve capital asset utilization, or secure information if it leaves the premises.

\subsubsection{Marketing}

Though marketing and sales through RFID spans mostly companies selling directly to consumers, it holds much potential. As the general population increases their integration of smartphones into everyday activities, and smartphone manufacturers include near field communication (NFC) readers in their new devices, the opportunity to use NFC/HF tags expands. Instead of having to scan a QR code or manually type in a web address, NFC tags can automate tailored customer interaction. UHF tags placed in/on items in retail stores can also help suggest related items to shoppers who pick up the tagged item. Early adopters of these experience-enhancing RFID systems struggled 
to perfect them, but the explosion of social media has softened the average consumer's acceptance of individualized marketing.

\subsubsection{Supply Chain Management}

As discussed earlier, Wal-Mart and the US Department of Defense mandated top suppliers to place RFID tags on incoming products in 2005. Combined, the organizations receive goods from a variety of industries including food and beverage, consumer electronics, retail, automotive, aerospace, defense, and healthcare. Almost all largescale businesses were affected by the mandates, either directly through having to implement RFID systems for supply chain management (SCM) or being forced to research the costs and benefits of RFID to not allow the technology to be a competitive advantage to the primary adopters. "Because the supply chain and logistics management cost could range from $6 \%$ to $13 \%$ of a company's revenue, reducing logistics cost and enhancing the visibility of SCM will benefit not only manufacturers but also retailers and consumers as well." [Challenges to global RFID adoption] (Wu et al. 1322). RFID systems that span multiple layers of the supply chain, referred to as openloop, are difficult to calculate ROI for, especially in companies further upstream. However, as Zhou discusses, the potential benefits RFID has on supply chain processes include "reduction in labor costs, increase in store selling area, acceleration of physical flows, reduction in profit losses, more efficient control of the supply chain through increased information accuracy, better knowledge of customer behavior, better knowledge of out-of-stock situations, reduction in delivery disputes, better management of perishable items, better management of returns, better tracking of quality problems, better management of product recalls and customer safety, and improved total quality control" (252). If the information and benefits are leveraged correctly, "RFID has the potential to greatly increase information visibility in a business supply chain at different 
stages including acquiring raw materials, manufacturing, transportation, and retailing." [RFID and item level information Visibility] (Zhou, 253). Although the promise of RFID in the supply chain management setting is large, there are many challenges that have slowed previous implementations and will continue to demand attention in the future. Wu et al. have found that these include "technology challenges, standard challenges, patent challenges, cost challenges, infrastructure challenges, return on investment (ROI) challenges, and barcode to RFID migration challenges" [Challenges to global RFID adoption] (1318).

\subsubsection{Warehouse Management}

Another application of RFID, somewhat related to supply chain, is warehouse management. Many organizations use warehouses to store items that are essential to production and/or operation. Warehousing is often non-value added but essential, and RFID provided ways to shorten, automate, or remove warehouse operations. The information needed for each item in a warehouse includes answers to questions such as where is it, how many are there, and how long has it been there. RFID has the ability to simplify the collection of all the necessary data, and do it faster than barcode, with less opportunity for human error.

\subsubsection{Industry Specific Uses}

In addition to applications that can serve different types of organizations, RFID is also used to solve industry-specific problems. Krotov and Junglas found that many new uses have been created when organizations follow a procedure: "Select an object. Then think about properties that the object may have. Next, determine how RFID can help to extract and use these properties either to enhance a transaction that the object participates in or to create a new transaction. Hence, new value propositions can be built either by improving existing transactions or creating new ones" [RFID as a Disruptive 
Innovation] (52). RFID Journal, an organization that publishes articles and holds international events oriented around RFID, has dedicated pages for the aerospace, apparel, automotive, chemical, consumer packaged goods, defense, health care, labeling, logistics, manufacturing, medical devices, packaging, pharmaceutical, retail, and transportation industries. Of the top employing industries in the United States, only education and energy are left off their list (which is not to say that those industries do not leverage the application-based RFID systems discussed earlier). Industry-specific uses of RFID are often kept in one vertical due to differences in products, services, materials, processes, and regulations. An example of this would be shipping and healthcare both being interested in using active UHF tags for tracking purposes, but shipping requires durable, weather-resistant tags with loose size constraints to put on static objects while healthcare would want small, lightweight tags to place on people. As businesses and industries look for ways to improve their bottom line, the number of ways RFID is used to solve unique problems expands. No matter what industry an organization falls in, "an increasing variety of enterprises are employing RFID to strengthen their managers' ability enhance organizational change and to manage growth in an increasingly competitive environment." [Determining technology trends and forecasts of RFID by a historical review] (Chao, Yang, Jen 277)

\subsubsection{Internet of Things}

The benefits of passive, wireless communication through RFID and NFC has spurred other innovative concepts that have potential to go beyond RFID. Originally termed at MIT's AutolD Lab, the Internet of Things (IOT) has gained popularity in the last few years. The concept has even been advertised on national television by companies such as Cisco, IBM, LG, and several major automakers. There are several definitions of the loT and many variances come from an emphasis on either the "internet" aspect or 
the "things" aspect. Miorandi et al. attempt to summarize loT: "from a conceptual standpoint, the loT builds on three pillars, related to the ability of smart objects to: (i) be identifiable, (ii) to communicate and (iii) to interact - either among themselves, building networks of interconnected objects, or with end-users or other entities in the network" (1498). They also examine it from a single component level and system level; as "smart" objects that exist with, and complement, other objects in the internet, and as a massive, dynamic and distributed network made of smart things that produce and consume information. Atzori, lera and Morabito describe the network as a "pervasive presence around us of a variety of things or objects - such as RFID tags, sensors, actuators, mobile phones, etc. - which, through unique addressing schemes, are able to interact with each other and cooperate with their neighbors to reach common goals" (2787).

It is not a stretch of the imagination to consider the integration of electronic objects into an internet-based network. In fact, the idea of a "smart home" has been around since The Jetsons ruled Saturday morning cartoons. The Internet of Things, however, goes beyond things already considered technology to include everyday objects. "Everyday objects include not only the electronic devices we encounter and use daily and technologically advanced products such as equipment and gadgets, but 'things' that we do not normally think of as electronic at all - such as food, clothing, and furniture; materials, parts, and equipment; merchandize and specialized items; landmarks, monuments and works of art; and all the miscellany of commerce, culture and sophistication" (Kosmatos, Tselikas, and Boucouvalas 6). The push to include nonelectronic things into the loT lends itself naturally to RFID technology. In fact, it can be argued that passive RFID technology was the seed that planted the loT concept. The growth of RFID and the loT are "not simply a result of technological push; it is also driven by the market pull, since enterprises are increasingly realizing the commercial benefits of applications that can be realized with Internet-of-Things technologies" 
(Miorandi et al. 1509). As the Internet drastically changed professional and personal interactions, the "IoT has the potential to add a new dimension to this process by enabling communications with and among smart objects, thus leading to the vision of ‘anytime, anywhere, anymedia, anything' communications” (Atzori, lera, and Morabito 2803). Though RFID cannot support the loT alone, they are symbiotic and advances in one will likely influence the other.

\subsection{Additive Manufacturing}

\subsubsection{Origins of AM}

Additive manufacturing (AM) is the process of creating an object from a computer-generated file by adding material. Years ago it was commonly referred to as Rapid Prototyping (RP) because its primary use was creating prototypes in a research and development stage. Now the term 3D Printing is used by the media to describe all AM technologies although, strictly speaking, 3D Printing is one method of additive manufacturing. Though the end goal is still to transform raw material into a man-made design, the overall technique differs from subtractive manufacturing and net shape processes such as molding, casting, and forming. Subtractive manufacturing, which is often called machining, starts with a block of material that reaches its final shape through removal processes. Net shape processes use heat to liquefy materials so they can flow into and solidify in molds or casts, or uses force to transform a malleable material into the desired shape. Additive manufacturing makes objects by creating layers in the shape of the top-view profile at a specified height. Because the material is being solidified layer by layer, no tooling is necessary for additive manufacturing. The absence of tooling eliminates certain design considerations that must be considered with machining, molding, casting, and forming. 
Though 3D Printing has only recently surfaced as a buzz-word, additive manufacturing has been around for decades. The widespread push for the technology group that would eventually become additive manufacturing came from the American automotive industry (Upcraft and Fletcher, 318), however the first documented solid model was created by Hideo Kodama at a research institute in Japan (Bogue, 307). The introduction and growth of computer aided design (CAD) in the mid-1980s gave designers the ability to communicate three-dimensional drawings on computers and, thus, led the way for the development of RP systems. The first rapid prototyping machine was patented by Charles Hull in 1986 and sold by 3D Systems (Horn and Harrysson, 258), a company that currently holds a large part of the personal and professional printer market. The development of a standard file format, STL, allowed any designer to create drawings for RP with CAD software that could save in .stl (opposed to .$d w g$, .ipt, .step, .g, etc.). The 1990s saw development of new companies and new technologies, however additive manufacturing didn't experience meteoric expansion until the mid-2000s. Since 2010 the additive manufacturing industry has opened up to regular consumers with desktop printers costing less than $\$ 5000$. Now additive manufacturing has moved from creating prototypes in the automotive industry to making models and end-usable parts in aerospace, healthcare, automotive, energy, and other industries (Guo and Leu, 216).

\subsubsection{Commonly Used and Referenced AM Technologies}

Since the first stereolithography (SLA) machine was built in 1986 dozens of other additive manufacturing technologies have been explored. A select few of those have become commonly used: stereolithography, selective laser sintering (SLS), threedimensional printing (3DP), fused deposition modelling (FDM), laminated object manufacturing (LOM), and electron bean melting (EBM). Each technology has its own 
method, however objects are "built rather similarly, due to the layered manufacturing principle" (Brajlih et al. 65). Table 1 includes the technologies and several of their properties.

\begin{tabular}{|c|c|c|c|}
\hline $\begin{array}{l}\text { AM } \\
\text { Process }\end{array}$ & Technology Summary & Material Type(s) & $\begin{array}{l}\text { Strengths/Weakn } \\
\text { esses }\end{array}$ \\
\hline SLA & $\begin{array}{l}\text { Photosensitive liquid resin solidified } \\
\text { by selective exposure to ultraviolet } \\
\text { light. New layer of resin added once } \\
\text { previous cross-section is complete }\end{array}$ & $\begin{array}{l}\text { Acrylates } \\
\text { Epoxies } \\
\text { Resins (can be glass, } \\
\text { ceramic, metal) }\end{array}$ & $\begin{array}{l}\text { High-resolution, } \\
\text { limited materials }\end{array}$ \\
\hline SLS & $\begin{array}{l}\text { Layers of powder are fused or } \\
\text { sintered together by laser beam(s) }\end{array}$ & $\begin{array}{l}\text { Metals } \\
\text { Sand } \\
\text { Ceramics } \\
\text { Polymers (pure or filled) }\end{array}$ & $\begin{array}{l}\text { No support } \\
\text { structure, very } \\
\text { high-temperature }\end{array}$ \\
\hline 3DP & $\begin{array}{l}\text { Layer of powder is deposited and } \\
\text { solidified by ink-jet printed binder. } \\
\text { New layer of powder added once } \\
\text { previous cross-section complete. }\end{array}$ & $\begin{array}{l}\text { Ceramics } \\
\text { Metals } \\
\text { Polymers }\end{array}$ & $\begin{array}{l}\text { Low-temperature, } \\
\text { no support } \\
\text { structure, low } \\
\text { surface-quality }\end{array}$ \\
\hline FDM & $\begin{array}{l}\text { Stream(s) of heated viscous material } \\
\text { deposited on build plate or previous } \\
\text { layer, cools to solid state. New layer } \\
\text { of material added once previous } \\
\text { cross-section is complete. }\end{array}$ & $\begin{array}{l}\text { Thermoplastics } \\
\text { Wax } \\
\text { Organics } \\
\text { Polymers and binders } \\
\text { containing glass, } \\
\text { metals, ceramics }\end{array}$ & $\begin{array}{l}\text { Inexpensive, can } \\
\text { print multiple } \\
\text { materials } \\
\text { simultaneously, }\end{array}$ \\
\hline LOM & $\begin{array}{l}\text { Thin sheets of material are laminated } \\
\text { together only on desired cross- } \\
\text { section of the layer, remaining } \\
\text { material cut away by knife or laser, } \\
\text { then new sheet applied or rolled on }\end{array}$ & $\begin{array}{l}\text { Paper } \\
\text { Polymers } \\
\text { Composites } \\
\text { Ceramics } \\
\text { Metals }\end{array}$ & $\begin{array}{l}\text { Full density, } \\
\text { internal cavities } \\
\text { easy, shrinkage } \\
\text { after post- } \\
\text { processing }\end{array}$ \\
\hline EMB & $\begin{array}{l}\text { Surface layer of powder is melted } \\
\text { together using a high-energy electron } \\
\text { beam focused by magnetic coils. } \\
\text { New layer of powder added once } \\
\text { previous cross-section complete }\end{array}$ & Metals & $\begin{array}{l}\text { High density, low } \\
\text { energy } \\
\text { consumption, } \\
\text { must be in } \\
\text { vacuum, } \\
\text { expensive, small } \\
\text { build volume }\end{array}$ \\
\hline
\end{tabular}




\subsubsection{Uses and Growth of AM}

When additive manufacturing was in its infancy stages it was mainly used for design, which is why the term rapid prototyping was often synonymous. Dimitrov, Schreve and Beer found that the design realm can be further broken down to concept modelling, proof of concept (customer presentation), and market research (137). Concept modelling takes place in the development phase of a product and can benefit from RP in several ways. First, the ability to create a physical model in a short time frame (hours compared to days or weeks) enables designers to make several iterations of different concepts without sacrificing lead time or funds. If color is added to the part, visual finite element analysis can easily be done with physical models. Once a design has been brought to a presentable stage, a part made by RP can be used to solicit customer feedback and approval. This is an advantage especially when communicating with customers who may not be comfortable interpreting CAD drawings. RP can also be a powerful tool for marketing due to its time and cost-effectiveness when building small amounts of varying designs.

The past decade has seen a growth and maturation of additive manufacturing technologies and they "are no longer used only as visualization tools or for assembly testing but also to produce final parts, even of metal." (Atzeni and Salmi, 1147). Wellestablished AM companies such as Stratasys and 3D Systems list many industries their technologies are used for including aerospace, architecture, automotive, defense, education, energy, entertainment, and healthcare/medical. Of those fields aerospace, automotive, energy and medical are widely covered in literature.

\subsubsection{Aerospace}

According to the U.S. Department of Commerce, the value of aircraft and parts shipments (both civil and defense) was $\$ 184.3 \mathrm{~B}$ in 2012. In a study of additive 
manufacturing applications Guo and Leu state that parts in the aerospace industry "often have complex geometries and are made usually from advanced materials, such as titanium alloys, nickel superalloys, special steels or ultrahigh-temperature ceramics, which are difficult, costly and time-consuming to manufacture. Additionally, aerospace production runs are usually small, limited to a maximum of several thousand parts. Therefore, AM technology is highly suitable for aerospace applications" (225). Another critical factor in aerospace parts is weight. By redesigning parts for additive manufacturing engineers "enable direct fabrication of lattice structures and controlled porosity" (Petrovic et al. 1072), which can reduce costs of fabrication, and the cost of energy consumed during construction and use. Stratasys boasts of the use of their FDM printers for the Osprey, NASA Mars Rover, and Piper Aircraft, among many others (www.stratasys.com). The applications include end-use parts, functional models, and tooling. Khajavi, Partanen and Holmstrom studied AM in the spare parts supply chain, specifically on the F-18 Super Hornet, and found "machine acquisition price and personnel intensiveness are major obstacles to a distributed deployment of [the] technology". However, the benefits include "lower overall operation costs, lower down time, higher potential for customer satisfaction, lower capacity utilization, higher flexibility, higher robustness to supply chain disruptions, reduced need for inventory management and logistics information systems, and potential for sustainability improvements as AM machines become smaller and more energy efficient" (58). Though their findings were from an aerospace application, the benefits can certainly be spread across other industries.

\subsubsection{Automotive}

The automotive industry also spends billions of dollars every year but differs from the aerospace industry in the sense that individuals and businesses directly purchase 
vehicles. The U.S. Census Bureau reports over 11 million new vehicles were purchased in the United States in 2010. Most of those vehicles are mass-produced and for those companies "new product development is critical... but developing a new product is often a very costly and time-consuming process" (Guo and Leu, 229). 3D Systems printers are assisting large-scale automotive production at GM in several different departmentsdesign, engineering, and manufacturing. Hankook Tires are also using 3D Systems printers to communicate designs and can have a full-scale model prepared overnight (www.3dsystems.com). Additive manufacturing has also been used in luxury and specialty automotive production for "small quantities of structural and functional parts, such as engine exhausts, drive shafts, gear box components and braking systems... [that] usually use light-weight alloys (e.g., titanium) and have highly complex structures" (Guo and Leu, 229).

\subsubsection{Energy}

Energy impacts all aspects of modern society and there is a constant push for innovation in harvesting, storing, distributing and using it. Guo and Leu describe an instance of AM contributing to the advancement of renewable energy by using SLS to build a critical component of a Polymer Electrolyte Membrane fuel cell (234). Like other AM applications, the benefits came from cost and time savings that conventional molding processes could not offer. 3D Systems has provided printers to several companies in the energy industry. Several organizations, such as Generac Power Systems and Nippon Katan Power, used AM machines to decrease the time and cost put into making product prototypes. Other energy companies use 3D printers to create lightweight casts for large parts like turbines and blades (www.3dsystems.com). 


\subsubsection{Biomedical/Healthcare}

Perhaps the most fascinating and groundbreaking uses of additive manufacturing have been in the healthcare industry. Petrovic et al. concluded that because the main field of AM is customizing parts with short fabrication series "biomedical parts are the target group that fits perfectly" (1071). In fact, the advantages of the technology group fit so closely that "the medical implications of rapid prototyping and additive manufacturing were recognized very soon after the technologies became commercially available" (Horn and Harrysson, 271). In a study of medical RP applications Hieu et al. state there are three main applications including: "design and manufacturing of biomodels, surgical aid tools and implants; development of surgical training models and medical devices; and design and manufacturing of scaffolds for tissue engineering" (285). The first application they list encompasses many uses so it can be further divided by making implants its own sub-category. There are numerous benefits that AM brings to creating medical implants due to their ability to "manufacture complex geometries and structures, to make rough, engineered surface for more effective bone integration and to allow implants to be personalized to match each patient's individual needs" (Guo and Leu, 232). Certain AM technologies have provided novel uses- "lattice structures fabricated with EB have also been utilized in a relatively new form of prosthetic attachment that involves the use of a transcutaneous osseointegrated implant. This is a bone anchored implant that breaches the skin barrier at the amputation site with an abutment that facilitates the attachment of prosthetic limbs directly to the skeletal system." (Horn and Harrysson, 273). With the development of biocompatible polymers, implants can be created that "are not aggressive to the human body and do not cause rejection" (Petrovic et al. 1068). The other portion of the first application listed by Hieu et al. has given surgeons the ability to practice and shorten surgeries preoperatively. Though two-dimensional images have been used for decades to plan before surgeries "models fabricated with additive 
processes provide a tool for surgeons to better understand unique, intricate anatomical relationships that are [otherwise] difficult to visualize" (Horn and Harrysson, 272). Thanks to biomodels and surgical aid tools created through AM processes "the surgeon's skills are enhanced; the precision, safety and speed of surgery are increased; and finally the complexity of surgery is reduced" (Hieu et al. 291).

Opposed to the patient specificity of biomodels and surgical aid tools, training models are used to educate students in a broader sense. Abnormal case studies that fall outside the physical properties of mass-produced educational models can be brought to life, which diversifies the training of future doctors and surgeons. Medical and dental devices have also benefitted from AM. A sibling technology known as three-dimensional scanning has been paired with AM to create braces-alternative Invisalign and "custom fitted in-the-ear hearing aids" (Horn and Harrysson, 273). Though other functional devices exist and compete with those examples, they lack the high level of customization and convenience.

Hieu's last application is perhaps the most futuristic. Currently and in the past, tissue scaffolding has relied on "solvent casting, melt molding, freeze drying, and foam replication to create the shape and architecture of a scaffold. These methods have limitations in the areas of manual interaction requirements, difficulty in the control of complicated internal architectures, and reproducibility. In contrast, fabrication of tissue scaffolds using AM technology allows versatility in the use of biomaterials and the fabrication of scaffolds with complex geometries and designed internal architectures" (Guo and Leu, 232). Scaffolds can be designed to be porous with their bounding geometry derived from "patient specific medical imaging data", allowing them to "provide structural support for seeded/deposited living cells" (Horn and Harrysson, 275). The development of flexible and biodegradable polymers would "permit real tissue engineering, being a base for the construction of human organs" (Petrovic et al. 1069). 
Though many of these applications have yet to be fully trusted and accepted by doctors and regulatory agencies, they have already begun to show promise towards improving the "safety, quality, and effectiveness of healthcare for the general population" (Huang et al. 1200).

\subsubsection{Select Future impacts of AM}

It would be prudent to allow minds to wander into how AM will evolve itself and society in the near and far future. Advances in AM and related technologies (CAD, materials, recycling, the internet, etc.) will bring about changes to the way objects are created which, in turn, will transform thoughts, processes and the organizational structures that surround manufacturing. Petrick and Simpson assert the "3D production ecosystem will have major effects in each of the three major stages of the design-builddeliver model. It will change the nature of design, it will increase the interactivity between design and production, and it will radically localize manufacturing" (14). This paper has already touched on changing the nature of design and increasing interactivity between design and production. Myriads of organizations have begun to experience the changes that $\mathrm{AM}$ brings to design and production. However, the radical localization of manufacturing is yet unseen.

Horn and Harryson explore localization and decentralization in depth. First it is necessary to examine why manufacturing shifted towards centralized mass production. At the turn of the 20th Century America heralded the industrial revolution. New transportation methods and energy sources along with lower wages of unskilled workers (opposed to skilled carpenters, blacksmiths, glass blowers, etc.) meant lower prices, a broader customer base, and ultimately more profit. Gaining economies of scale "required simplified designs developed according to a series of rules that favored reproducible parts optimized for high-volume manufacturing and material-handling methods" (Petrick 
and Simpson, 13). Henry Ford's implementation of the assembly line further developed mass production. At that time in history the culture and technology were suited for mass production so the creation of objects transitioned from small-scale to large-scale and the basic principles have carried mass production into the 21 st Century.

Creating molds, casts and dies that enable large-quantity production is very expensive. The result of high costs is that "within a given mass production system there is an inverse relationship between the quantity of a product that is produced and the variety of product designs available. It is necessary [to] recognize that production tooling is not only expensive, but it also constrains the design of products based on innate limitations imposed by the various mass production processes" (Horn and Harrysson, 257). AM, unlike other manufacturing processes, does not require any tooling. By eliminating the need for extra, costly components for building, AM "facilitates the economical production of small lot sizes of parts" (Horn and Harrysson, 258). Being able to fabricate small batches in a cost-effective manner can reduce production lead time, allow more flexibility in the supply chain, and potentially transition manufacturing to mass customization and individualization instead of mass production. Because tooling is no longer required, many design for manufacturability (DFM) constraints are loosened. This opens the door for further product individualization as customers can suggest design changes without having any education in DFM. Though the potential is there, "the question of how mass customization and the decentralization/distribution of manufacturing will truly influence the economy, supply chain networks, and even the environment is yet unanswered" (Horn and Harryson, 281).

Taking individual manufacturing one step further, Lipson et al. predict "as new research leads to multimaterial functional freeform fabrication, we expect that incorporation of elastomers, lubricants, actuators, and sensors, electronics and power devices will allow faithful replication and electronic sharing of an ever-increasing scope 
of physical models and artifacts" (1033). With full and automated integration of internal components consumers may gain the ability to do more than just share and create models; they may be able to fabricate their own devices from home. As the internet democratized the "availability and distribution of information, 3D printing has the potential to do the same for the creation of physical products by initiating the regime of 'personal manufacturing'” (Bogue, 311). For every significant advance in a new technology, an old one becomes obsolete. "Throughout history, key innovations in manufacturing technology have had a profound impact on our society and culture" and an examination of AM suggests that it "may become a truly disruptive technology" (Horn and Harrysson, 256).

\subsection{Supply Chain Management}

\subsubsection{Fundamentals of Supply Chain}

As manufacturing transitioned from localized, specialty shops to centralized, mass production factories a need arose to amass large quantities of materials. Organizations, such as the Ford Motor Company, decided to simplify the processes of discovering, procuring, transporting, designing, and building by purchasing smaller companies that offered services in any combination of those processes. This amalgamation of organizations to control everything from raw material production to final sale of the main product, termed vertical integration (VI), became a popular form of organizing and operating massive companies. When vertical integration was a popular model, buyers and sellers competed for different resources. However, as markets expanded and began to globalize, organizations could no longer afford to handle the logistics of controlling an entire vertical while providing high-quality, low-cost products. The American auto industry experienced new competition as viable contenders like Toyota, Honda, and Nissan started to win market space with more dependable and 
cheaper cars. Williams, Esper and Ozment state "with the need to cut costs and focus on core competencies, many firms began to spin off units acquired via vertical integration and partner with other firms that provided the spun-off expertise. Consequently, the concept of supply chain management developed, as firms were attempting still to realize the cost management benefits of vertical integration while not carrying the burden of firm ownership along the supply chain" (707). Other drivers that contributed to the birth of supply chain management were "trends in global sourcing, an emphasis on time and quality-based competition, and their respective contributions to greater environmental uncertainty" (Mentzer et al. 2).

Mentzer et al. claim a distinction between supply chain (SC) and supply chain management (SCM); the former being a phenomena or "something that exists (often referred to as distribution channels), while the latter requires overt management efforts by the organizations within the supply chain" (4). They continue to define the supply chain as a "set of three or more entities directly involved in the upstream and downstream flows of products, services, finances, and/or information from a source to a customer" (Mentzer et al. 4). Supply chain management, on the other hand, can be defined as "set of approaches used to efficiently integrate suppliers, manufacturers, warehouses, and stores so that merchandise is produced and distributed at the right quantities, to the right locations, and at the right time in order to minimize system wide costs while satisfying service-level requirements" (Mehrjerdi, Excellent Supply Chain Management 53). This integration saw a "shift in inter-firm relations, from primarily arm's length to collaborative" (Williams, Esper, and Ozment, 708)

Different sizes of supply chains are occasionally recognized in literature. Scott, Lundgren and Thompson break SCs into simple and extended; whereas simple chains recognize a level above and below the focus organization, extended chains look beyond the firms immediately upstream and downstream (Figure 1). Figure 1 also demonstrates 
a bilateral flow between companies: materials flow forward (from raw material extractors to final customers) while information and funds flow backward (from final customers to raw material extractors) (Beamon, 281).

A. Simple supply chain

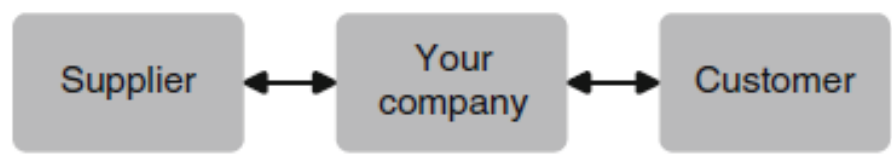

B. Extended supply chain

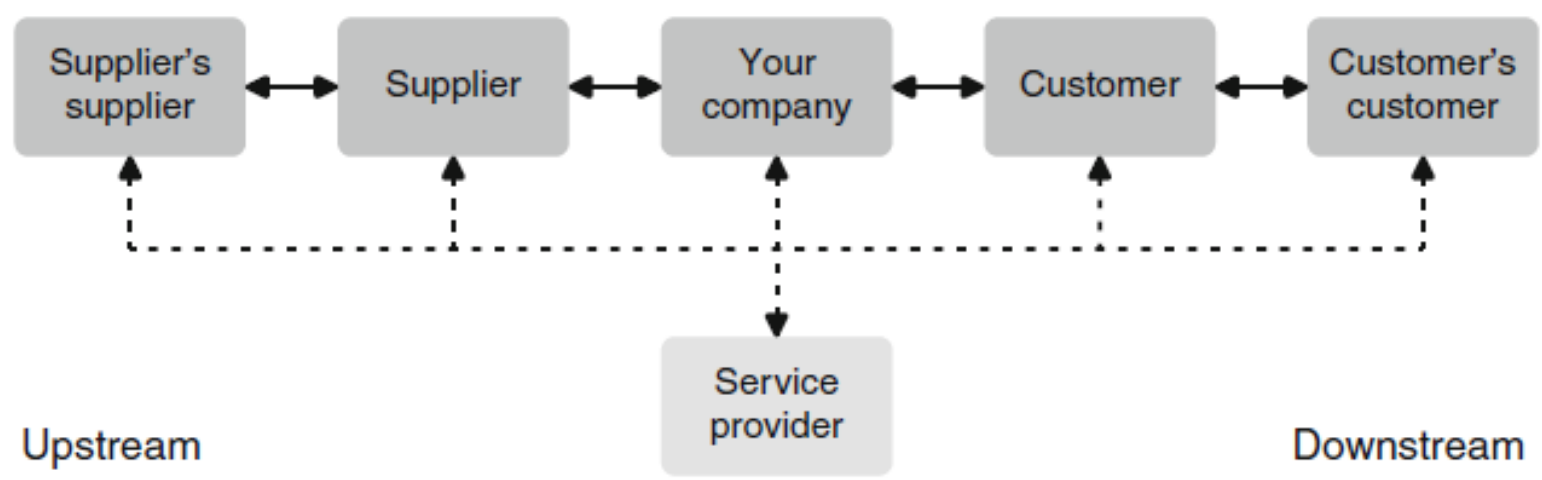

Figure 1-Simple and Extended SC (Scott, Lundgren, and Thompson, 5)

There are many ways to organize a supply chain and many considerations that must be taken into account. A way of accounting for all the considerations is by evaluating value drivers. According to An and Fromm, "a supply chain value driver is an operational metric that passes two important tests. First, it must be directly affected by a supply chain solution or initiative. Second, the metric must have an impact - albeit an indirect one - on at least one of the firm's Key Performance Indicators (KPIs). Think of a supply chain value driver as a 'lever' that an initiative can turn to impact business performance" (4). They go on to create a sample list of value drivers that includes forecast accuracy, demand planning cycle time, supply planning cycle time, manufacturing cycle time, and supply lead time. Another thing that all organizations within a supply chain must take into account is what triggers production. According to 
Scott, Lundgren and Thompson, "supply chains can be triggered by product supply (commodities) or by customer demand (customised products). The degree of customisation dictates how much and in which format the supplying company holds inventory: no stock at all, raw or basic materials only or sub-assemblies of their products as in the famous example of Dell computers. The strategies and associated decoupling of product supply from customer demand form a crucial part of supply chain management" (4).

There are other factors besides production triggers that should be considered when an organization is determining the optimum level of inventory and, relatedly, shaping supplier requirements and buyer policies. Inventory levels are always being managed against the risk of being out of stock. Levels may be raised to decrease the risk of running out of stock, particularly in situations that demand a high level of service (e.g. backup parts for a nuclear power plant). This brings a level of comfort, but works against business improvement initiatives such as reducing working capital and seeking higher returns on capital employed. In contrast, there is also a benefit to holding low inventory due to an increase in a "customer's ability to cope with changes in product specifications at the firm-level" (Stevenson and Spring, 955). Stevenson and Spring also point out that in a chain that employs just-in-time (JIT), low holdings in one firm means higher holdings and less agility elsewhere. Scott, Lundgren, and Thompson claim that "the aim [of supply chain management] is to minimise total supply chain costs, which can be achieved through holding little (but not too little!) inventory" (7).

A danger of holding small amounts of inventory, first identified by Jay Forrester in 1961 , is higher susceptibility to a negative phenomenon known as the bullwhip effect. In short, the bullwhip effect occurs when random meaningless sales fluctuations are converted by the system into annual or seasonal production cycles (Badar, Sammidi, and Gardner, 53). Without perfect and instantaneous communication upstream, a retailer 
in a supply chain can send a shock through the entire chain that increases in amplitude on a sinusoidal path. The beer game is a popular simulation that exemplifies the bullwhip effect with a four-echelon supply chain. At each organizational level, costs are attributed to inventory levels and penalties given to stock-outs as players adjust holdings based on random customer demand all the way downstream. Supply chain practitioners are often educated on the bullwhip effect by the beer game. Ongoing consideration of value drivers, production triggers, inventory levels, and the bullwhip effect moves individual entities and entire systems closer toward intelligent supply chain management. Mehrjerdi asserts "the excellent supply chain uses strategic SCM to excel across speed, quality, cost, flexibility and makes automatic data collection and on-time decision making possible" (Excellent Supply Chain Management 54) in order for it to be agile, adaptable, and aligned.

\subsection{2 e-Commerce}

The advent of the internet changed many things, as well as supply chains and their management. Supply chains were not strangers to the idea of fast electronic communication when the internet gained wide traction. Electronic data interchange (EDI) was in place to communicate between two firms that installed interoperable systems. Though EDI enabled automated transfer of information, implementation was costly and only worked between organizations that went into the venture together. Because of its cost, firms often chose to maintain SC relationships to leverage their investment rather than optimize cost or quality. The World Wide Web, on the other hand, offered relatively inexpensive communication with anybody else who had a computer and internet access.

Not only did this nearly eliminate a barrier to entry between new supply chain partners, it opened companies to easily-accessible information about other suppliers and buyers. It did not take long for communities to form online and create e-commerce. "The 
'one-to-one', specific nature of traditional EDI has been replaced by the 'one-to-many', 'many-to-one', and 'many-to-many' capabilities of the Internet-based e-supply chain. Thus, firms operating in the [electronic] SC environment have access to many more trading partners, or potential trading partners, increasing their opportunities for valueadded processes" (Williams, Esper, and Ozment, 711).

Williams, Esper and Ozment also comment on how the access to more trading partners changes relationships within supply chains. While organizations in traditional supply chains often built trusting alliances to increase stability and gain long-range cost benefits, e-commerce offers the benefit of adaptability in highly dynamic environments. E-commerce has hybridized the business relationship paradigms of both the vertical integration and supply chain eras: keep partnerships until needs change or are no longer met and then exit/enter new partnerships with little lead time or financial loss. "The ability of the e-supply chain to rotate and re-link sheds light on the change in the underlying philosophy brought about with this structure. The objective in ESCM is meeting goals, not maintaining collaborative relationships as with traditional SCM. Hence, the relative value of partnerships and alliances has become a salient issue" (Williams, Esper and Ozment, 708). In addition to changing the nature of SC relationships, e-commerce may enable companies to reexamine their supply chain priorities. Many traditional strategies focused on optimizing a one aspect of the chain like inventory levels, forecast accuracy, lead time, internal and/or external capacity, and price. The expanse of information and partnerships available through e-commerce may enable firms to consider more than one parameter at a time, depending on immediate needs.

\subsubsection{Supply Chain and RFID}

Several advances in technology have enabled better management of supply chains. In addition to EDI and the internet increasing communications between 
organizations, enterprise resource planning (ERP) has allowed for more integrated information storing and sharing. However, neither communication tools nor back-end databases follow the actual items being moved within the supply chain. This task is left to data capturing technology. Bar code has long been the standard tool for data capture, but RFID got a huge boost with Wal-Mart and the DoD's 2005 supplier mandates. Zelbst et al. believe that the use of RFID enables the information sharing technologies to provide the "necessary operational, tactical, and strategic information to supply chain partners on a real-time, synchronous basis" (582). The efficient capture of data on products moving through the supply chain is key to the real-time component of information generation and supply and, compared to bar code, RFID is a more efficient (Zelbst et al. 587). Baddar, Sammidi, and Gardner also claim that RFID can help dampen the bullwhip effect.

When examining RFID strictly monetarily, the direct benefits are different for each participant. In researching the impacts of RFID on SC costs Ustandag and Tanyas ascertained retailers experience the highest savings. While the decrease in lost sales may have an impact on the entire supply chain, manufacturers and distributers may see less direct benefits than retailers. Tajima takes a different approach at quantifying RFID benefits in the supply chain. Rather than just looking at money spend and saved that can be directly tied to RFID implementation, Tajima explored RFID as a competitive advantage. Figure 2 (Tajima, 270) shows two paths RFID provides towards gaining short-term advantages and long-term advantages. Short term competitive advantages come directly from exploiting the technology for the use it was intended for, which likely leads to direct process adjustment and improvement, and eventually an advantage. The long term advantages come from using RFID to explore facets of the manufacturing, distributing, storing, and selling that may have been previously unseen. On top of the short-term and long-term competitive advantage models, Tajima found 15 distinct 


\section{benefits that RFID can provide to manufacturers, distributors/logistics providers,}

retailers, and the entire supply chain as organized in Figure 3 (268).
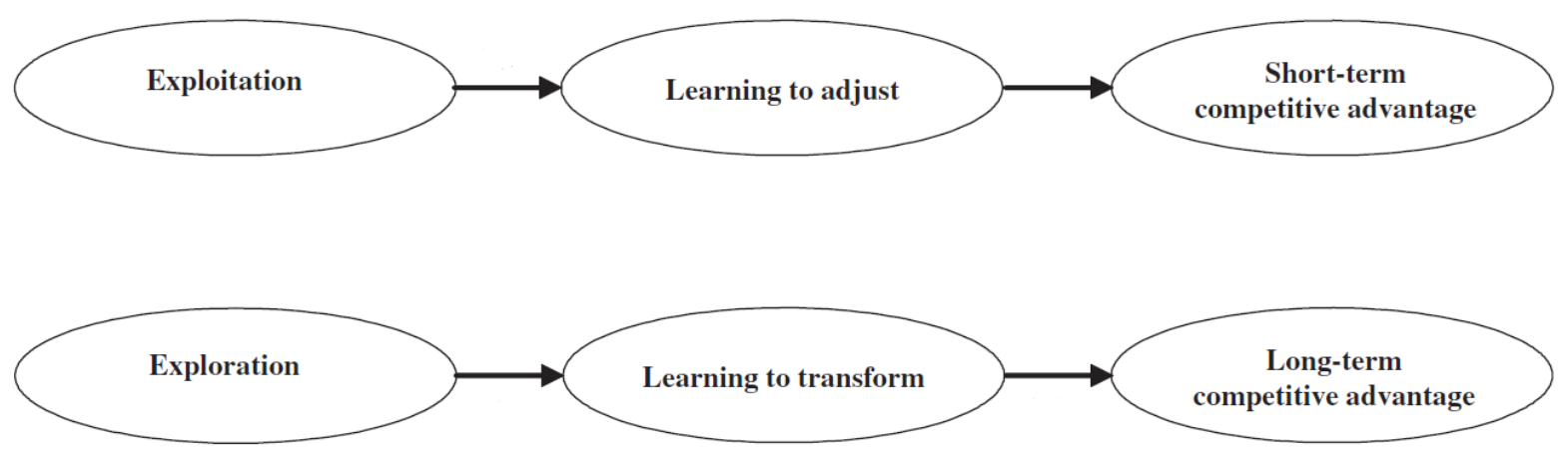

Figure 2- Competitive Advantage models for RFID in Supply Chain

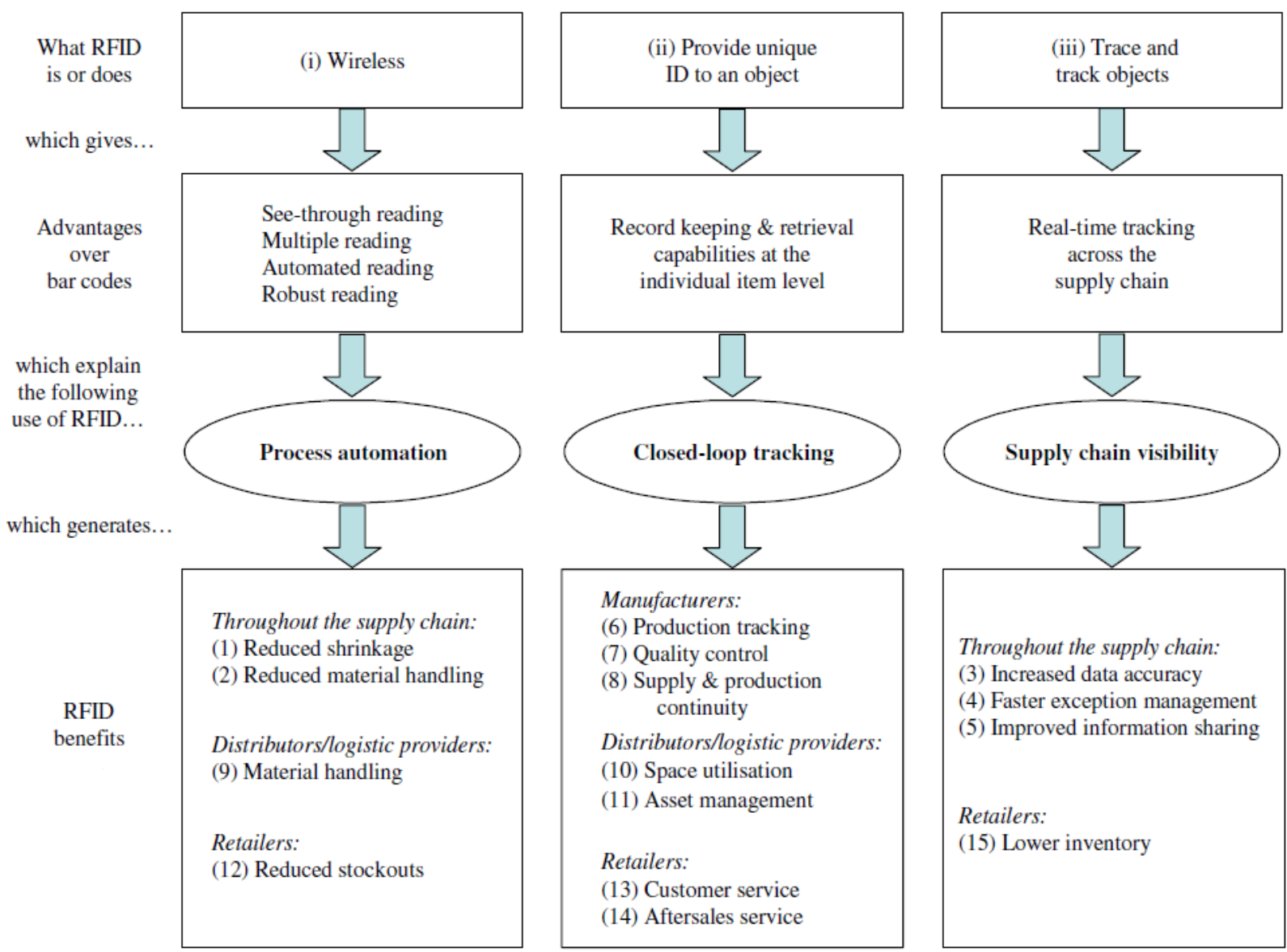

Figure 3- RFID benefits to the supply chain organized by echelon 


\subsubsection{Supply Chain and Additive Manufacturing}

Though AM has existed in manufacturing longer than RFID has, it only recently has matured past sole utilization as a rapid prototyping tool. As previously discussed, organizations are looking at using AM to create end-usable spare parts. AM may also begin to transition manufacturing from mass production to mass customization.

Furthermore, with the development of more automated and multi-material 3D printers may come a new era of household commodity in-home manufacturing. This has the potential to radically change supply chain strategies. Just as e-commerce altered relationships and priorities in SCM, additive manufacturing may further disrupt management models. 


\section{Methodology}

\subsection{Determination of AM and RFID Technologies to Test}

In order to test the feasibility of integrating RFID into 3D printed objects, a $2^{k}$ screening experiment was devised. The main goal was to see if any factors affected the RFID tag's read range, which was the dependent variable of the experiment. There were two major decisions that needed to be made before the test was fully designed: the type of AM technology that would be used to create the objects, and the type of RFID tag that would be inserted. As previously discussed, one of this paper's major areas of interest was how additive manufacturing may affect the proliferation of the Internet of Things. The concern is that household 3D printing may disrupt total connectivity of "things". With this in mind, FDM printing was chosen as the AM method to be tested due to its predominance in non-commercial settings. The other decision was the type of RFID tag to be inserted in the objects. Considering the limited budget of this experiment, active tags were ruled out due to their cost. This left passive LF, HF, and UHF tags. The common applications and properties of passive UHF tags made it a clear choice.

\subsection{Selection of Factors and Levels}

Once the experiment was narrowed to testing UHF tag readability in FDM created objects, factors were chosen. The physics of passive UHF tags leaves them susceptible to detuning around plastics from the dielectric effect. Absorption (energy lost when RF strikes an object), diffraction (RF bending when it strikes edges or narrow gaps), and refraction (RF changing direction between dissimilar media) may also affect the read range of passive UHF tags in FDM printed objects. Even if an inlay was tested in substrate created by traditional plastic manufacturing of the same material and dimensions, the RF may behave differently due to the layered process, inherent semidense nature, and controlled semi-density of AM. Four independent variables were 
chosen due to: 1 . the possibility that the factors may have an effect on the dependent variable and 2. their ability to be manipulated using standard software that supports FDM printing. In addition to the two qualifying measures, each independent variable has a direct or indirect effect on physical quality, print duration, energy consumption, and material cost. The four factors are material, infill, speed, and thickness.

Almost every desktop FDM printer has the capability to build with acrylonitrile butadiene styrene (ABS) and polylactide (PLA, a.k.a. polylactic acid). ABS and PLA have different temperatures at which they can be smoothly deposited from a FDM nozzle, which affects total energy spent making an object. ABS is generally heated to $220^{\circ} \mathrm{C}$ for normal printing whereas PLA is heated to $190^{\circ} \mathrm{C}$, making it more energyefficient. PLA is also considered a "bioplastic" because of its derivation from biological resources. A small amount of time is reduced from printing with PLA since the printer does not have to heat its nozzle or build plate as much, though the savings are insignificant unless the object is tiny. Both were used in the experiment, giving the "materials" factor two levels.

Infill is a property the user defines when generating the code that instructs the printer how to create the object. In basic terms, infill percentage is synonymous with internal material density. This has direct impacts on the amount of material used to print an object and, consequently, the time it takes to print. An object would have an estimated material volume equal to:

$[($ infill $\%) \times($ volume $)]+[(1-$ infill $\%) \times($ surface area $) \times($ outer shell thickness $)]$

$$
-[(1-\text { infill } \%) \times(\text { variable surface shell overlap })]
$$

A $1 \times 1 \times 1$ inch cube with 0.1 inch outer shell thickness (somewhat user defined) with $50 \%$ infill would have a used material volume of:

$$
\begin{aligned}
& {\left[(0.50) \times\left(1 \mathrm{in}^{3}\right)\right]+\left[(1-0.50) \times\left(6 \mathrm{in}^{2}\right) \times(0.10 \mathrm{in})\right]-\{(1-0.50)} \\
& \quad \times[8(1 \mathrm{in} \times 0.1 \mathrm{in} \times 0.1 \mathrm{in})+4(0.8 \mathrm{in} \times 0.1 \mathrm{in} \times 0.1 \mathrm{in})]\}=0.744 \mathrm{in}^{3}
\end{aligned}
$$


Which can be simplified to

$\left(1\right.$ in $\left.^{3}\right)-\left\{(1-0.50) \times[1 \text { in }-2(0.1 \text { in })]^{3}\right\}=0.744 i n^{3}$

since the space between the solid outer surface and inner fill area can be easily

calculated as a difference of volumes for a cube. The calculation becomes much more complicated for shapes with irregular geometries, especially when there is curvature. For a cube of the same dimensions and $10 \%$ infill, the used material volume would be $\left(1\right.$ in $\left.^{3}\right)-\left\{(1-0.10) \times[1 \text { in }-2(0.1 \text { in })]^{3}\right\}=0.5392$ in $^{3}$

The software that generates code to build an object determines the solid versus free space in a lattice form based on the size of the object. Two objects of the same dimensions, one having $50 \%$ infill and the other $10 \%$, will have empty spaces of different top-view height and width. However, if the object with $50 \%$ infill had a top-view footprint five times larger than the object with $10 \%$ infill, the actual height and width of free space would be about the same. To control the height and width of internal free spaces, they should be directly modeled into the CAD file and printed with $100 \%$ infill. This difference in internal density cannot be observed in traditionally manufactured plastics. It is possible that RF waves could experience different levels (compared to traditional manufacturing and other infill percentages) of detuning, absorption, diffraction and refraction because of the internal spaces.

Speed settings realistically affect three different print properties. The first two are directly tied together; extruder feed rate and travel rate. In order for material to be deposited across a specified length at a given total volume, the rate at which the material is deposited much change in relation to the rate at which the length is traveled. The last property, print temperature, is indirectly tied to the extruder feed rate. Increasing the print temperature assists the extruder to push filament through its nozzle faster. Changing the print speed also affects the quality of an object in a few ways. First, the surface finish is generally of lower quality. Second, the cool rate is effected in two ways: 
at higher speeds the difference between recently-deposited plastic and ambient temperatures is greater, and the time to the next layer of plastic deposited on time is decreased. This makes the object more vulnerable to warping and losing dimensional fidelity. Warping and unintended (and somewhat unpredictable) dimensional changes could potentially lead to variations in detuning, absorption, diffraction and refraction. Different speed settings also result in varied energy consumption per object created.

Object thickness as a factor, which is synonymous with tag depth in this case, needs little explaining. A designer could have reasons for both making an object thinner or thicker, and placing an RFID tag deeper under the surface of the object. From a 3D printing point of view, the size of an object directly relates to the speed at which it can be produced and how much material is consumed in the process. To EM waves, different object thickness may influence absorption amount. Material type, infill percentage, print speed, and object thickness are all common properties that designers who utilize FDM printers have the ability to control. They are often changed based on the object, designer, and organization requirements. For this reason, it was important for this experiment to search for and point out any effect the properties may have on RFID tag readability.

To capture the main effects and any interactions a four factor, two level fullfactorial design with 10 replications per point was created. This yielded 16 unique treatments and 160 runs. Each factor had a "high" and "low" level. Most FDM printers only have the ability to print ABS and PLA, so no further exploration into the material levels was necessary. Infill levels of 10 and 50 percent were determined empirically: from previous experience with FDM printing it was evident that there was a significant increase in material from 10 to 50 , however printing at $50 \%$ infill didn't consume an inordinate amount of material or time (as 75 or 100 would have). Speed levels were also developed somewhat empirically from software defaults. The program used to convert 
CAD files in .stl format to gcode readable by the printer is a popular, open-source software that supports different FDM printer models from several vendors. Users can easily choose between default and accelerated speed settings without any understanding of why, or by how much the feed rate, travel rate, and print temperature settings are adjusted. Finally, thicknesses of 0.2 and 0.4 inches per substrate half were chosen because they are in similar range to mass-produced passive UHF tags encapsulated in plastic substrate (like those made by Confidex, Xerafy and others).

\subsection{Design and Creation of Test Subjects}

In order to eliminate noise variation, a dependable RFID inlay needed to be used in the experiment. The inlay also needed to have a good starting read range, and be commonly utilized for tracking or similar purposes (versus animal tagging, access control, etc.). For these reasons, and previous experience by committee member Dr. Tali Freed and the author, the Alien Squiggle inlay was selected to be used in this experiment (see vendor data sheet in Appendix B, Figure 21).

Once the passive UHF inlay was selected, CAD models of the substrate design at each thickness were drafted based on the inlay's dimensions (Figure 4). The models were created in Autodesk Inventor 2014. Autodesk was chosen as the CAD software because the student version offers more features than Pro-E and SolidWorks. One of the most important features was the ability to export CAD to the stl file format. Additive manufacturing has adopted stl as an unofficial standard due to the way it creates geometries. Furthermore, the open-source software used to create gcode for FDM printers (ReplicatorG) only recognizes .stl files for conversion. 


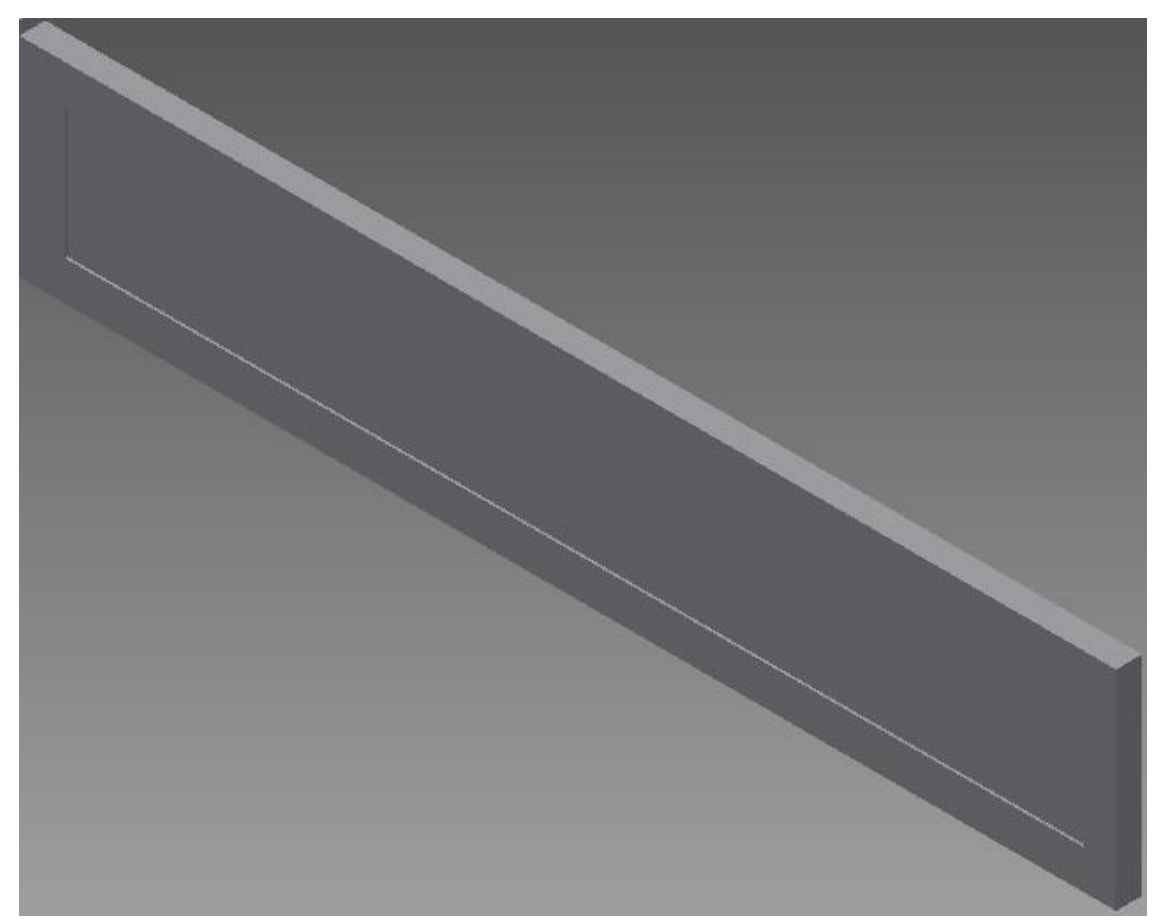

Figure 4- CAD model of 0.2 inch thickness substrate with depression for inlay

Test prints of the substrate designs was done with ABS and PLA. After verifying the designs would print with no issues, and that the depressions would fit a real inlay without noticeable extra space, the substrate designs were replicated to fit as many on the build plate as possible. Since all the post-processing (including taking the printed object off the build plate and removing any support structures) of FDM printers is currently manual (for all printers, not just the one used in this experiment), print jobs cannot be queued. This means that user intervention is required to complete one print job and initiate the next. In addition, the printer's extruder and build plate take time to climb from ambient temperature to print temperatures ( 190 to $230^{\circ} \mathrm{C}$ for the extruder, 50 to $110^{\circ} \mathrm{C}$ for the build plate). These two factors made it most time and energy-efficient to print as many substrate halves at a time as possible. Two different layouts were tested, and the one that visually appeared to have the least warping was eventually chosen to be the design to print all the substrate halves (Figure 5). 


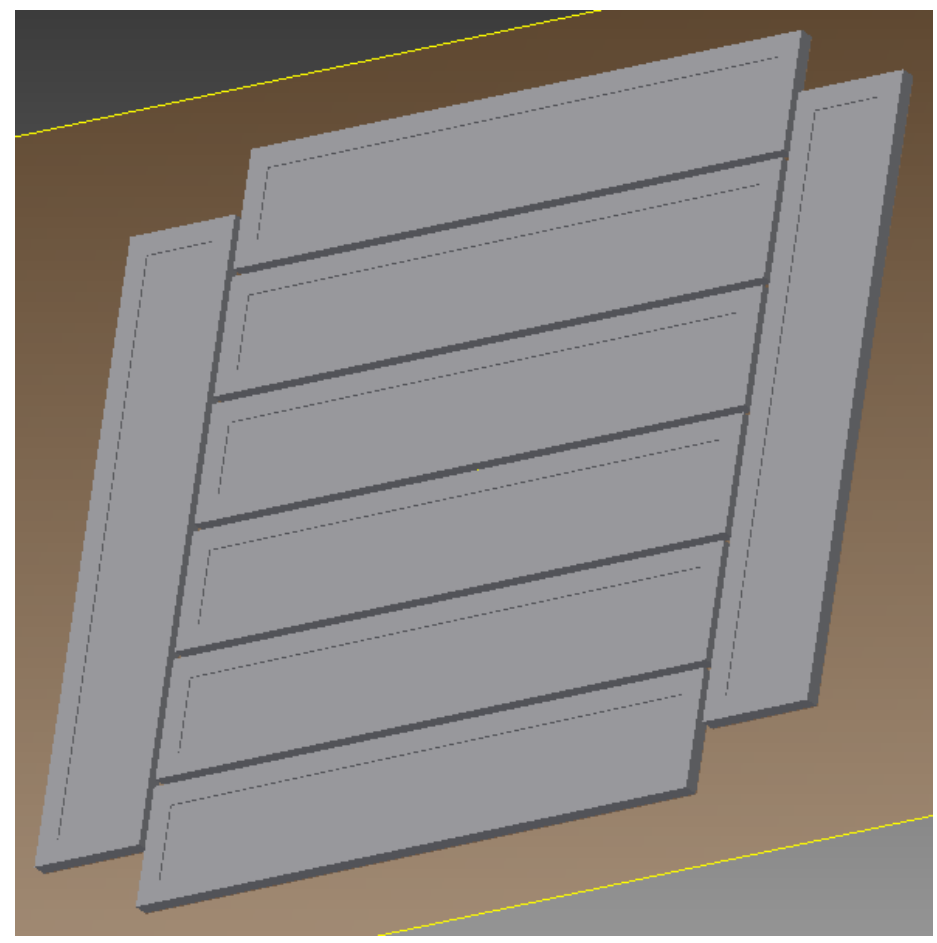

Figure 5- Final Design of 0.2 inch Thickness Substrate

From the finalization of the substrate CAD models at 0.2 and 0.4 inch thicknesses, .stl files were saved for each of the 16 treatments. Then gcode was created in ReplicatorG for each treatment, which accounted for the material, infill, and speed factors. ReplicatorG provides designers with four options regarding support structure when converting .stl to gcode. These include: no raft or support, raft with no support, raft with exterior support, and raft with full support. Because the substrate design did not have any edges hanging over empty space, no support structures were necessary. However, adding raft (a checkered base level with thick diameter plastic that extends slightly past the object's bottom-layer profile) can reduce warping and help maintain dimensional fidelity of objects that have a relatively large profile compared to their height (as the test substrate had). Adding raft does have disadvantages. The extra plastic adds to the total material consumed and time per print. This has negative cost and environmental impacts. Furthermore, the raft must be manually removed from the underside of the printed object. This can be a time-consuming process; for each of the 
48 prints in this experiment it took anywhere from 10-45 minutes to remove the raft. A simple calculation using an average of 27.5 minutes for each of the 48 runs gives 22 total labor-intensive hours spent on removing raft alone. Post-processing time was predictable, but the amount was unexpected.

JMP was used to create a randomized print order. Each print yielded eight identical halves, which created four full substrates per print. Because the original experimental design called for a minimum of 10 replications per point, each unique substrate model was printed three times. This increased the number of available replicates to 12 per point and the total data collection points to 192 (up from 160). The print order was created using JMP, which provided 48 (three replicates of 16 unique treatments) randomly-ordered runs. Printing of the substrate then commenced.

Once all the substrate halves were printed, the inlays were inserted and the halves connected. The inlays were "wet" (having a clear, thin adhesive backing) so their placement on the bottom half was simple and routine as seen in Figure 6. Connecting the substrate halves took some consideration. First, it needed to be efficient from a time and cost standpoint. Second, the halves needed to be easily separated in case a dead or weak tag was placed inside (this actually occurred half a dozen times). Lastly, the connection needed to be consistent to avoid noise being added to the dependent variable. Viable options were using glue/epoxy/silicon, tape, or heat to connect the halves. By nature, heating the halves enough to melt them together changes some of the structure and makes separation a destructive process. It was cost-prohibitive to create an automated process for dispensing a consistent amount of glue, epoxy or silicon to the same area for each substrate. Separation of the halves would have been less destructive than the first process, however it would not have been quick or easy. This left using tape to conjoin the substrate halves. Tape was inexpensive, easily accessible, quickly applicable, and allowed for the easiest separation in case of a bad 
inlay. To reduce noise, the halves were joined by a single piece of painter's tape taken from the same roll and placed around the middle of every pair of substrate halves (Figure 7).

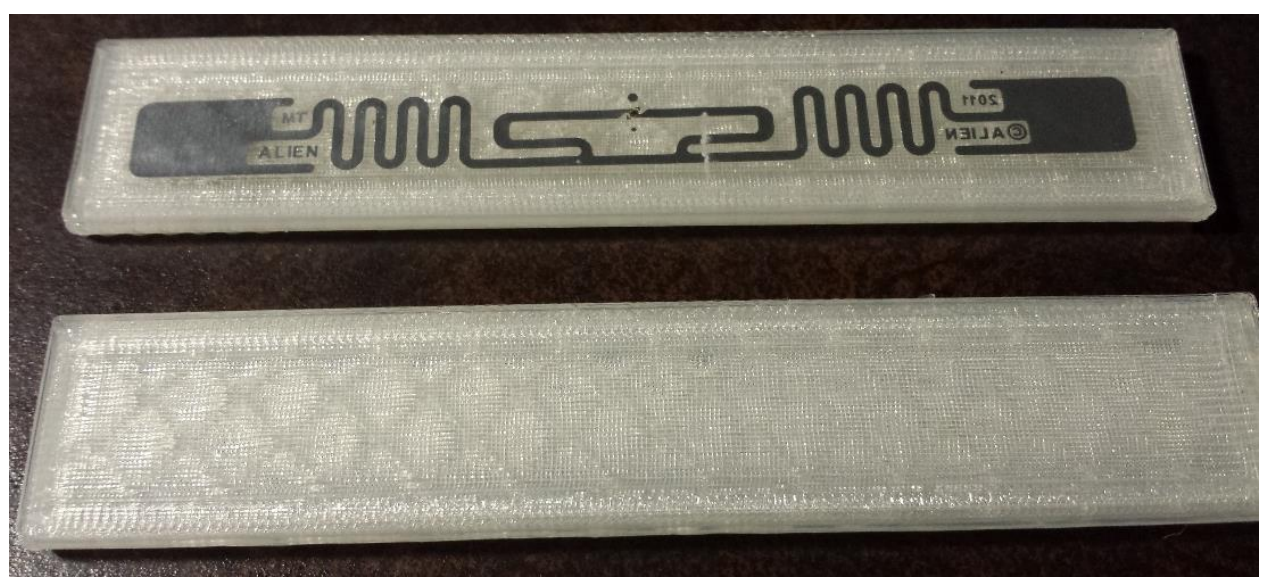

Figure 6- RFID inlay and unconnected substrate halves

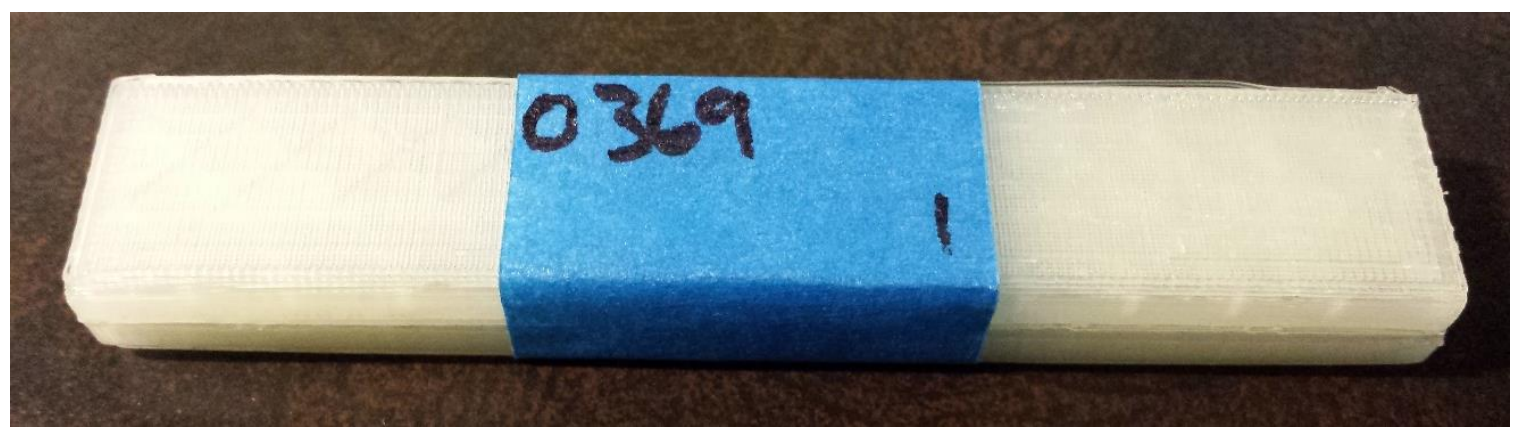

Figure 7- Assembled Substrate Halves

\subsection{Physical Setup and Testing}

As discussed in the RFID literature review section, every system is made of tags, readers/antennas, and a back end. The remaining system components were borrowed from Poly GAIT, the Cal Poly Laboratory for Global Automatic Identification Technologies directed by Dr. Tali Freed. The lab has many Poynting circularly-polarized antennas that have proven to be reliable. A structure made from PVC was used to position an antenna and keep it at a constant height and orientation (Figure 8, Note: 
three antenna are shown but only one was connected to the reader to remove the possibility of outgoing wave interference).

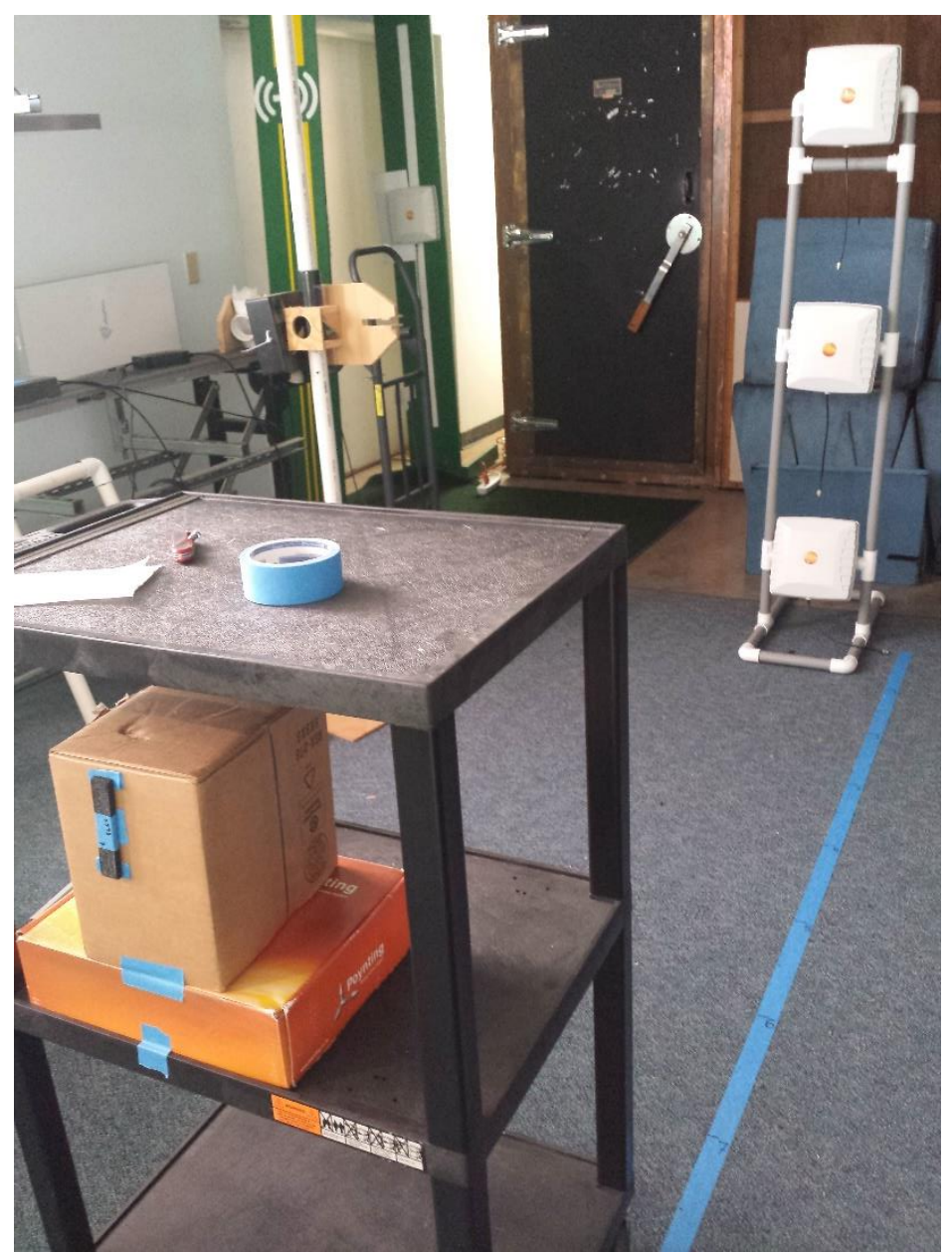

Figure 8- Experimental Setup: cart, measurement/guide tape, and antenna

Poly GAIT also owns several Sirit Infinity 510 readers. Although Sirit was acquired by 3M and the Infinity 510 was discontinued, several lab computers still have reader testing software installed. The software, Reader Start Tool (RST) and Reader Test Tool (RTT) allow users to plug a reader directly into a computer via Cat 5 cable and test various commands and event procedures. Antenna settings can also be adjusted with the RTT. One page of the RTT logs the number of arrivals per tag, which is basically the number of times the tag is "seen" by any of the antennas connected to the reader. Observing the distance at which tag arrivals are registered is a good method of determining tag read 
range. Therefore, the Sirit Infinity 510 was used as the reader and its RTT was used as the back-end to capture and display data. Antenna power levels were set so tags that weren't being tested wouldn't be picked up. By reducing the antenna output, the tag's full read range could not be determined. Experimentally, this was acceptable because the goal was to discover any factor or interaction effects, not determine the maximum range.

The last steps before starting the experiment were creating a consistent rangetesting method and establishing a measurement system. Because readability is affected by a tag's orientation in relation to an antenna, it was important to maintain a consistent orientation at all ranges. To do this, and to keep a constant travel height, a box was placed on a rolling cart for the tags to attach on. Then, a piece of painter's tape was placed on the ground, perpendicular to the antenna faces, that dual-served as a track/guide for the cart and a measurement system. Marks were made on the tape every three inches from the base of the antenna structure.

When the test environment was completely set up, tags were individually brought closer to the antenna and the last four digits of the tag ID were written on the tape for positive identification. The tag was then attached to the box on the cart and moved towards the antennas at an approximate rate of three inches every five seconds. When the RTT registered that particular tag, the distance was recorded, the tag was removed, and the process was repeated for the next tag in line. If a tag did not register in the normal range, it was tested at a closer range. Any distance that was noticeably less than the average distance of the replicates collected of the same treatment was ruled as inlay variability and the inlay was replaced. This way, noise introduced by inlay variability was reduced.

One notable problem was encountered during experimentation. Several tags started to register a few feet beyond the normal range. This would have been acceptable, however the tags would hit a cold spot (zero reads) before the cart was 
moved to the average range. Only one antenna was active during the experiment to eliminate the possibility of creating such a zone. Although a spectrum analysis was not performed on the environment during experimentation, there were no visible sources of EM (i.e. other antenna, radios, electronics, etc.) in the area that would have likely caused such a focused dead zone. Because the dependent variable in the experiment was tag read range, which implies the furthest distance a tag can consistently be read, any measurement that was preceded by an interval of zero reads was disqualified. 


\section{Results}

\subsection{Statistical Analysis}

\subsubsection{Initial Analysis}

After the data was collected it was analyzed in Minitab (see Table 8, Appendix A). The "Analyze Factorial Design" in Minitab's DOE section was used to conduct an ANOVA test. An Analysis of Variance would provide p-values to test the hypotheses:

$$
\begin{gathered}
H_{0}: \mu_{A}=\mu_{B}=\mu_{C}=\mu_{D}=\mu_{A B}=\mu_{A C}=\mu_{A D}=\mu_{B C}=\mu_{B D}=\mu_{C D}=\mu_{A B C}=\mu_{A B D}=\mu_{A C D} \\
=\mu_{B C D}=\mu_{A B C D}
\end{gathered}
$$

$H_{1}: \mu_{i} \neq \mu_{j}$ for at least one pair $(i, j)$

where $A, B, C$, and D stand for each of the main effects (material, infill, speed, and thickness) and combinations (e.g. AB) stand for interactions between factors. In plain language, the null hypothesis $\left(\mathrm{H}_{0}\right)$ states the means of all main effects and interactions of factors are equal. The alternative hypothesis $\left(\mathrm{H}_{1}\right)$ states at least one of the means of the effects or interactions is different. If a p-value is lower than the level of statistical significance $(\alpha)$, which is 0.10 for this screening experiment, the null hypothesis can be rejected.

There are several assumptions that are made about the data when doing an ANOVA test: normality, constant variance, and independence. Figures 16 and 17 (Appendix A) show a histogram of the raw data on top of a normal curve and a group of residual plots. The histogram shows a weak resemblance between the raw data and a normal distribution. The Normal Probability Plot and Versus Fits (which tests constant variance) in Figure 17 also make somewhat weak cases. One outlier is clearly shown (later pointed out as an "unusual observance" in the initial ANOVA). This means that the data does not definitively meet the assumptions for ANOVA (discussed later). The 
analysis was continued with the understanding that any significant findings could be validated better in a modified version of this experiment.

The initial analysis did not return any $p$-values below 0.10 . In fact, the only value close was attributed to the interaction of material and thickness, at $p=0.163$ (Table 8 , Appendix A). Several unusual observations were pointed out (Table 9, Appendix A). From here, two main paths were taken: 1. keeping the unusual observations and doing another ANOVA without third order interactions with p-values above 0.40 and 2 . removing the unusual observations and doing another ANOVA.

\subsubsection{Analysis Path 1}

As shown in Table 2, an ANOVA was done without the following third-order interactions: material * infill * speed (ABC), material * speed * thickness (ACD), and infill ${ }^{*}$ speed * thickness (BCD). This yielded two significant interactions: material * thickness (AD) with a p-value of 0.028 and material * infill * thickness (ABD) with a p-value of 0.060. Figure 18 (Appendix A) also exhibits the significance of the interactions. Though $A D$ and $A B D$ are significant, the effect they have is miniscule (Table 3 )

In addition to revealing significant effects, Table 2 shows speed, and any interaction it is included in, has relatively high $p$-values. Speed was removed from the model and an ANOVA was run again. Table 10 (Appendix A) demonstrates that removing speed did not lower $p$-values for other effects enough to make any more significant. 
Table 2- ANOVA without selected 3rd order interactions

\begin{tabular}{|lrrrrrrr}
\hline Analysis of Variance for Read Range (coded units) & & & \\
Source & DF & Seq SS & Adj SS & Adj MS & F & P \\
Main Effects & 4 & 0.20238 & 0.16301 & 0.040753 & 1.01 & 0.405 \\
Material & 1 & 0.00586 & 0.02447 & 0.024474 & 0.61 & 0.438 \\
Infill & 1 & 0.02693 & 0.04684 & 0.046841 & 1.16 & 0.283 \\
Speed & 1 & 0.05962 & 0.01758 & 0.017578 & 0.43 & 0.511 \\
Thickness & 1 & 0.10997 & 0.04117 & 0.041173 & 1.02 & 0.314 \\
-Way Interactions & 6 & 0.37160 & 0.42043 & 0.070071 & 1.73 & 0.116 \\
Material*Infill & 1 & 0.03875 & 0.08117 & 0.081167 & 2.01 & 0.158 \\
Material*Speed & 1 & 0.03444 & 0.06184 & 0.061844 & 1.53 & 0.218 \\
Material*Thickness & 1 & 0.18629 & 0.19844 & 0.198441 & 4.91 & 0.028 \\
Infill*Speed & 1 & 0.01614 & 0.00467 & 0.004672 & 0.12 & 0.734 \\
Infili*Thickness & 1 & 0.08976 & 0.04117 & 0.041173 & 1.02 & 0.314 \\
Speed*Thickness & 1 & 0.00622 & 0.02447 & 0.024474 & 0.61 & 0.438 \\
3-Wy Interactions & 1 & 0.14534 & 0.14534 & 0.145343 & 3.59 & 0.060 \\
Material*Infill*Thickness & 1 & 0.14534 & 0.14534 & 0.145343 & 3.59 & 0.060 \\
Residual Error & 167 & 6.75205 & 6.75205 & 0.040431 & & \\
Lack of Fit & 3 & 0.02478 & 0.02478 & 0.008260 & 0.20 & 0.895 \\
Pure Error & 164 & 6.72727 & 6.72727 & 0.041020 & & \\
Total & 178 & 7.47137 & & & &
\end{tabular}

Table 3- Effects and Coefficients without selected 3rd order interactions

\begin{tabular}{lrrrrr|} 
Estimated Effects and Coefficients for Read Range (coded units) & \\
Term & Effect & Coef & SE Coef & T & P \\
Constant & & 8.55393 & 0.01623 & 526.94 & 0.000 \\
Material & 0.02537 & 0.01269 & 0.01631 & 0.78 & 0.438 \\
Infill & 0.03495 & 0.01747 & 0.01623 & 1.08 & 0.283 \\
Speed & -0.02150 & -0.01075 & 0.01631 & -0.66 & 0.511 \\
Thickness & -0.03276 & -0.01638 & 0.01623 & -1.01 & 0.314 \\
Material*Infill & 0.04621 & 0.02310 & 0.01631 & 1.42 & 0.158 \\
Material*Speed & 0.04015 & 0.02008 & 0.01623 & 1.24 & 0.218 \\
Material*Thickness & 0.07225 & 0.03612 & 0.01631 & 2.22 & 0.028 \\
Infill*Speed & -0.01109 & -0.00554 & 0.01631 & -0.34 & 0.734 \\
Infill*Thickness & -0.03276 & -0.01638 & 0.01623 & -1.01 & 0.314 \\
Speed*Thickness & 0.02537 & 0.01269 & 0.01631 & 0.78 & 0.438 \\
Material*Infill*Thickness & 0.06183 & 0.03092 & 0.01631 & 1.90 & 0.060 \\
\hline
\end{tabular}

\subsubsection{Analysis Path 2}

The seven data points termed "unusual observations" in the original ANOVA test (Table 9, Appendix A) were removed from the original data set. An ANOVA test was run again (Table 11, Appendix A). There were no effects or interactions with $p$-values below 0.10, although several increased and others decreased (Figure 19, Appendix A). The material * infill * speed interaction had a p-value of 0.108 , but the analysis did not continue with the removal of high $p$-value third-order interactions as it did in Path 1 . This was because there were five more unusual observations pointed out (Table 12, 
Appendix A). The data points were removed from the modified set and an ANOVA test was run. This time several effects were considered significant (Figure 20, Appendix A), however 9 more unusual observations were listed (Table 13, Appendix A). This path of analysis was stopped because all the unusual data points were around one measurement increment ( 3 inches $=0.25$ feet $)$ away from the original data set average 8.5475 (Table 6, Appendix A). If the software recommended removing data points outside the standard deviation, which was less than the smallest measurement increment in the original data set (Table 6), the data would no longer accurately represent the experiment.

\subsubsection{Kruskal-Wallis Test}

In the event of a data set not being normal, non-parametric tests can be used to analyze it. The Kruskal-Wallis test is used to observe the equality of treatment means and often serves as an alternative to ANOVA when normality cannot be justified. Unfortunately, only one factor can be analyzed at a time. A Kruskal-Wallis test was performed on each of the main effects of the experiment: material, infill, speed, and thickness. Tables 14 - 17 (Appendix A) show no significance of any single factor on read range.

\subsection{Experiment Results}

By removing insignificant third-order interactions from the original ANOVA test, the interactions of material * thickness and material ${ }^{*}$ infill * thickness had p-values of 0.028 and 0.060 respectively. Thus, the null hypothesis could be rejected at $\alpha=0.10$. Generally, the interactions of highest order are used to explain variability. In this experiment, however, the three-factor effect had a $p$-value that could be eliminated in a study with a higher level of significance (0.95). In case this study inspires future research and the experimenter prefers $\alpha=0.05$, interaction plots for both material * thickness and 
material * infill * thickness are included (Figures 9 and 10). The magnitude of both effects are on the scale of hundredths of an inch. The researcher believes that such small effects do not make a practical difference to the read range of a passive UHF RFID tag. Furthermore, the data does not strongly support the assumptions of normality and equal variance that must be met for a valid ANOVA test. Hence, the applicable conclusion of this experiment is that no claim can be made for material, infill, speed, or thickness of a 3D printed object having an effect on passive UHF tag read range.

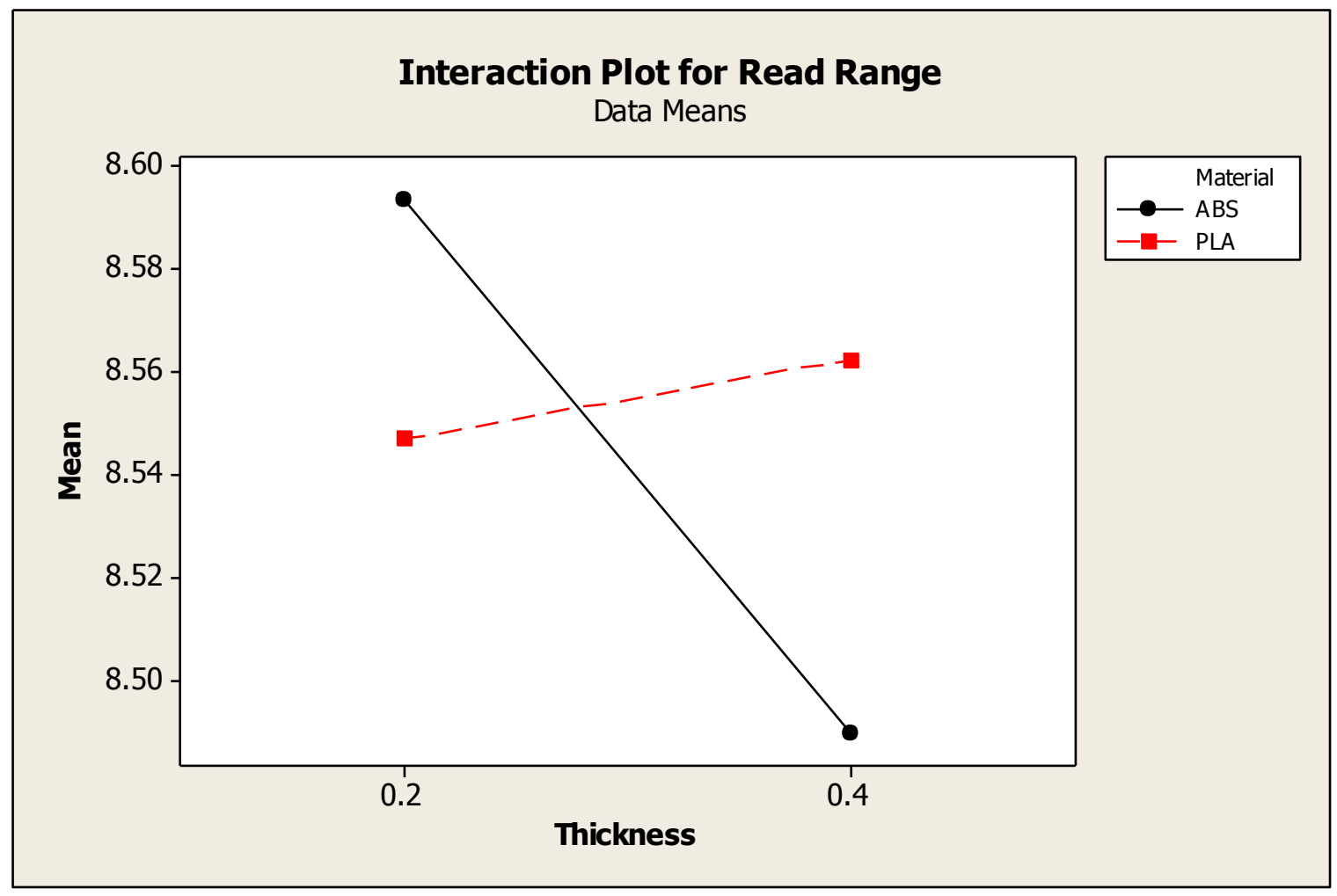

Figure 9- Interaction Plot for Material and Thickness 


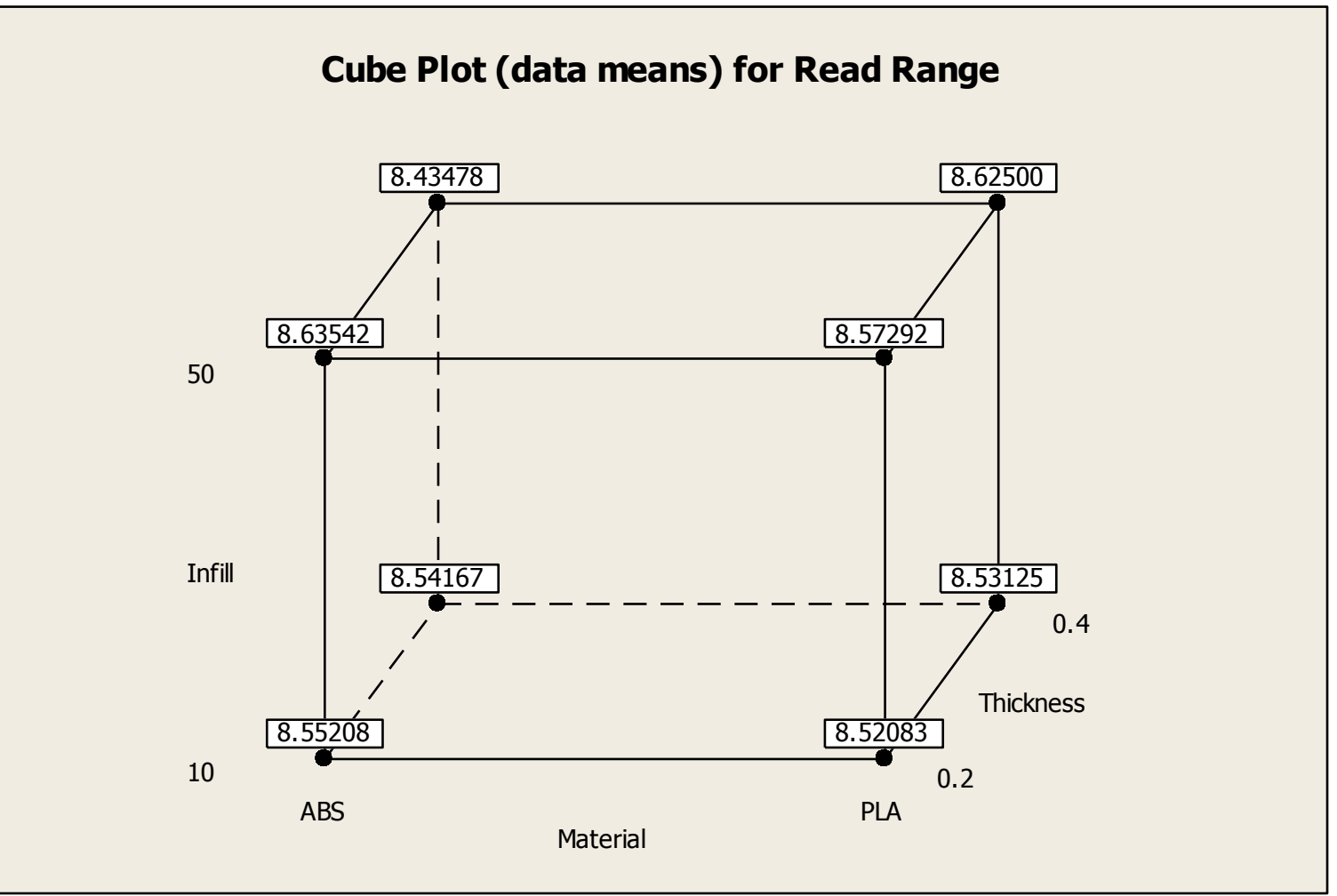

Figure 10- Cube Plot (3D Interaction) for Material, Infill and Thickness

The difference in means from an interaction of Material * Thickness, and Material * Infill * Thickness can be somewhat explained by the dielectric effect (brought up in Section 2.1.3). Every medium has a dielectric constant, notated as $\chi$ or $\varepsilon_{\mathrm{r}}$, with vacuum equal to 1 and increasing from that base. Media with higher dielectric constants act more as electric insulators in the sense that they resist an electric field. Due to the atomic structures of non-conductive substances, molecules are liable to be polarized in the presence of an external electric field, which produces an opposing internal electric field. If an RFID inlay is completely embedded in a material that experiences this effect, known as a dielectric, it can suffer. An EM wave's speed travelling through a dielectric changes from c to:

$$
v=\frac{c}{\sqrt{\varepsilon_{r}}}
$$


This affects the resonance of the RFID antenna. The dielectric constants of materials that may come into contact with RFID tags varies greatly: air $~ 1$; wood $\sim 2$ to 6 ; paper 3; rubber $~ 3$ to 4 ; glass $\sim 4$ to 10 ; water $\sim 80$. The constants of the materials used in this experiment lie within ranges that depend on chemical variations, with $A B S$ ranging from 2.0 to 3.5 and PLA ranging from 3.0 to 3.8. It should be noted that the manufacturers of the filament used to create the substrate in this experiment chose to withhold information at this level of detail. Even so, the dielectric constant values for ABS and PLA are very similar and would present similar obstacles to the RF. This confirms the conclusion that, though there may be a difference in read range, it is negligible from a practical standpoint.

The differences in read range might also stem from the inlays. A batch of 48 inlays were tested independently of the original experiment to observe their read range without substrate. The bare inlay read range mean of 8.5781 and standard deviation of 0.1171 (Table 7, Appendix A) is very close to the experiment's mean of 8.5475 standard deviation of 0.2049 (Table 6, Appendix A). This difference in standard deviations, which is less than $1 / 8$ inch, suggests that the original experiment's Material * Thickness and Material * Infill * Thickness interactions may exist. It also confirms that the effects are practically negligible. A more in-depth examination of the effect that the inlays may have on the experimental results is discussed in the next section.

\subsection{Suggestions for Additional Experimentation}

This experiment had a number of areas that can be improved upon in future studies. First is the issue of high-read zones outside of what can be considered the read range. There are two options that may assist researchers in at least explaining the phenomena, if not eliminating it: spectrum analysis and removing unwanted EM waves. Mapping an environment with a spectrum analyzer is common practice in RFID 
implementations with stringent accuracy, speed, or location resolution requirements. If the removal of unwanted EM waves is possible, this is a preferred alternative. Faraday cages that block outside radiation allow an experiment to be run in "ideal" conditions.

Decreasing the measurement increments may provide more insight when analyzing data. The data collected in this experiment could have fit a normal distribution very well, but the granularity of the measurements compounded with the narrow range of data points made it hard to do anything more than speculate on a shape. The experimenter must consider the real costs and benefits of gathering more precise data points. If, for some reason, antennas are severely limited in power output, or HF tags are being tested, differences on the scale of decimal-inches could be worth noticing.

Unknown noise from inlay-to-inlay differences can be reduced by measuring the read range of each inlay on a common surface and treating them as covariates in the ANOVA. This way, any difference in read range can be solely attributed to the independent variables of the experiment. Finally, if the researcher were to expand the scope of this experiment without time or financial constraints, additional levels would be added to the infill and thickness factors. It is conceivable that those factors may affect read range at values that were not tested here. 


\section{Discussion}

\subsection{Experiment}

The result of the experiment has several direct and immediately applicable ramifications. For all practical purposes printing with ABS or PLA, at infill percentages between 10 and 50, at the ReplicatorG's default and accelerated speed, with an inlay between 0.2 and 0.4 inches below the surface, has a negligible effect on the tag's read range. This enables designers who wish to identify FDM printed objects with UHF RFID tags to modify the object's most commonly changed properties (inside the tested bounds) without concern for how it might affect the RFID tag. Additional research with expanded parameters should be conducted to allow designers to confidently push the limits even more.

When the spirit of the testing is combined with the literary research conducted on RFID, AM, and SCM, the breadth of current and future applications explode. As it currently stands, integrating RFID into FDM printed items is completely feasible, if not efficient because of time needed for manual steps. Without having tested any other additive manufacturing techniques with RFID, no conclusive statements can be made at this time about merging objects created with technologies other than FDM. However, if the competence does not currently exist, it is not unreasonable to claim that engineering is on the cusp of being able to incorporate RFID in any item created through AM. A historical study of RFID and AM shows significant advances in capabilities when a market has professed a need. Barring extreme circumstances, it is safe to forecast the development of technologies that will facilitate fully automated integration of RFID into objects created with FDM. The repercussions of this ability will be felt in many fields. 


\subsection{Possible Present Interactions}

\subsubsection{Automatic Identification of Part Revisions and Models}

Additive manufacturing enables organizations to cost-effectively create highly customized objects. In R\&D, this facilitates failing fast and failing often to reach a good design in a quick timeframe. If a product in development has several models or revisions with minute differences, it may be impossible to visually distinguish them. Furthermore, certain validation checks like aerodynamic testing and tangible finite element analysis prohibit non-automatic identification with a physical label. Other organizations are using AM to create custom tools to support the adage "fit the tool to the job, not the job to the tool". Particularly in aerospace and biomedical/healthcare environments, traceability is paramount due to regulation and audits by bodies like the FAA and FDA. RFID promotes seamless identification and tracking of development parts and specialty tools. Besides the intangible benefits that come from instrumenting such items with internal RFID tags, it is fairly easy to realize a ROI through the reduction of human effort and error, as well as safeguarding against the direct and indirect penalties of audit findings.

\subsubsection{Anti-Counterfeiting}

Counterfeiting is an issue that affects every industry. Advances in 3D scanning and multi-color, multi-material 3D printing will make everybody more vulnerable to counterfeiting and its associated consequences. It can impact everything from an extended supply chain down to an independent artisan. In a supply chain, raw materials, components, sub-assemblies, and final products can all be forged. Take, for example, a wheel for the Mars Rover: a block of titanium can be replaced with a hollow or filled block of titanium-plated steel between the RM supplier and manufacturer, and the precision-machined wheel can be replaced with a porous aluminum replicate coated with titanium en route from the manufacturer to a NASA lab. That specialty product has a 
small and easily traceable chain, but is still in danger. Products that are mass produced and transported by large distribution companies are much more open to the threat of illegal forgery. By placing RFID tags on all objects moving through a supply chain, counterfeiting can at least be detected between any sequential processing points.

The counterfeiting of hand-made items produced by an individual or small workshop may have less severe financial impacts on a macro view. However, the individual's livelihood is still under attack. Placing an irremovable RFID or NFC tag inside the customized object can provide the artisan with a method of verifying the authenticity of his/her object. This can help to maintain the value of a single object and the entire collection.

Counterfeiting certain objects can also gain access objects or places that have much more intrinsic value than the item being counterfeited. Keys are an excellent example. Many large companies have already gone to RFID badges for external and internal access control. However, many businesses and the overwhelming majority of households still rely on physical keys for keeping unwanted visitors out. Prior to additive manufacturing, a key could be illegally duplicated if it was stolen and reproduced by a locksmith with few scruples. However, the original had to be missing from its rightful owner to counterfeit the key and, if the victim noticed at any time prior to duplication, the locks could be changed. The author demonstrated the ability of a key to be inconspicuously recreated through 3D printing with two pictures of his parents' house key captured by a cell phone camera (Figures 11 and 12). 


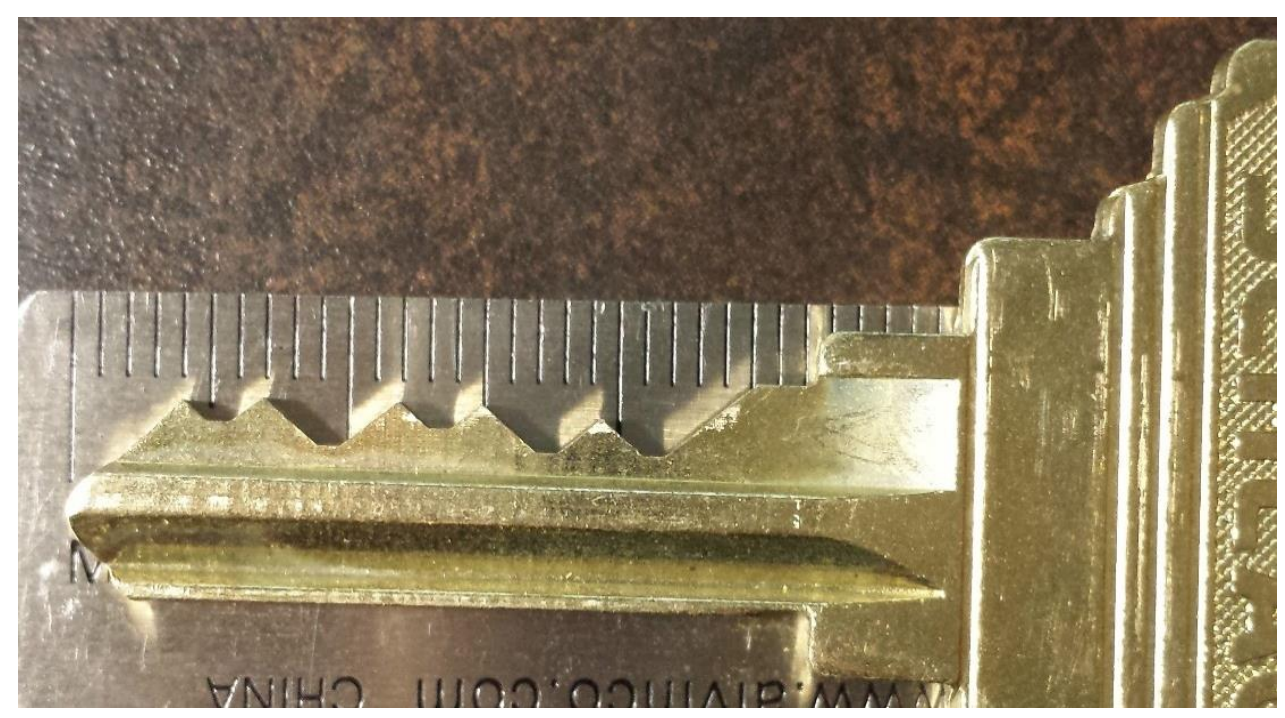

Figure 11- Side profile of house key

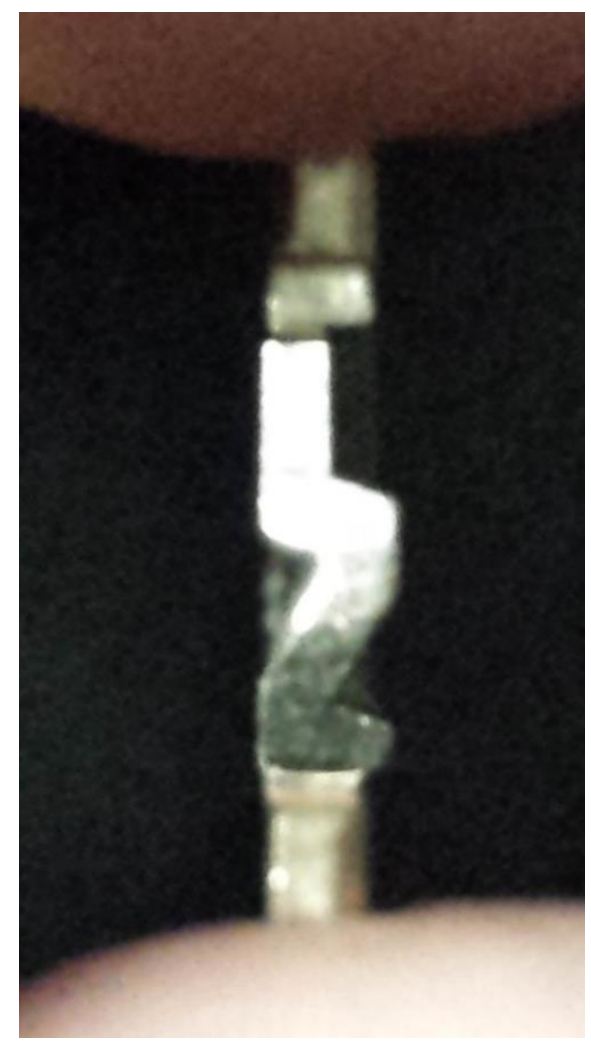

Figure 12- Front profile of house key

It took 30 seconds to take pictures of the front and side profiles of the key and measure its width and length. A working plastic replicate (Figure 14) was drafted in a CAD program (Figure 13), converted to gcode, and printed within an hour. The value of the 
key itself is a few dollars, but access to a household or business (with no signs of forced entry) is easily worth five or more digits. Savvy security companies can use this frightening reality to push for the ubiquitous adoption of RFID-based access control systems.

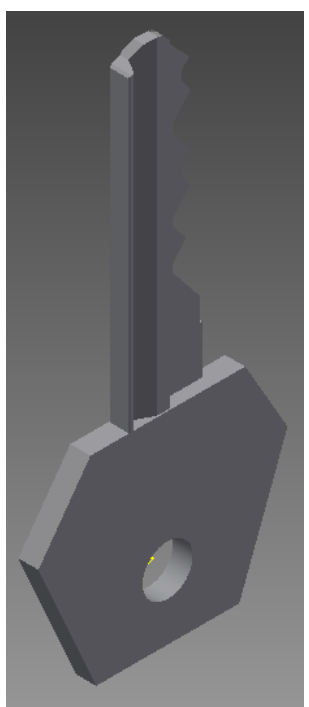

Figure 13- CAD model of house key

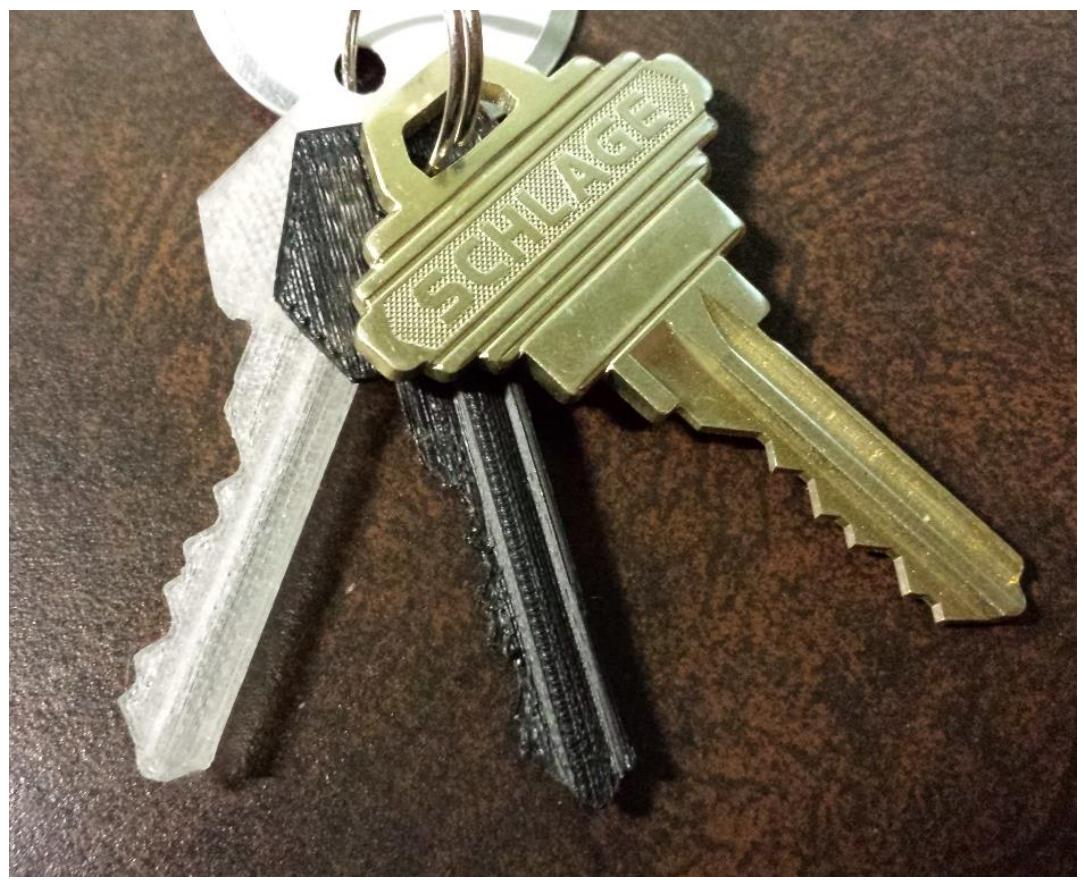

Figure 14 - Functional 3D Printed house keys 
The US government experienced the effects of models being placed online when the blueprints for a 3D printed gun were uploaded in 2012. Since information can be somewhat uncontrollably disseminated through the internet, physical objects (in the form of CAD models) can be spread too. Even if a governmental agency or company finds out a model was shared online and manages to shut it down, the damage has already been done. Those files can be used to create counterfeit duplicates of the original. If the real entities are tagged, distinguishing between real and fake becomes much easier.

\subsubsection{Customization of form factor}

"Fit the tool to the job, not the job to the tool" can be directly applied to the RFID industry. Companies such as Omni-ID, Confidex, Metalcraft, Xerafy, TROI, and GAO RFID who produce or convert tags with rigid, three-dimensional form factors all carry standard lines of products. When product customization is marketed, it means tailoring the exterior colors and print to match the purchasing organization's wishes, not modifying the physical design to meet specific needs. Tag purchasers are forced to choose which fit their needs best, or is least obtrusive to a product or process. The results of this report's experiment indicate that tag providers can add true form factor customization to their services. This could move RFID from an inconvenience to an asset in the minds of business executives who ultimately approve the purchase and implementation of a system. It can also increase the areas of use in organizations who already operate RFID systems. This expansion would be beneficial to the RFID industry and its customers.

One company, William Frick, has begun to use FDM printing to create prototype designs for customers. However, as of May 2014, this service is not listed on any main page of the company website. Furthermore, they are solely using it for rapid prototyping purposes. While this is a step in the right direction, it is far from fully utilizing the benefits 
that 3D printing has to offer. Flomio, a small company focused on NFC applications, offers "custom 3D printables" on their website. They also fall short of true customization by limiting the order with two size and three color options.

\subsection{Possible Future Interactions}

\subsubsection{The Internet of Things}

The internet of things was briefly introduced in section 2 , but mostly with regard to RFID. There are two main networks that must be established for the loT to be realized: a virtual network that exists to store and share data, and a physical network that exists to provide and consume data from the virtual network. The virtual network may not have reached its final form, however the internet in its current state can fully support this portion of the loT. This leaves the task of concept realization to the physical network side. In modern society most "things" are purchased, not created, by consumers. At some point before a consumer begins to use their purchased object, it must be introduced to the physical network. Leaving this job to consumers, who should have no assumed level of technical and/or mechanical competence, could stunt the growth of the loT from incomplete object integration and the negative press of failed promises that would follow (deserved or undeserved).

The charge of bringing objects into the physical network is left on object manufacturers. Since manufacturing has transitioned to the supply chain model from vertical integration, the question arises of who in the supply chain is responsible for adding the network capability? Though each final product only needs a single network enabler, the entire supply chain could gain from having full visibility from the raw material supplier level. Academics, consultants, and industry leaders have already spent time studying this challenge with RFID. In fact, RFID is widely viewed as the leading candidate for the technology that drives the physical network of the loT. Even though the 
answer to the question posed earlier has not been completely answered, a decade of research exists to point individual companies and entire supply chains in the right direction.

An evolution in additive manufacturing may disrupt the idea of the physical network enablement being left to producers (instead of consumers). The recent public fascination with $3 \mathrm{D}$ printing will likely drive the industry to create inexpensive, automated multi-material desktop printers. Embrace of this technology from early adopters could easily be in the next several years. At this point a large sector of the additive manufacturing industry and the Internet of Things may come to an impasse: AM as a home-factory technology competing with the loT that is structured to be enabled in traditional factories. Without active research and development centered on bridging these two concepts and technology groups, additive manufacturing may lose the homeuser market to the inherently more consumer-friendly loT. Conversely, if development of the Internet of Things falls behind the development of more functional and user-friendly 3D printers, the loT (and RFID industry) may lose the battle. The best case scenario for the AM, IoT and RFID industries is active collaboration to ensure none lose out on their own massive growth potential.

\subsubsection{THz Imaging}

The RFID industry has the potential to be threatened by new automatic identification methods born of additive manufacturing. In 2013 Karl Willis of Carnegie Mellon and Andrew Wilson of Microsoft Research published an introduction to a novel identification tag they named InfraStructs. This technology utilizes Terahertz imaging to detect layers of strategically designed gaps in objects created by FDM. These layered gaps reflect Terahertz radiation back to the imaging device, which analyzes the gaps and turns them into unique identifiers. This allows a "tag" to be directly printed into an 
object. On the tag level, direct fabrication offers cost and time advantages over inserting RFID inlays into 3D printed objects. However, it has major disadvantages when compared on a system level in terms of hardware maturity, privacy, adoption level, depth and breadth of research, and post-fabrication application versatility. Leaders in the RFID industry should watch the InfraStructs project and Terahertz imaging closely to spot advances that could lead to a partial market-space takeover. The RFID industry may also opt to support the joint development of tagging objects through direct 3D fabrication and $\mathrm{THz}$ imaging so it too can benefit from inevitable advances in the technology.

\subsubsection{Modification of Low-Volume, High-Mix Supply Chains}

Supply chains are always battling inventory levels. Low holdings increase flexibility and lower operating costs but they also leave companies and entire chains more vulnerable to stock-outs. High holdings provide a buffer against stock-outs but risk losing investments in the cases of lower than expected demand, design changes, and material/product expiration (especially an issue in food/beverage and consumer electronics). Advances in additive manufacturing that enable the creation of end-usable parts may modify certain supply chain strategies by changing the way inventory levels are determined. Studies have already been conducted to research the viability of providing spare parts to the F-18, as discussed in Section 2. The main prohibitive factor was the costs associated with the AM machine used to create spare parts, not technological feasibility. In time the cost factor will diminish and many more applications will open up. Creating spare parts and other low-volume, high mix products from AM methods could eliminate everybody but the RM supplier/distributor and the final customer. This could have a large effect on all the organizations that stand between the beginning and end of such supply chains. 
This shortening of certain supply chains may also affect the RFID industry. Smaller supply chains translates to less tracking of materials, components, assemblies and products that move through supply chains. Since the need to track would be removed, so would the need for tracking tools. If AM successfully replaces portions of the SC, the RFID industry must expect less sales in tags and hardware, less consulting bids, and fewer renewed system maintenance contracts.

\subsection{A Brief Commentary on Governmental and Legislative Issues}

Technological advances and struggles are not the only factors that play into industry growth. Laws passed by states and the federal government can stunt possibilities. This is not inherently negative. The general population is probably grateful that the federal government acted swiftly to remove 3D printable gun files posted online, and anybody who carries a RFID-enabled credit card feels safer in states that have passed anti-skimming laws. Regulations controlled by federal agencies also limit the total conceivable advancement. Industries should work with governmental and nongovernmental organizations to understand the direction that RFID, loT and AM are traveling in, and to promote the ethical use of each technology group.

\subsection{Symbiotic Relationships}

Radio frequency identification, additive manufacturing, and supply chain management are all tied to each other directly and indirectly. Figure 15 demonstrates each industry's purpose in terms of "things": RFID exists to identify things, AM exists to create things, and SCM exists to distribute things. When one industry evolves "things" change in reaction to the original advance, which forces the other industries to adapt. Key inter-industry reactions are also pointed out in Figure 15. The only potential negative relationship exists between additive manufacturing and supply chain management. As discussed in Section 5.3, AM will serve to decrease the complexities of supply chains. 
This may result in cost reductions for end customers; the sectors that additive manufacturing can affect will shrink if/when AM begins to transform small-quantity manufacturing. In the end, the net result will be an improvement in supply chain efficiency.

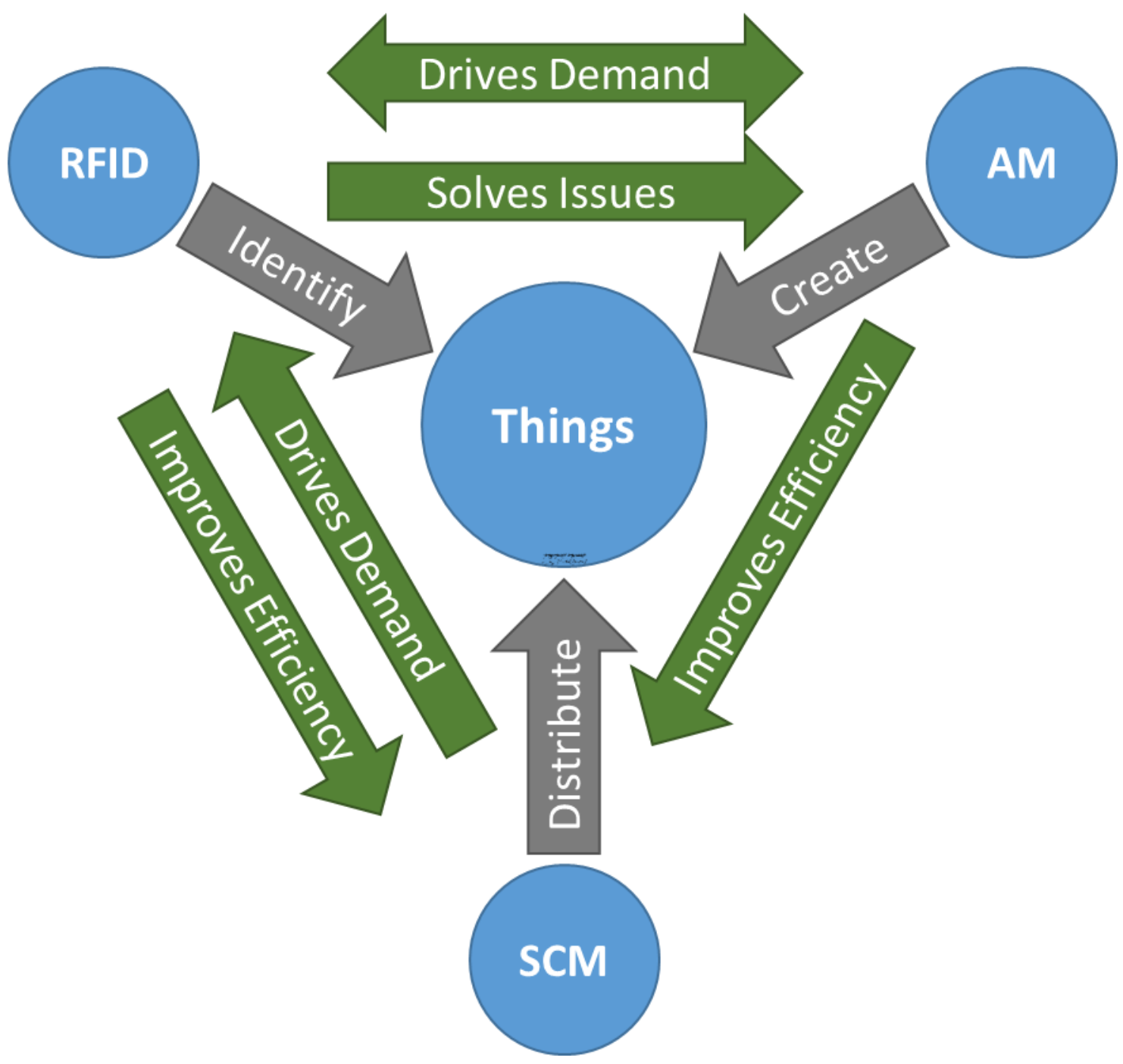

Figure 15- RFID, Additive Manufacturing, Supply Chain Relationship Diagram

As pointed out in the literature review, the industries that RFID and AM focus specific solutions for mirror each other. This can be explained by their "things" driven purposes. An additional layer of connectivity is added to RFID and AM through each of 
the industries they both serve. Breakthroughs in common industries will reshape how RFID and AM interact with that industry, and may also influence how they interact with each other. The industry-driven changes in RFID and AM may also impact SCM. The depth and breadth of these interdependencies creates symbiotic relationships between radio frequency identification, additive manufacturing, and supply chain management. 


\section{Conclusion}

Additive manufacturing began to transform research and development in the 1980s and, through persistent maturation, has become a disruptive technology. Without many of the design constraints of subtractive and net shape manufacturing techniques, additive manufacturing has spurred innovation. This paper sought to investigate how advances in additive manufacturing may transform the radio frequency identification industry and supply chain management. A screening experiment was designed to test the feasibility of integrating Passive UHF RFID into objects created with a FDM printer. After testing different plastic materials, infill percentages, print speeds, and object thicknesses, no factor appeared to have a practical effect on RFID read range.

Several applications taken from the experiment results and textual research were discussed. Some topics like using RFID to identify 3D printed objects, providing anticounterfeiting measures with RFID, and using additive manufacturing to customize RFID form factor are immediately relevant. Other discussions looked into future interactions between RFID, AM and SCM. A theory of the symbiotic relationships between the three industries centered on physical objects stands as the culmination of the experiment and literary research. Academics and professionals concerned with any of the subjects examined in this study should constantly be following news and trends in each industry to ensure collaboration and maximum potential growth. 


\section{Bibliography}

3D Printers, 3D Printing, 3D Parts and Rapid Prototyping. N.p., n.d. Web. 05 May 2014. $<$ http://www.3dsystems.com/>.

Ahuja, Sanjay, and Pavan Potti. "An Introduction to RFID Technology." Communications and Network, 2.3 (2010): 183-186.

An, Chae, Hansjörg Fromm "Supply Chain Management on Demand: Strategies, Technologies, Applications." Berlin, Heidelberg: Springer Berlin Heidelberg, 2005.

Atzeni, Eleonora, and Alessandro Salmi. "Economics of Additive Manufacturing for Endusable Metal Parts." The International Journal of Advanced Manufacturing Technology, 62.9 (2012): 1147-1155.

Atzori, Luigi, Antonio lera, and Giacomo Morabito. "The Internet of Things: A Survey."Computer Networks, 54.15 (2010): 2787-2805.

Badar, M Affan, Shyamsundarreddy Sammidi, and Leslie Gardner. "Reducing the Bullwhip Effect in the Supply Chain: A Study of Different Ordering Strategies." Journal of Technology Studies, 39.1 (2013): 52.

Beamon, BM. "Supply Chain Design and Analysis: Models and Methods." International Journal of Production Economics, 55.3 (1998): 281-294.

Bishop, Todd. "See-through Breakthrough: Microsoft Shows How Terahertz Scans Can Reveal Hidden Tags inside Objects - GeekWire." GeekWire. N.p., 22 July 2013. Web. 12 Mar. 2014. <http://www.geekwire.com/2013/seethrough-scanningmicrosoft-researchers-show-terahertz-imaging-reveal-hidden-tags/>.

Bogue, Robert. "3D Printing: The Dawn of a New Era in Manufacturing?." Assembly Automation, 33.4 (2013): 307-311.

Bolić, Miodrag, David Simplot-Ryl, and Ivan Stojmenović. "3.4 The Environment."RFID Systems: Research Trends and Challenges. Chichester, West Sussex: Wiley, 2010. N. pag. Print.

Brajlih, Tomaz, Bogdan Valentan, Joze Balic, and Igor Drstvensek. "Speed and Accuracy Evaluation of Additive Manufacturing Machines." Rapid Prototyping Journal, 17.1 (2011): 64-75.

Chao, Chia-Chen, Jiann-Min Yang, and Wen-Yuan Jen. "Determining Technology Trends and Forecasts of RFID by a Historical Review and Bibliometric Analysis from 1991 to 2005." Technovation, 27.5 (2007): 268-279.

Chawla, V, and Dong Sam Ha. "An Overview of Passive RFID."IEEE Communications Magazine, 45.9 (2007): 11-17.

"Dielectric Constant, Strength, \& Loss Tangent." RF Cafe. N.p., n.d. Web. 23 May 2014. <http://www.rfcafe.com/references/electrical/dielectric-constants-strengths.htm>.

Dimitrov, D, K Schreve, and N. de Beer. "Advances in Three Dimensional Printing State of the Art and Future Perspectives." Rapid Prototyping Journal, 12.3 (2006): 136-147.

Dobkin, Daniel Mark. The RF in RFID. Amsterdam: Elsevier / Newnes, 2008. Print.

Dolgui, Alexandre, Jean-Marie Proth "Supply Chain Engineering: Useful Methods and Techniques." London: Springer London, 2010.

Goodrum, Paul M, Matt A McLaren, and Adam Durfee. "The Application of Active Radio Frequency Identification Technology for Tool Tracking on Construction Job Sites." Automation in Construction, 15.3 (2006): 292-302. 
Guo, Nannan, and Ming Leu. "Additive Manufacturing: Technology, Applications and Research Needs." Frontiers of Mechanical Engineering, 8.3 (2013): 215-243.

Hieu, L. C., et al. "Medical Rapid Prototyping Applications and Methods." Assembly Automation 25.4 (2005): 284-92. ProQuest. Web. 1 May 2014.

Horn, Timothy J, and Ola L A Harrysson. "Overview of Current Additive Manufacturing Technologies and Selected Applications." Science Progress, 95.Pt 3 (2012): 255282.

Huang, Samuel, Peng Liu, Abhiram Mokasdar, and Liang Hou. "Additive Manufacturing and Its Societal Impact: A Literature Review." The International Journal of Advanced Manufacturing Technology, 67.5 (2013): 1191-1203.

llie-Zudor, E, Z Kemeny, F van Blommestein, L Monostori, and A van der Meulen. "A Survey of Applications and Requirements of Unique Identification Systems and RFID Techniques." Computers in Industry, 62.3 (2011): 227-252.

Khajavi, SH, J Partanen, and J Holmstrom. "Additive Manufacturing in the Spare Parts Supply Chain." Computers in Industry, 65.1 (2014): 50-63.

Kosmatos, Evangelos A, Nikolaos D Tselikas, and Anthony C Boucouvalas. "Integrating RFIDs and Smart Objects into a Unified Internet of Things

Architecture." Advances in Internet of Things, 1.1 (2011): 5-12.

Krotov, Vlad, and Iris Junglas. "RFID as a Disruptive Innovation." Journal of Theoretical and Applied Electronic Commerce Research, 3.2 (2008): 44.

Kruth, J.-P, M.C Leu, and T Nakagawa. "Progress in Additive Manufacturing and Rapid Prototyping." CIRP Annals - Manufacturing Technology, 47.2 (1998): 525-540.

Lipson, H, FC Moon, J Hai, and C Paventi. "3-D Printing the History of Mechanisms." Journal of Mechanical Design, 127.5 (2005): 1029-1033.

Malhotra, Manoj K, and Alan W Mackelprang. "Are Internal Manufacturing and External Supply Chain Flexibilities Complementary Capabilities?." Journal of Operations Management, 30.3 (2012): 180-200.

Manetti, Joseph. "How Technology is Transforming Manufacturing." Production and Inventory Management Journal, 42.1 (2001): 54.

Mehrjerdi, YZ. "The Collaborative Supply Chain." Assembly Automation, 29.2 (2009): 127-136.

Mehrjerdi, Yahia Zare. "Excellent Supply Chain Management." Assembly Automation, 29.1 (2009): 52-60.

Mentzer, John T., et al. "Defining Supply Chain Management." Journal of Business Logistics 22.2 (2001): 1-26. ProQuest. Web. 3 May 2014.

Min, Hokey, and Gengui Zhou. "Supply Chain Modeling: Past, Present and Future." Computers \& Industrial Engineering, 43.1 (2002): 231-249.

Miorandi, D, S Sicari, F De Pellegrini, and I Chlamtac. "Internet of Things: Vision, Applications and Research Challenges." Ad Hoc Networks, 10.7 (2012): 14971516.

Montgomery, Douglas C. Design and Analysis of Experiments. 7th ed. Hoboken, NJ: John Wiley \& Sons, 2009. Print.

Moore, Nigel. "Supply Chain Management." Work Study 47.5 (1998): 172-

4. ProQuest. Web. 3 May 2014.

"News." Nameplates, Custom Printed Labels, Custom Signs, RFID Tags, Utility Markers. William Frick \& Company, n.d. Web. 12 May 2014.

$<$ http://www.fricknet.com/News/>. 
"NFC Custom 3D Printables | Create an AR Experience - Flomio." Flomio. N.p., n.d.

Web. 12 May 2014. <http://flomio.com/shop/nfc-tags/nfc-custom-3d-printables/>.

Petrick, Irene J, and Timothy W Simpson. "3D Printing Disrupts Manufacturing: How

Economies of One Create New Rules of Competition: 3D Printing May Represent

a Disruption to the Manufacturing Industry as Profound as the Industrial

Revolution." Research-Technology Management, 56.6 (2013): 12-16.

Petrovic, V, JVH Gonzalez, OJ Ferrando, JD Gordillo, JRB Puchades, and LP Grinan.

"Additive Layered Manufacturing: Sectors of Industrial Application Shown

Through Case Studies." International Journal of Production Research, 49.2/4

(2011): 1061-1079.

Professional 3D Printing. N.p., n.d. Web. 05 May 2014. <http://www.stratasys.com/>

"Quick Introduction to RFID." PolyGAIT RFID Tutorial. Poly GAIT, n.d. Web. 25 Apr.

2014. <http://www.polygait.calpoly.edu//tutorial.htm>.

"Relative Permittivity - Dielectric Constant." The Engineering Toolbox. N.p., n.d. Web. 23

May 2014. <http://www.engineeringtoolbox.com/relative-permittivityd_1660.html>.

Sanghera, Paul. RFID Study Guide and Practice Exam. Rockland, MA: Syngress, 2007. Print.

Scott, Colin, Henriette Lundgren, and Paul Thompson. "Introduction to Supply Chain Management." Guide to Supply Chain Management, (2011): 1-8.

Stevenson, Mark, and Martin Spring. "Supply Chain Flexibility: An Inter-firm Empirical Study." International Journal of Operations \& Production Management, 29.9 (2009): 946-971.

Swaminathan, Jayashankar M, and Sridhar R Tayur. "Models for Supply Chains in EBusiness." Management Science, 49.10 (2003): 1387-1406.

Tajima, May. "Strategic Value of RFID in Supply Chain Management." Journal of Purchasing and Supply Management, 13.4 (2007): 261-273.

"The 2012 Statistical Abstract." Motor Vehicle Sales. United States Census Bureau, n.d. Web. 01 May 2014.

http://www.census.gov/compendia/statab/cats/wholesale_retail_trade/motor_vehi cle_sales.html

U.S. Department of Commerce, 14 Nov. 2013. Web. 01 May 2014. <http://www.trade.gov/mas/manufacturing/oaai/tg_oaai_003646.asp>.

Upcraft, Steve, and Richard Fletcher. "The Rapid Prototyping Technologies." Assembly Automation, 23.4 (2003): 318-330.

Ustundag, Alp, and Mehmet Tanyas. "The Impacts of Radio Frequency Identification (RFID) Technology on Supply Chain Costs." Transportation Research, 45.1 (2009): 29-38.

Welbourne, E, L Battle, G Cole, K Gould, K Rector, S Raymer, M Balazinska, and G Borriello. "Building the Internet of Things Using RFID: The RFID Ecosystem Experience." IEEE Internet Computing, 13.3 (2009): 48-55.

Williams, Lisa, Terry Esper, and John Ozment. "The Electronic Supply Chain." International Journal of Physical Distribution \& Logistics Management, 32.8 (2002): 703-719.

Willis, Karl D., and Andrew D. Wilson. "InfraStructs: Fabricating Information inside Physical Objects for Imaging in the Terahertz Region." ACM Digital Library. ACM Transactions on Graphics, July 2013. Web. 11 Mar. 2014. 
<http://www.karlddwillis.com/wp/wp- content/uploads/2011/03/SIGGRAPH2013InfraStructs.pdf>.

Wu, N.C, M.A Nystrom, T.R Lin, and H.C Yu. "Challenges to Global RFID Adoption." Technovation, 26.12 (2006): 1317-1323.

Zelbst, Pamela, Kenneth W. Green Jr, Victor Sower, and Gary Baker. "RFID Utilization and Information Sharing: The Impact on Supply Chain Performance." The Journal of Business \& Industrial Marketing, 25.8 (2010): 582-589.

Zhou, Wei. "RFID and Item-level Information Visibility." European Journal of Operational Research, 198.1 (2009): 252-258. 


\section{Appendices}

\section{Appendix A- Data and Statistical Analysis}

Table 4- Raw Data

\begin{tabular}{|c|c|c|c|c|c|}
\hline Order & Material & Infill & Speed & Thickness & Read Range \\
\hline 1 & ABS & 10 & high & 0.2 & 8.5 \\
\hline 2 & ABS & 10 & high & 0.2 & 8.5 \\
\hline 3 & ABS & 10 & high & 0.2 & 8.5 \\
\hline 4 & ABS & 10 & high & 0.2 & 8.5 \\
\hline 5 & ABS & 10 & high & 0.2 & 8.5 \\
\hline 6 & ABS & 10 & high & 0.2 & 8.5 \\
\hline 7 & ABS & 10 & high & 0.2 & 8.5 \\
\hline 8 & ABS & 10 & high & 0.2 & 8.5 \\
\hline 9 & ABS & 10 & high & 0.2 & 8.5 \\
\hline 10 & ABS & 10 & high & 0.2 & 8.5 \\
\hline 11 & ABS & 10 & high & 0.2 & 8.5 \\
\hline 12 & ABS & 10 & high & 0.2 & 8.5 \\
\hline 13 & ABS & 10 & high & 0.4 & 8.5 \\
\hline 14 & ABS & 10 & high & 0.4 & 8.5 \\
\hline 15 & ABS & 10 & high & 0.4 & 8.5 \\
\hline 16 & ABS & 10 & high & 0.4 & 8.5 \\
\hline 17 & ABS & 10 & high & 0.4 & 8.5 \\
\hline 18 & ABS & 10 & high & 0.4 & 8.5 \\
\hline 19 & ABS & 10 & high & 0.4 & 8.5 \\
\hline 20 & ABS & 10 & high & 0.4 & 8.75 \\
\hline 21 & ABS & 10 & high & 0.4 & 8.5 \\
\hline 22 & ABS & 10 & high & 0.4 & 8.75 \\
\hline 23 & ABS & 10 & high & 0.4 & 8.5 \\
\hline 24 & ABS & 10 & high & 0.4 & 8.5 \\
\hline 25 & ABS & 10 & low & 0.2 & 8.5 \\
\hline 26 & ABS & 10 & low & 0.2 & 8.75 \\
\hline 27 & ABS & 10 & low & 0.2 & 8.75 \\
\hline 28 & ABS & 10 & low & 0.2 & 8.5 \\
\hline 29 & ABS & 10 & low & 0.2 & 8.75 \\
\hline 30 & ABS & 10 & low & 0.2 & 8.5 \\
\hline 31 & ABS & 10 & low & 0.2 & 8.5 \\
\hline 32 & ABS & 10 & low & 0.2 & 8.75 \\
\hline 33 & ABS & 10 & low & 0.2 & 8.75 \\
\hline 34 & ABS & 10 & low & 0.2 & 8.5 \\
\hline 35 & ABS & 10 & low & 0.2 & 8.5 \\
\hline 36 & ABS & 10 & low & 0.2 & 8.5 \\
\hline 37 & ABS & 10 & low & 0.4 & 8.5 \\
\hline 38 & ABS & 10 & low & 0.4 & 8.5 \\
\hline 39 & ABS & 10 & low & 0.4 & 8.75 \\
\hline 40 & ABS & 10 & low & 0.4 & 8.5 \\
\hline 41 & ABS & 10 & low & 0.4 & 8.75 \\
\hline 42 & ABS & 10 & low & 0.4 & 8.75 \\
\hline 43 & ABS & 10 & low & 0.4 & 8.5 \\
\hline 44 & ABS & 10 & low & 0.4 & 8.5 \\
\hline 45 & ABS & 10 & low & 0.4 & 8 \\
\hline 46 & ABS & 10 & low & 0.4 & 8.75 \\
\hline 47 & ABS & 10 & low & 0.4 & 8.5 \\
\hline 48 & ABS & 10 & low & 0.4 & 8.5 \\
\hline 49 & ABS & 50 & high & 0.2 & 8.5 \\
\hline 50 & ABS & 50 & high & 0.2 & 8.5 \\
\hline 51 & ABS & 50 & high & 0.2 & 8.5 \\
\hline
\end{tabular}




\begin{tabular}{|c|c|c|c|c|c|}
\hline 52 & ABS & 50 & high & 0.2 & 8.5 \\
\hline 53 & ABS & 50 & high & 0.2 & 8.5 \\
\hline 54 & ABS & 50 & high & 0.2 & 8.75 \\
\hline 55 & ABS & 50 & high & 0.2 & 8.5 \\
\hline 56 & ABS & 50 & high & 0.2 & 8.75 \\
\hline 57 & ABS & 50 & high & 0.2 & 8.5 \\
\hline 58 & ABS & 50 & high & 0.2 & 8.75 \\
\hline 59 & ABS & 50 & high & 0.2 & 8.75 \\
\hline 60 & ABS & 50 & high & 0.2 & 8.5 \\
\hline 61 & ABS & 50 & high & 0.4 & 8.5 \\
\hline 62 & ABS & 50 & high & 0.4 & 8.5 \\
\hline 63 & ABS & 50 & high & 0.4 & 8 \\
\hline 64 & ABS & 50 & high & 0.4 & 8.5 \\
\hline 65 & ABS & 50 & high & 0.4 & 8.5 \\
\hline 66 & ABS & 50 & high & 0.4 & 8.5 \\
\hline 67 & ABS & 50 & high & 0.4 & 8.75 \\
\hline 68 & ABS & 50 & high & 0.4 & 8.75 \\
\hline 69 & ABS & 50 & high & 0.4 & 8 \\
\hline 70 & ABS & 50 & high & 0.4 & 8 \\
\hline 71 & ABS & 50 & high & 0.4 & 8.5 \\
\hline 72 & ABS & 50 & high & 0.4 & 8.5 \\
\hline 73 & ABS & 50 & low & 0.2 & 8.5 \\
\hline 74 & ABS & 50 & low & 0.2 & 8.5 \\
\hline 75 & ABS & 50 & low & 0.2 & 8.5 \\
\hline 76 & ABS & 50 & low & 0.2 & 8.5 \\
\hline 77 & ABS & 50 & low & 0.2 & 8.75 \\
\hline 78 & ABS & 50 & low & 0.2 & 8.5 \\
\hline 79 & ABS & 50 & low & 0.2 & 8.5 \\
\hline 80 & ABS & 50 & low & 0.2 & 8.5 \\
\hline 81 & ABS & 50 & low & 0.2 & 8.75 \\
\hline 82 & ABS & 50 & low & 0.2 & 10.25 \\
\hline 83 & ABS & 50 & low & 0.2 & 8.5 \\
\hline 84 & ABS & 50 & low & 0.2 & 8.5 \\
\hline 85 & ABS & 50 & low & 0.4 & 8.5 \\
\hline 86 & ABS & 50 & low & 0.4 & 8.5 \\
\hline 87 & ABS & 50 & low & 0.4 & 7.75 \\
\hline 88 & ABS & 50 & low & 0.4 & 8.5 \\
\hline 89 & ABS & 50 & low & 0.4 & 8.5 \\
\hline 90 & ABS & 50 & low & 0.4 & 8.5 \\
\hline 91 & ABS & 50 & low & 0.4 & 8.5 \\
\hline 92 & ABS & 50 & low & 0.4 & 8.5 \\
\hline 93 & ABS & 50 & low & 0.4 & 8.5 \\
\hline 94 & ABS & 50 & low & 0.4 & 8.5 \\
\hline 95 & ABS & 50 & low & 0.4 & 8.75 \\
\hline 96 & ABS & 50 & low & 0.4 & \\
\hline 97 & PLA & 10 & high & 0.2 & 8.5 \\
\hline 98 & PLA & 10 & high & 0.2 & 8.5 \\
\hline 99 & PLA & 10 & high & 0.2 & 8.5 \\
\hline 100 & PLA & 10 & high & 0.2 & 8.5 \\
\hline 101 & PLA & 10 & high & 0.2 & 8.5 \\
\hline 102 & PLA & 10 & high & 0.2 & 8.5 \\
\hline 103 & PLA & 10 & high & 0.2 & 8.5 \\
\hline 104 & PLA & 10 & high & 0.2 & 8.5 \\
\hline 105 & PLA & 10 & high & 0.2 & 8.5 \\
\hline 106 & PLA & 10 & high & 0.2 & 8.75 \\
\hline 107 & PLA & 10 & high & 0.2 & 8.75 \\
\hline 108 & PLA & 10 & high & 0.2 & 8.5 \\
\hline 109 & PLA & 10 & high & 0.4 & 8.5 \\
\hline 110 & PLA & 10 & high & 0.4 & 8.5 \\
\hline
\end{tabular}




\begin{tabular}{|c|c|c|c|c|c|}
\hline 111 & PLA & 10 & high & 0.4 & 8.25 \\
\hline 112 & PLA & 10 & high & 0.4 & 8.5 \\
\hline 113 & PLA & 10 & high & 0.4 & 8.5 \\
\hline 114 & PLA & 10 & high & 0.4 & 8.5 \\
\hline 115 & PLA & 10 & high & 0.4 & 8.5 \\
\hline 116 & PLA & 10 & high & 0.4 & 8.25 \\
\hline 117 & PLA & 10 & high & 0.4 & 8.75 \\
\hline 118 & PLA & 10 & high & 0.4 & 8.75 \\
\hline 119 & PLA & 10 & high & 0.4 & 8.75 \\
\hline 120 & PLA & 10 & high & 0.4 & 8.75 \\
\hline 121 & PLA & 10 & low & 0.2 & 8.5 \\
\hline 122 & PLA & 10 & low & 0.2 & 8.5 \\
\hline 123 & PLA & 10 & low & 0.2 & 8.5 \\
\hline 124 & PLA & 10 & low & 0.2 & 8 \\
\hline 125 & PLA & 10 & low & 0.2 & 8.5 \\
\hline 126 & PLA & 10 & low & 0.2 & 8.5 \\
\hline 127 & PLA & 10 & low & 0.2 & 8.5 \\
\hline 128 & PLA & 10 & low & 0.2 & 8.5 \\
\hline 129 & PLA & 10 & low & 0.2 & 8.5 \\
\hline 130 & PLA & 10 & low & 0.2 & 8.75 \\
\hline 131 & PLA & 10 & low & 0.2 & 8.5 \\
\hline 132 & PLA & 10 & low & 0.2 & 8.75 \\
\hline 133 & PLA & 10 & low & 0.4 & 8.5 \\
\hline 134 & PLA & 10 & low & 0.4 & 8.5 \\
\hline 135 & PLA & 10 & low & 0.4 & 8.5 \\
\hline 136 & PLA & 10 & low & 0.4 & 8.5 \\
\hline 137 & PLA & 10 & low & 0.4 & 8.5 \\
\hline 138 & PLA & 10 & low & 0.4 & 8.5 \\
\hline 139 & PLA & 10 & low & 0.4 & 8.5 \\
\hline 140 & PLA & 10 & low & 0.4 & 8.5 \\
\hline 141 & PLA & 10 & low & 0.4 & 8.5 \\
\hline 142 & PLA & 10 & low & 0.4 & 8.5 \\
\hline 143 & PLA & 10 & low & 0.4 & 8.75 \\
\hline 144 & PLA & 10 & low & 0.4 & 8.5 \\
\hline 145 & PLA & 50 & high & 0.2 & 8.5 \\
\hline 146 & PLA & 50 & high & 0.2 & 8.25 \\
\hline 147 & PLA & 50 & high & 0.2 & 8.25 \\
\hline 148 & PLA & 50 & high & 0.2 & 8.75 \\
\hline 149 & PLA & 50 & high & 0.2 & 8.5 \\
\hline 150 & PLA & 50 & high & 0.2 & 8.5 \\
\hline 151 & PLA & 50 & high & 0.2 & 8.5 \\
\hline 152 & PLA & 50 & high & 0.2 & 8.5 \\
\hline 153 & PLA & 50 & high & 0.2 & 8.75 \\
\hline 154 & PLA & 50 & high & 0.2 & 8.75 \\
\hline 155 & PLA & 50 & high & 0.2 & 8.75 \\
\hline 156 & PLA & 50 & high & 0.2 & 8.75 \\
\hline 157 & PLA & 50 & high & 0.4 & \\
\hline 158 & PLA & 50 & high & 0.4 & \\
\hline 159 & PLA & 50 & high & 0.4 & \\
\hline 160 & PLA & 50 & high & 0.4 & \\
\hline 161 & PLA & 50 & high & 0.4 & \\
\hline 162 & PLA & 50 & high & 0.4 & \\
\hline 163 & PLA & 50 & high & 0.4 & \\
\hline 164 & PLA & 50 & high & 0.4 & \\
\hline 165 & PLA & 50 & high & 0.4 & \\
\hline 166 & PLA & 50 & high & 0.4 & \\
\hline 167 & PLA & 50 & high & 0.4 & \\
\hline 168 & PLA & 50 & high & 0.4 & \\
\hline 169 & PLA & 50 & low & 0.2 & 8.5 \\
\hline
\end{tabular}




\begin{tabular}{|r|r|r|r|r|r|}
\hline 170 & PLA & 50 & low & 0.2 & 8.5 \\
\hline 171 & PLA & 50 & low & 0.2 & 8.5 \\
\hline 172 & PLA & 50 & low & 0.2 & 8.5 \\
\hline 173 & PLA & 50 & low & 0.2 & 8.5 \\
\hline 174 & PLA & 50 & low & 0.2 & 8.5 \\
\hline 175 & PLA & 50 & low & 0.2 & 8.75 \\
\hline 176 & PLA & 50 & low & 0.2 & 8.75 \\
\hline 177 & PLA & 50 & low & 0.2 & 8.5 \\
\hline 178 & PLA & 50 & low & 0.2 & 8.5 \\
\hline 179 & PLA & 50 & low & 0.2 & 8.75 \\
\hline 180 & PLA & 50 & low & 0.2 & 8.75 \\
\hline 181 & PLA & 50 & low & 0.4 & 8.75 \\
\hline 182 & PLA & 50 & low & 0.4 & 8.5 \\
\hline 183 & PLA & 50 & low & 0.4 & 8.5 \\
\hline 184 & PLA & 50 & low & 0.4 & 8.75 \\
\hline 185 & PLA & 50 & low & 0.4 & 8.5 \\
\hline 186 & PLA & 50 & low & 0.4 & 8.75 \\
\hline 187 & PLA & 50 & low & 0.4 & 8.5 \\
\hline 188 & PLA & 50 & low & 0.4 & 8.5 \\
\hline 189 & PLA & 50 & low & 0.4 & 8.5 \\
\hline 190 & PLA & 50 & low & 0.4 & 8.75 \\
\hline 191 & PLA & 50 & low & 0.4 & 8.75 \\
\hline 192 & PLA & 50 & low & 0.4 & \\
\hline & & & & & 0.4 \\
\hline
\end{tabular}


Table 5- Bare Inlay Read Range Raw Data

\begin{tabular}{|c|c|}
\hline Order & Read Range \\
\hline 1 & 8.75 \\
\hline 2 & 8.5 \\
\hline 3 & 8.5 \\
\hline 4 & 8.5 \\
\hline 5 & 8.75 \\
\hline 6 & 8.5 \\
\hline 7 & 8.75 \\
\hline 8 & 8.5 \\
\hline 9 & 8.5 \\
\hline 10 & 8.75 \\
\hline 11 & 8.5 \\
\hline 12 & 8.5 \\
\hline 13 & 8.5 \\
\hline 14 & 8.5 \\
\hline 15 & 8.5 \\
\hline 16 & 8.5 \\
\hline 17 & 8.5 \\
\hline 18 & 8.75 \\
\hline 19 & 8.5 \\
\hline 20 & 8.75 \\
\hline 21 & 8.5 \\
\hline 22 & 8.5 \\
\hline 23 & 8.5 \\
\hline 24 & 8.75 \\
\hline 25 & 8.5 \\
\hline 26 & 8.75 \\
\hline 27 & 8.5 \\
\hline 28 & 8.75 \\
\hline 29 & 8.5 \\
\hline 30 & 8.5 \\
\hline 31 & 8.5 \\
\hline 32 & 8.5 \\
\hline 33 & 8.5 \\
\hline 34 & 8.5 \\
\hline 35 & 8.5 \\
\hline 36 & 8.75 \\
\hline 37 & 8.5 \\
\hline 38 & 8.5 \\
\hline 39 & 8.5 \\
\hline 40 & 8.75 \\
\hline 41 & 8.5 \\
\hline 42 & 8.5 \\
\hline 43 & 8.75 \\
\hline 44 & 8.75 \\
\hline 45 & 8.75 \\
\hline 46 & 8.5 \\
\hline 47 & 8.5 \\
\hline 48 & 8.75 \\
\hline
\end{tabular}

Table 6- Descriptive Statistics of Original Data Set

\begin{tabular}{|lrrrrrrr|}
\hline Variable & Mean & StDev & Minimum & Q1 & Median & Q3 & Maximum \\
Read Range & 8.5475 & 0.2049 & 7.7500 & 8.5000 & 8.5000 & 8.7500 & 10.2500
\end{tabular}


Table 7- Descriptive Statistics of Bare Inlay Read Range

$\begin{array}{lrrrrrrr}\text { Variable } & \text { Mean } & \text { StDev } & \text { Minimum } & \text { Q1 } & \text { Median } & \text { Q3 } & \text { Maximum } \\ \text { Range } & 8.5781 & 0.1171 & 8.5000 & 8.5000 & 8.5000 & 8.7500 & 8.7500\end{array}$

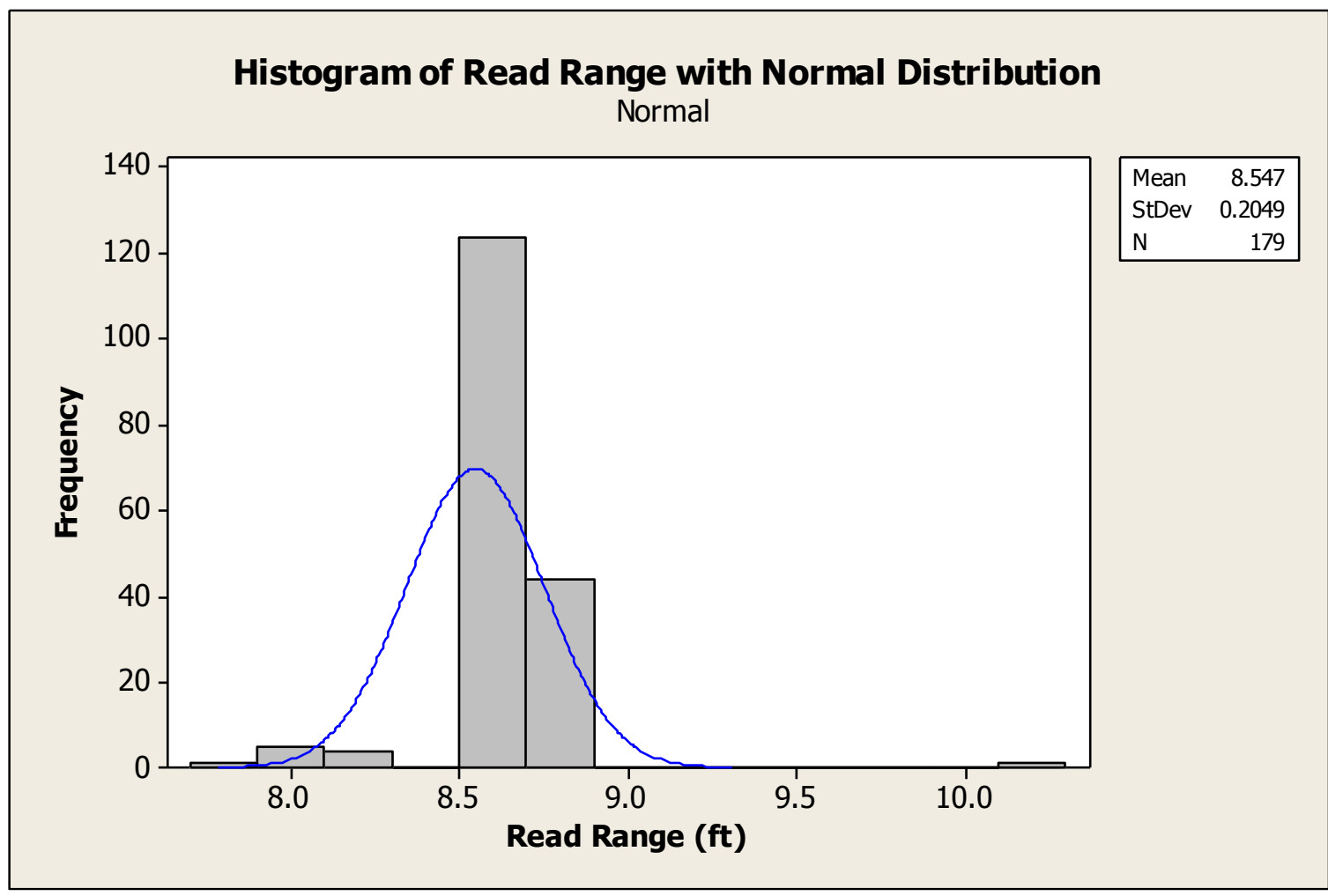

Figure 16- Histogram of Raw Data 


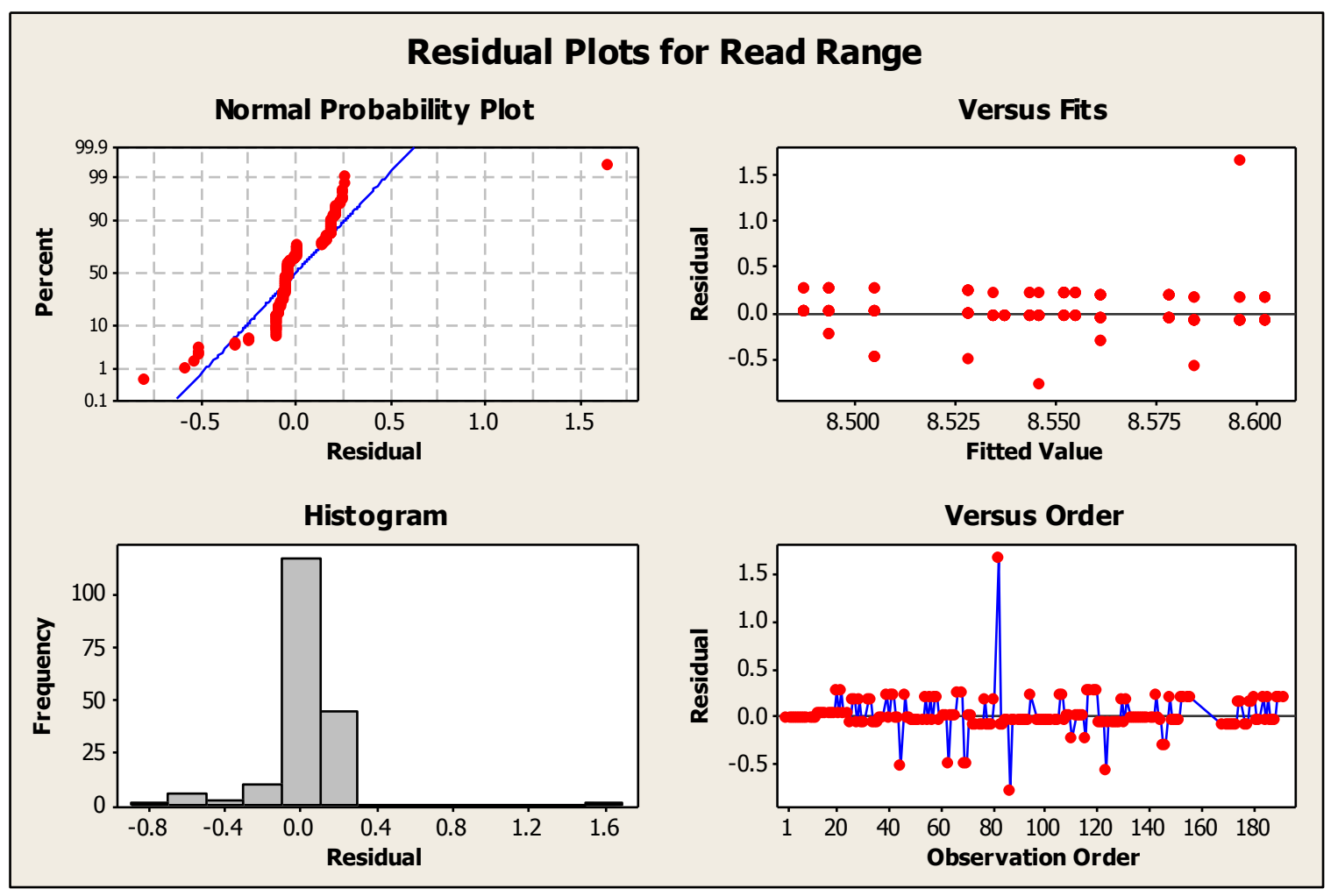

Figure 17- Residual Plots of Raw Data

Table 8- ANOVA of all terms up to 3-Way Interactions

\begin{tabular}{|lrrrrrrr}
\hline Analysis of Variance for Read Range (coded units) & & & & \\
Source & DF & Seq SS & Adj SS & Adj MS & F & P \\
Main Effects & 4 & 0.20238 & 0.16883 & 0.042208 & 1.03 & 0.394 \\
Material & 1 & 0.00586 & 0.00306 & 0.003064 & 0.07 & 0.785 \\
Infill & 1 & 0.02693 & 0.01042 & 0.010417 & 0.25 & 0.615 \\
Speed & 1 & 0.05962 & 0.02993 & 0.029925 & 0.73 & 0.394 \\
Thickness & 1 & 0.10997 & 0.05273 & 0.052734 & 1.29 & 0.259 \\
2-Way Interactions & 6 & 0.37160 & 0.36350 & 0.060583 & 1.48 & 0.189 \\
Material*Infill & 1 & 0.03875 & 0.02460 & 0.024600 & 0.60 & 0.440 \\
Material*Speed & 1 & 0.03444 & 0.01628 & 0.016276 & 0.40 & 0.530 \\
Material*Thickness & 1 & 0.18629 & 0.08049 & 0.080487 & 1.96 & 0.163 \\
Infill*Speed & 1 & 0.01614 & 0.01494 & 0.014944 & 0.36 & 0.547 \\
Infill*Thickness & 1 & 0.08976 & 0.05273 & 0.052734 & 1.29 & 0.259 \\
Speed*Thickness & 1 & 0.00622 & 0.00306 & 0.003064 & 0.07 & 0.785 \\
3-Way Interactions & 4 & 0.17012 & 0.17012 & 0.042530 & 1.04 & 0.390 \\
Material*Infill*Speed & 1 & 0.01107 & 0.00586 & 0.005859 & 0.14 & 0.706 \\
Material*Infill*Thickness & 1 & 0.13442 & 0.05427 & 0.054270 & 1.32 & 0.252 \\
Material*Speed*Thickness & 1 & 0.02250 & 0.02344 & 0.023437 & 0.57 & 0.451 \\
Infill*Speed*Thickness & 1 & 0.00213 & 0.00213 & 0.002128 & 0.05 & 0.820 \\
Residual Error & 164 & 6.72727 & 6.72727 & 0.041020 & & \\
Pure Error & 164 & 6.72727 & 6.72727 & 0.041020 & & \\
Total & 178 & 7.47137 & & & & \\
& & & & & &
\end{tabular}


Table 9- Unusual Observances

\begin{tabular}{|rrrrrrr|}
\hline \multicolumn{6}{|l|}{ Unusual Observations for Read Range } \\
Obs & Stdorder & Read Range & Fit & SE Fit & Residual & St Resid \\
45 & 45 & 8.0000 & 8.5417 & 0.0585 & -0.5417 & $-2.79 \mathrm{R}$ \\
63 & 63 & 8.0000 & 8.4167 & 0.0585 & -0.4167 & $-2.15 \mathrm{R}$ \\
69 & 69 & 8.0000 & 8.4167 & 0.0585 & -0.4167 & $-2.15 \mathrm{R}$ \\
70 & 70 & 8.0000 & 8.4167 & 0.0585 & -0.4167 & $-2.15 \mathrm{R}$ \\
82 & 82 & 10.2500 & 8.6875 & 0.0585 & 1.5625 & $8.06 \mathrm{R}$ \\
87 & 87 & 7.7500 & 8.4545 & 0.0611 & -0.7045 & $-3.65 \mathrm{R}$ \\
124 & 124 & 8.0000 & 8.5000 & 0.0585 & -0.5000 & $-2.58 \mathrm{R}$ \\
\multicolumn{7}{|c}{} \\
$R$
\end{tabular}

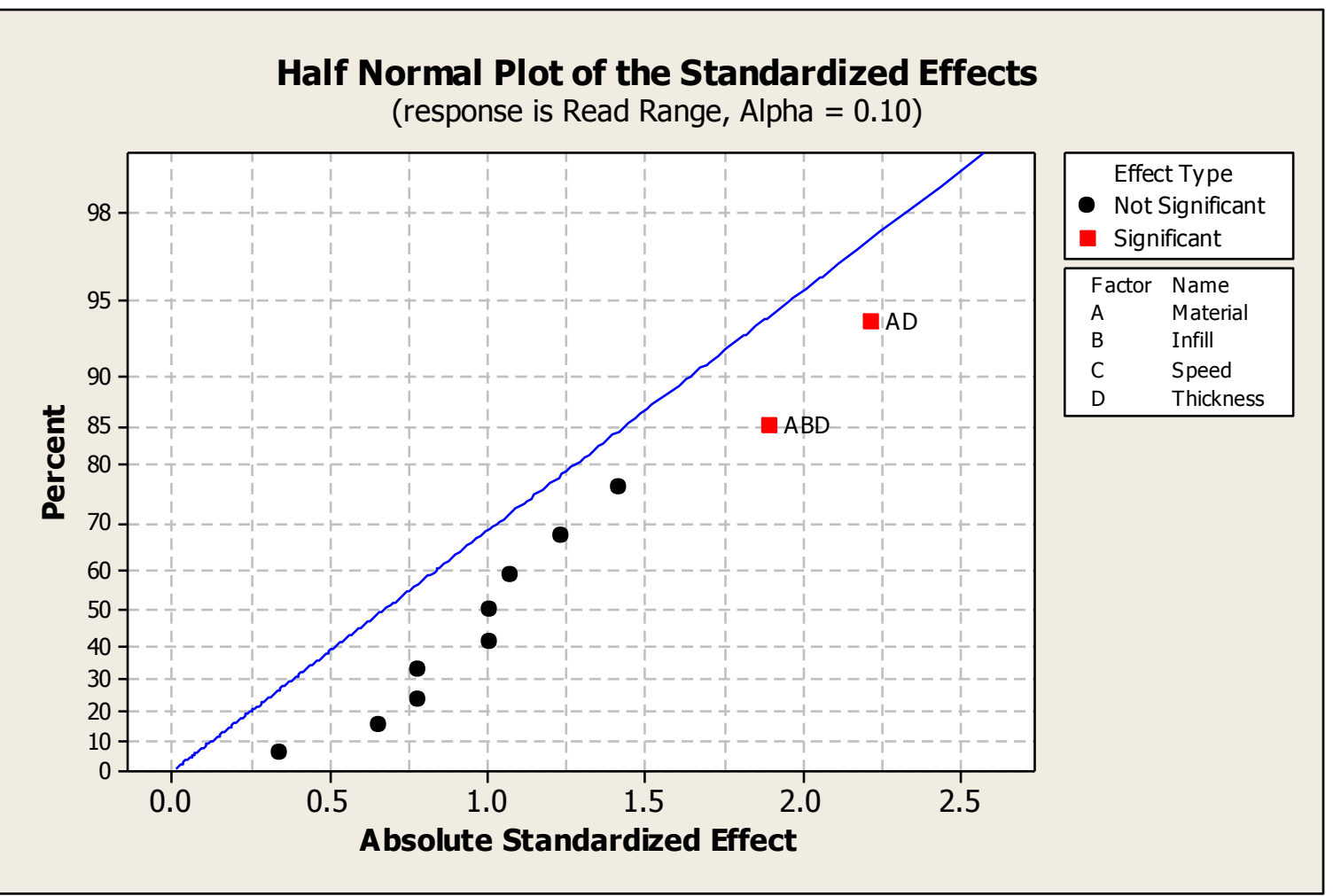

Figure 18- Half Normal Plot without selected $3^{\text {rd-order interactions }}$

Table 10- ANOVA without Speed in main or interaction effects

\begin{tabular}{|lrrrrrr|}
\hline Analysis of Variance for Read Range (coded units) & & & \\
Source & DF & Seq SS & Adj SS & Adj MS & F & P \\
Main Effects & 3 & 0.12984 & 0.13208 & 0.04403 & 1.09 & 0.353 \\
Material & 1 & 0.00586 & 0.01965 & 0.01965 & 0.49 & 0.486 \\
Infill & 1 & 0.02693 & 0.03968 & 0.03968 & 0.99 & 0.322 \\
Thickness & 1 & 0.09705 & 0.05856 & 0.05856 & 1.46 & 0.229 \\
2-Wy Interactions & 3 & 0.31749 & 0.34801 & 0.11600 & 2.88 & 0.037 \\
Material*Infill & 1 & 0.04912 & 0.07614 & 0.07614 & 1.89 & 0.171 \\
Material*Thickness & 1 & 0.18797 & 0.19859 & 0.19859 & 4.93 & 0.028 \\
Infili*Thickness & 1 & 0.08040 & 0.05856 & 0.05856 & 1.46 & 0.229 \\
3-Way Interactions & 1 & 0.14270 & 0.14270 & 0.14270 & 3.55 & 0.061 \\
Material*Infill*Thickness & 1 & 0.14270 & 0.14270 & 0.14270 & 3.55 & 0.061 \\
Residual Error & 171 & 6.88134 & 6.88134 & 0.04024 & & \\
Pure Error & 171 & 6.88134 & 6.88134 & 0.04024 & & \\
Total & 178 & 7.47137 & & & & \\
\hline
\end{tabular}


Table 11- ANOVA after removing unusual observances in original test

\begin{tabular}{|lrrrrrrr}
\hline Analysis of Variance for Read Range (Outliers Removed) & (coded units) \\
Source & DF & Seq SS & Adj SS & Adj MS & F & P \\
Main Effects & 4 & 0.04034 & 0.03535 & 0.0088369 & 0.62 & 0.648 \\
Material & 1 & 0.00071 & 0.00061 & 0.0006056 & 0.04 & 0.837 \\
Infill & 1 & 0.02219 & 0.00916 & 0.0091569 & 0.64 & 0.423 \\
Speed & 1 & 0.01744 & 0.00762 & 0.0076199 & 0.54 & 0.465 \\
Thickness & 1 & 0.00000 & 0.00000 & 0.0000006 & 0.00 & 0.995 \\
-Way Interactions & 6 & 0.06192 & 0.02736 & 0.0045595 & 0.32 & 0.925 \\
Material*Infill & 1 & 0.03203 & 0.01675 & 0.0167497 & 1.18 & 0.279 \\
Material*Speed & 1 & 0.00170 & 0.00019 & 0.0001894 & 0.01 & 0.908 \\
Material*Thickness & 1 & 0.00304 & 0.00061 & 0.0006056 & 0.04 & 0.837 \\
Infill*Speed & 1 & 0.01665 & 0.00542 & 0.0054221 & 0.38 & 0.538 \\
Infill*Thickness & 1 & 0.00166 & 0.00001 & 0.0000142 & 0.00 & 0.975 \\
Speed*Thickness & 1 & 0.00684 & 0.00041 & 0.0004120 & 0.03 & 0.865 \\
3ay Interactions & 4 & 0.08569 & 0.08569 & 0.0214216 & 1.51 & 0.203 \\
Material*Infill*Speed & 1 & 0.05644 & 0.03712 & 0.0371212 & 2.61 & 0.108 \\
Material*Infill*Thickness & 1 & 0.02391 & 0.00765 & 0.0076481 & 0.54 & 0.464 \\
Material*Speed*Thickness & 1 & 0.00000 & 0.00135 & 0.0013468 & 0.09 & 0.759 \\
Infill*Speed*Thickness & 1 & 0.00534 & 0.00534 & 0.0053352 & 0.38 & 0.541 \\
Residual Error & 157 & 2.23065 & 2.23065 & 0.0142080 & & \\
Pure Error & 157 & 2.23065 & 2.23065 & 0.0142080 & & \\
Total & 171 & 2.41860 & & & & & \\
& & & & & &
\end{tabular}

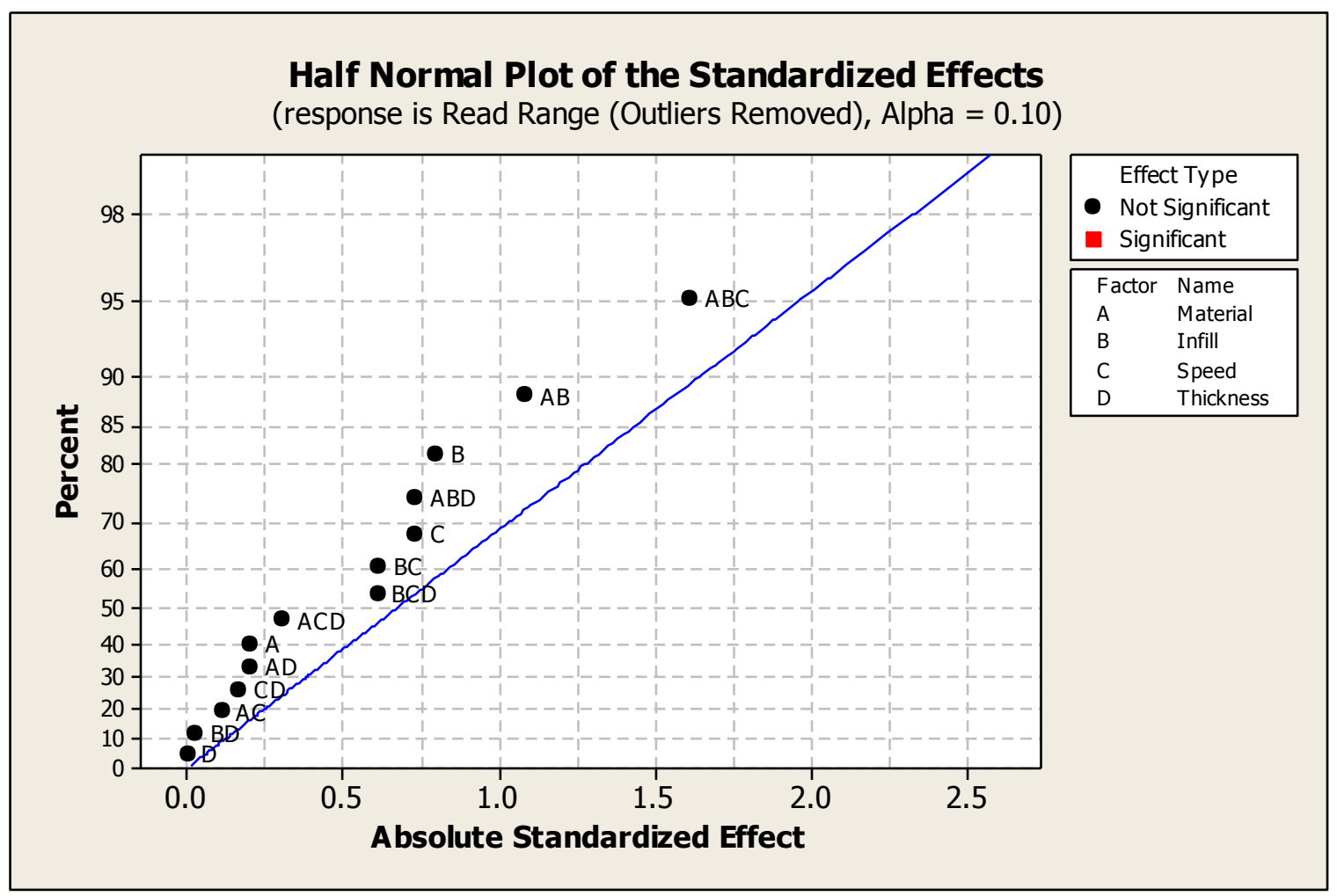

Figure 19- Half Normal Plot after removing 7 unusual observations from original data 
Table 12- Unusual Observances after removing 7 data points from original data

\begin{tabular}{|c|c|c|c|c|c|c|}
\hline & & $\begin{array}{l}\text { ead Range } \\
\text { (Outliers }\end{array}$ & & & & \\
\hline Obs & StdOrder & Removed) & Fit & SE Fit & Residual & St Resid \\
\hline 111 & 111 & 8.25000 & 8.54167 & 0.03441 & -0.29167 & $-2.56 R$ \\
\hline 116 & 116 & 8.25000 & 8.54167 & 0.03441 & -0.29167 & $-2.56 R$ \\
\hline 143 & 143 & 8.75000 & 8.52083 & 0.03441 & 0.22917 & $2.01 R$ \\
\hline 146 & 146 & 8.25000 & 8.56250 & 0.03441 & -0.31250 & $-2.74 R$ \\
\hline 147 & 147 & 8.25000 & 8.56250 & 0.03441 & -0.31250 & $-2.74 R$ \\
\hline
\end{tabular}

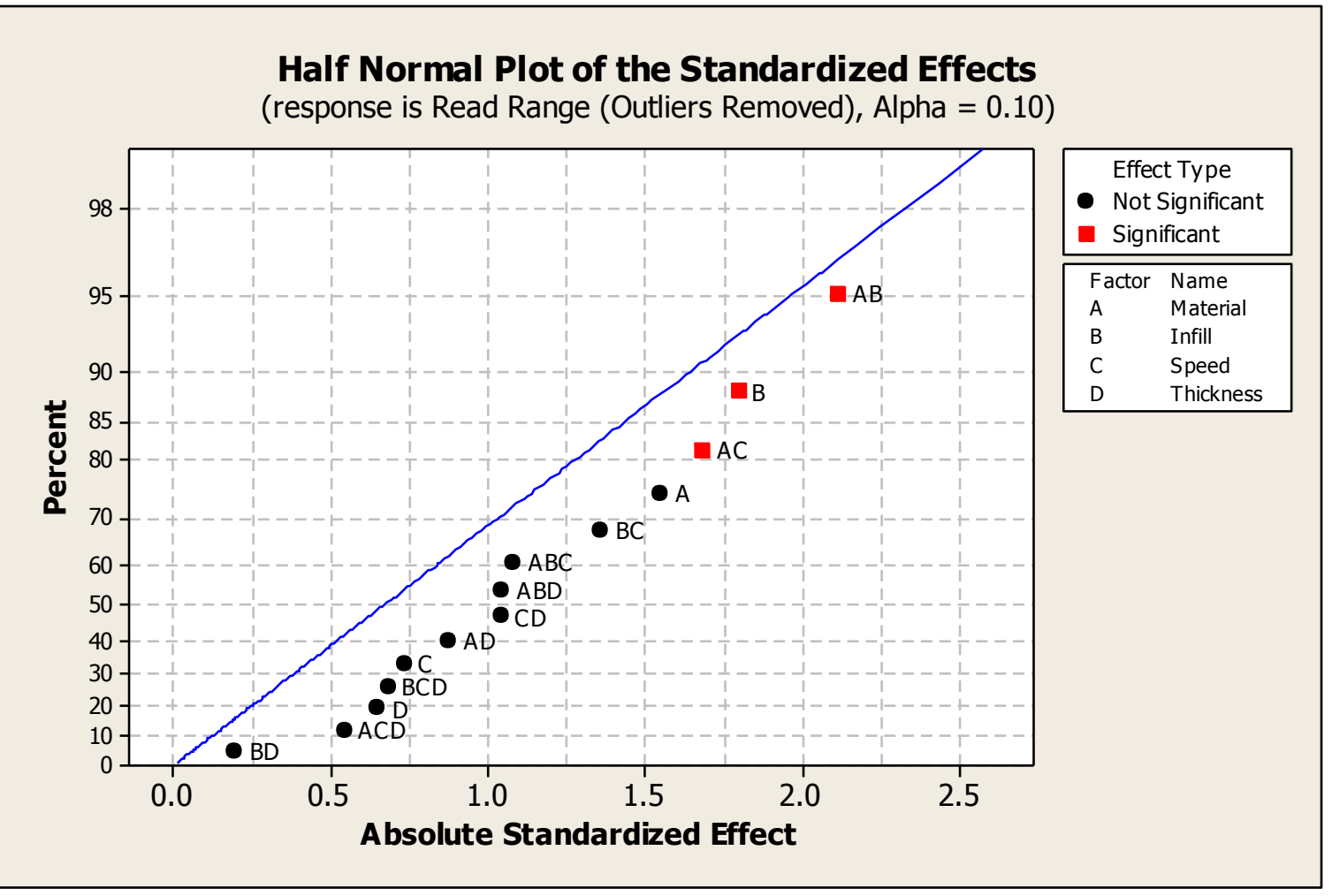

Figure 20- Half Normal Plot after removing 5 unusual observances from modified data

Table 13- Unusual Observances after removing 5 data points from modified data

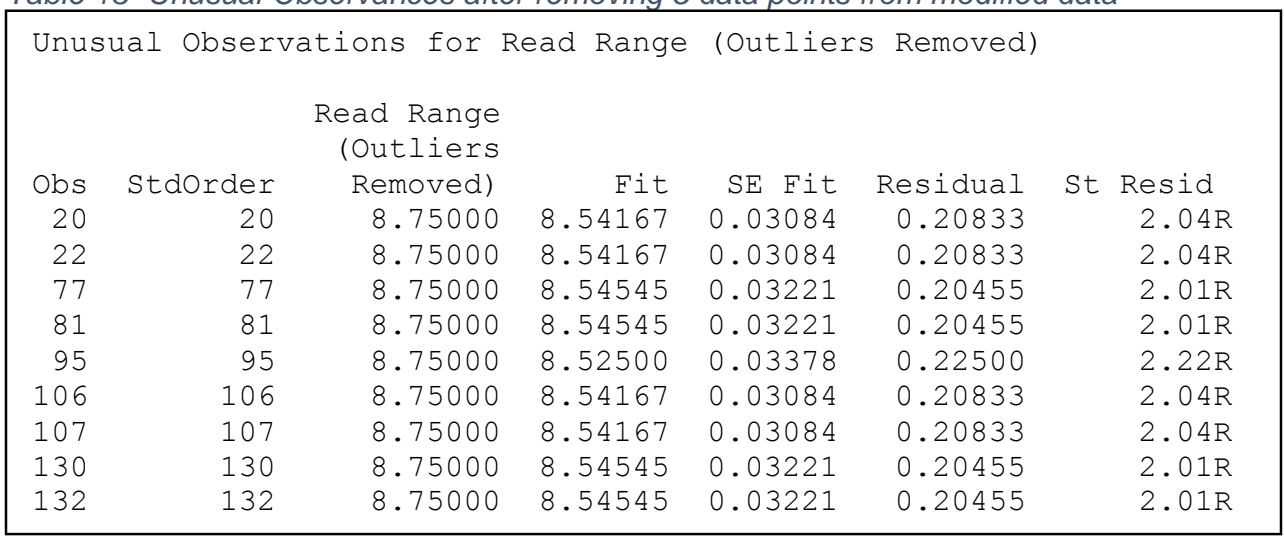


Table 14- Kruskal-Wallis Test for Material

\begin{tabular}{|c|c|c|c|c|c|}
\hline Material & $\mathrm{N}$ & Median & Ave & Rank & Z \\
\hline ABS & 95 & 8.500 & & 87.7 & -0.64 \\
\hline PLA & 84 & 8.500 & & 92.6 & 0.64 \\
\hline Overall & 179 & & & 90.0 & \\
\hline $\mathrm{H}=0.41$ & $\mathrm{DF}=$ & $1 \mathrm{P}$ & 0.522 & & \\
\hline $\mathrm{H}=0.63$ & $\mathrm{DF}=$ & $1 \mathrm{P}=$ & 0.428 & (ac & justed for ties) \\
\hline
\end{tabular}

Table 15- Kruskal-Wallis Test for Infill

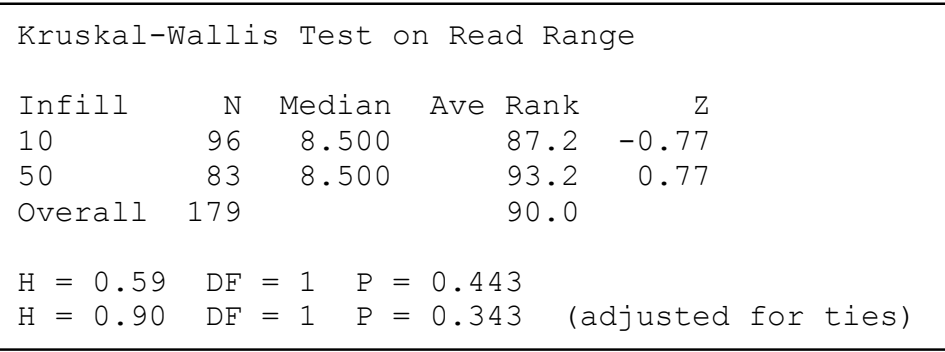

Table 16-Kruskal-Wallis Test for Speed

$\begin{array}{lrrrr}\text { Kruskal-Wallis Test on Read Range } \\ \begin{array}{l}\text { Speed } \\ \text { low }\end{array} & \mathrm{N} & \text { Median } & \text { Ave Rank } & \mathrm{Z} \\ \text { high } & 84 & 8.500 & 93.5 & 0.97 \\ \text { Overall } & 179 & 8.500 & 86.0 & -0.97 \\ 90.0 & \\ \mathrm{H}=0.94 & \mathrm{DF}=1 \quad \mathrm{P}=0.332 & \\ \mathrm{H}=1.44 & \mathrm{DF}=1 \quad \mathrm{P}=0.230 \quad \text { (adjusted for ties) }\end{array}$

Table 17-Kruskal-Wallis Test for Thickness

\begin{tabular}{|c|c|c|c|c|c|}
\hline Thickness & $\mathrm{N}$ & Median & Ave & Rank & Z \\
\hline 0.2 & 96 & 8.500 & & 92.6 & 0.71 \\
\hline 0.4 & 83 & 8.500 & & 87.0 & -0.71 \\
\hline Overall & 179 & & & 90.0 & \\
\hline $\mathrm{H}=0.51$ & $\mathrm{DF}=$ & $\mathrm{P}=$ & .477 & & \\
\hline $\mathrm{H}=0.78$ & $\mathrm{DF}=$ & $\mathrm{P}=$ & .378 & $\left(\mathrm{ad}^{-}\right)$ & usted for ties) \\
\hline
\end{tabular}




\section{Appendix B-Specifications}

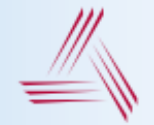

ALIEN

ALN 9740 Squiggle Inlay

\section{ALN-9740 Specifications}

\section{Dry Inlay}

Antenna Width

Antenna Length

Web Width (-R)

Web Width (-SR)

Web Pitch

Core Width (-R)

Core Width (-SR)

Core ID

Core Material

Interleaf Material

Interleaf Width

Inlays per Roll

Maximum Roll OD

Roll Labeling Data

\section{Wet Inlay}

\section{Inlay Width}

Inlay Length

Web Width

Web Pitch

Core Width

Core ID

Core Material

Inlays per Roll

Maximum Roll $O D$

Roll Labeling Data

White (-WRW)

Overlay Adhesive (-WRW)

Inlay Adhesive

Adhesive Application

Temperature

Adhesive Service

Temperature

Release Liner
$3.732 "$ [94.8mm]

$0.319^{\prime \prime}[8.1 \mathrm{~mm}]$

$4.252^{\prime \prime}$ [108.0mm]

$3.874 "$ [98.4mm]

$0.625 "$ [15.875mm]

4.252" [108.0mm]

$3.874 "$ [98.4mm]

6" [152.4mm]*

Fiberboard

Paper

$1.5^{\prime \prime}[38.1 \mathrm{~mm}]$

20,000 Nominal

$<12$ " [304.8mm]

Roll \#, Quantity

3.866" [98.2mm]

0.484 " [12.3mm]

3.992" [101.4mm]

0.625 " [15.875mm]

4.752" [120.7mm]

6" [152.4mm]*

Fiberboard

20,000 Nominal

$<16^{\prime \prime}$ [406.4mm]

Roll \#, Quantity

TT Printable White Film

Overlay

General Purpose Permanent

General Purpose Permanent

$>+25^{\circ} \mathrm{F}\left[-4^{\circ} \mathrm{C}\right]$

$-40^{\circ} \mathrm{F}$ to $+200^{\circ} \mathrm{F}$

$\left[-40^{\circ} \mathrm{C}\right.$ to $\left.+93.3^{\circ} \mathrm{C}\right]$

$40 \#$ SCK

\section{Environmental}

Shelf Life

Recommended Storage

Storage Limits

Non-condensing

Operating Limits

Bend Diameter

Pressure

Drop Resistance

Write Cycles

RoHs

REACH

ESD Limit- HBM / CDM

$-40^{\circ} \mathrm{F}$ to $+158^{\circ} \mathrm{F}$

$\left[-40^{\circ} \mathrm{C}\right.$ to $\left.+70^{\circ} \mathrm{C}\right]$

$20 \%$ to $90 \% \mathrm{RH}$

Non-condensing

$>1.97^{\prime \prime}[50 \mathrm{~mm}]$

$<5 \mathrm{~N} / \mathrm{mm}^{2}$

Per ASTM D5276

$100,000 @ 25^{\circ} \mathrm{C}$

2002/95/EC, 2005/618/EC.

2011/65/EU Compliant

1907/2006/EC Compliant

(SVHC and ECHA)

$5.0 \mathrm{kV} / 1.5 \mathrm{kV}$

\section{RFID}

Protocols Supported

Integrated Circuit

EPCglobal Certificate

Operating Frequency

EPC Size

User Memory

TID

Unique TID

Access Password

Kill Password

ISO/IEC 18000-6C

EPCglobal Class 1 Gen 2

Alien Higgs-4

950110126000001084

$840-960 \mathrm{MHz}$

128 Bits

128 Bits

32 Bits

64 Bits

32 Bits

32 Bits

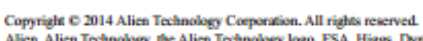

Alien, Alien Tatanobge, Ae Alien Teatnology logo, FSA, Higge,

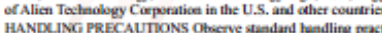

DPscific application.

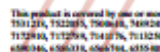

nyming

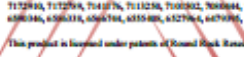

Figure 21- Alien Squiggle specifications 


\section{Descliption of Greator}

Basic Parameters

\begin{tabular}{|c|}
\hline Extruder number \\
\hline Overall Dimensions \\
\hline Shipping Size \\
\hline Shipping Weight \\
\hline Input File Format \\
\hline Compatibility \\
\hline Software \\
\hline Print From \\
\hline Input Voltage \\
\hline Power \\
\hline
\end{tabular}

Positioning Precision

Print Precision

Layer Thickness

Build Size

Stock Nozzle Diameter

Speed

Flow Velocity

Extruder Temperature Heated Build Platform

Heated Buid Platform

Filament Species

Filament Color

Filament Diameter
Dual

$320 \times 467 \times 381 \mathrm{~mm} \mid 12.6 \times 18.4 \times 15$ in

$565 \times 430 \times 525 \mathrm{~mm}$

$13 \mathrm{~kg}$ (without materials)

STL / X3G

Linux, OSX, Mac and Windows

Replicator $\mathrm{G}$

SD card or over USB

AC $100-240 \mathrm{~V}, 50 / 60 \mathrm{H}$

$220 \mathrm{~W}$

\section{Technical parameters}

$0.0025 \mathrm{~mm}$ on $Z$ axis; $0.011 \mathrm{~mm}$ on $X Y$ axes

$0.1-0.2 \mathrm{~mm}$

$0.1-0.5 \mathrm{~mm}$

$225 \times 145 \times 150 \mathrm{~mm} / 8.9 \times 5.7 \times 5.9 \mathrm{in}$

Stock $0.4 \mathrm{~mm}$

$40-100 \mathrm{~mm} / \mathrm{s}$

Approximately $24 \mathrm{cc} / \mathrm{hr}$

Recommended Maximum $230^{\circ} \mathrm{C}$

$120 \mathrm{C}$ Maximum (Warming a little bit in the winter and cooling slightly in the summer)

\section{Filament Parameters}

ABS / PLA

White, Black, Yellow, Red, Blue, Green, Transparent

$1.75-1.8 \mathrm{~mm}$

Figure 22- FlashForge Creator (FDM 3D Printer) specifications 